\title{
The Impact of Social Network Advice on Software Security Decisions
}

by

\author{
Bruna Freitas \\ A Thesis submitted to \\ the Faculty of Graduate Studies and Research \\ in partial fulfilment of \\ the requirements for the degree of \\ Master of Applied Science \\ in Systems and Computer Engineering \\ Department of Systems and Computer Engineering \\ Carleton University \\ Ottawa, Ontario, Canada
}

October 2012

Copyright (C)

2012 - Bruna Freitas 
Library and Archives

Canada

Published Heritage

Branch

395 Wellington Street

Ottawa ON K1A ON4

Canada
Bibliothèque et

Archives Canada

Direction du

Patrimoine de l'édition

395 , rue Wellington

Ottawa ON K1A ON4

Canada
Your file Votre référence

ISBN: 978-0-494-94244-4

Our file Notre référence

ISBN: 978-0-494-94244-4
NOTICE:

The author has granted a nonexclusive license allowing Library and Archives Canada to reproduce, publish, archive, preserve, conserve, communicate to the public by telecommunication or on the Internet, loan, distrbute and sell theses worldwide, for commercial or noncommercial purposes, in microform, paper, electronic and/or any other formats.

The author retains copyright ownership and moral rights in this thesis. Neither the thesis nor substantial extracts from it may be printed or otherwise reproduced without the author's permission.
AVIS:

L'auteur a accordé une licence non exclusive permettant à la Bibliothèque et Archives Canada de reproduire, publier, archiver, sauvegarder, conserver, transmettre au public par télécommunication ou par l'Internet, prêter, distribuer et vendre des thèses partout dans le monde, à des fins commerciales ou autres, sur support microforme, papier, électronique et/ou autres formats.

L'auteur conserve la propriété du droit d'auteur et des droits moraux qui protege cette thèse. $\mathrm{Ni}$ la thèse ni des extraits substantiels de celle-ci ne doivent être imprimés ou autrement reproduits sans son autorisation.
In compliance with the Canadian Privacy Act some supporting forms may have been removed from this thesis.

While these forms may be included in the document page count, their removal does not represent any loss of content from the thesis.
Conformément à la loi canadienne sur la protection de la vie privée, quelques formulaires secondaires ont été enlevés de cette thèse.

Bien que ces formulaires aient inclus dans la pagination, il n'y aura aucun contenu manquant. 


\section{Abstract}

Malicious software (malware) is one significant threat to Internet security. Malware are designed to harm a computer or network, and can be installed on one's machine without their consent. Attacks are often done by deceiving people into downloading malicious software that is posing as useful software. We believe that if people had understandable advice easily available to them when they are about to make a decision on whether to download software or not, they would be inclined to use the advice, reducing their chances of putting their computers at security risk. Therefore, the main objective of this research is to understand if social networks can improve computer security by facilitating security advice. We designed and developed a system and web browser extension to provide social network advice to users considering downloading software. We then ran an empirical study to compare the advice coming from a trusted person to the advice coming from other more general social networks. We compared five different sources of advice in total. The provided advice could also present to the participant an alternate program, that had better security. We didn't

find much evidence that the advice had a different effect based on the advisor, but the study confirmed our hypothesis that presenting alternative software will improve security. 


\section{Acknowledgments}

This work could not have been completed without the dedicate support I received from many people, to whom I'm deeply grateful. First, and foremost to my supervisors. Dr. Robert Biddle, for the great opportunities he gave me in his lab, and for his patience, enthusiasm and immeasurable knowledge. Dr. Ashraf Matrawy, for the constructive criticism, excellent advice and for keeping me focused and organized during this work. My friends at the lab (especially Elizabeth, Stevenson, Sonia, Judith and Maryanna), whose help was invaluable during my studies. My family, who are my constant source of love and support. Finally Rafael, who has been, always, my pillar, my joy and my guiding light. 


\section{Table of Contents}

$\begin{array}{ll}\text { Abstract } & \text { iii }\end{array}$

Acknowledgments $\quad$ iv

Table of Contents v v

$\begin{array}{ll}\text { List of Acronyms } & \text { ix }\end{array}$

1 Introduction $\quad 1$

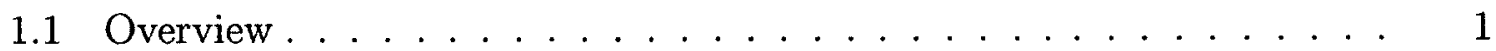

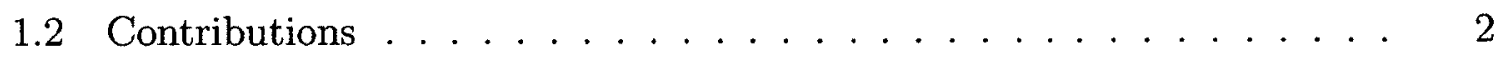

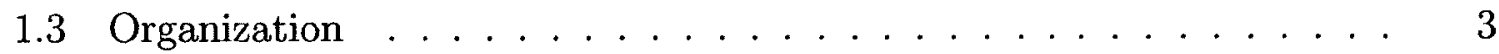

2 Literature Review $\quad 4$

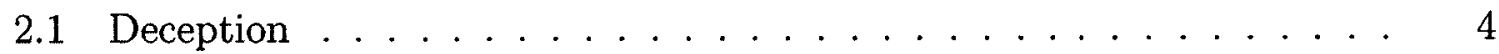

2.2 Social Networks . . . . . . . . . . . . . . . . 6

2.3 Reputation-based systems . . . . . . . . . . . . . . . 9 9

2.4 Decision Making . . . . . . . . . . . . . . 13

2.5 Related Work . . . . . . . . . . . . . . . . . 18

2.5.1 Web of Trust . . . . . . . . . . . . . 18

2.5.2 Work of Chia et al. . . . . . . . . . . . . 19

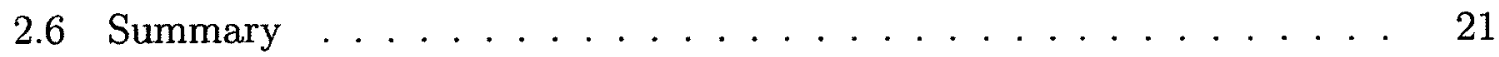


3 Problem Statement $\quad 22$

3.1 Threat model .......................... 22

3.2 Security/productivity trade-off . . . . . . . . . . . . . . 23

3.3 The role of advice . . . . . . . . . . . . . . . . . . 24

4 Solution framework $\quad 27$

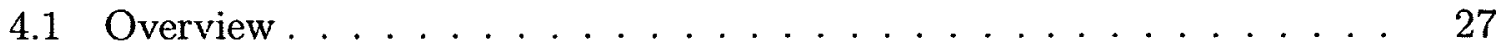

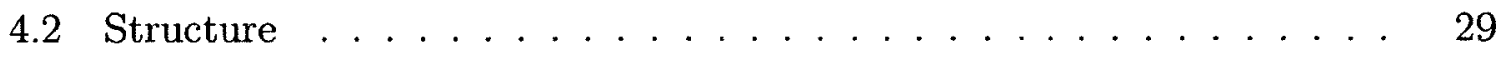

4.2 .1 Advice ........................ 29

4.2.2 Viewing the inforrnation ............. . . 31

4.2 .3 Small Groups . . . . . . . . . . . . . . . . . . 31

4.2.4 Group Members . . . . . . . . . . . . . . . . 32

4.2 .5 Captains ...................... . . . 32

4.2 .6 Group Owner ..................... 33

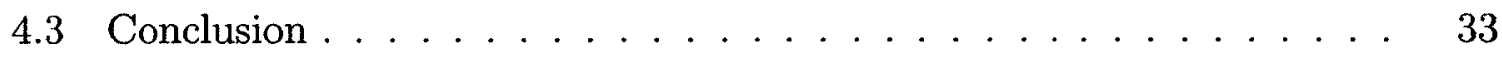

5 System Implementation $\quad 34$

5.1 Technology . . . . . . . . . . . . . . . . . . . . . 34

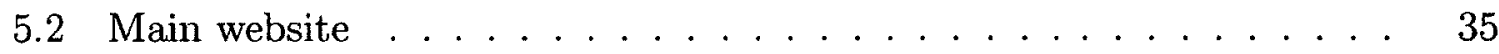

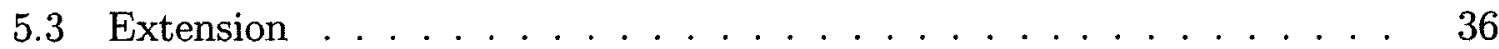

5.4 Use case . . . . . . . . . . . . . . . . . . . . 40

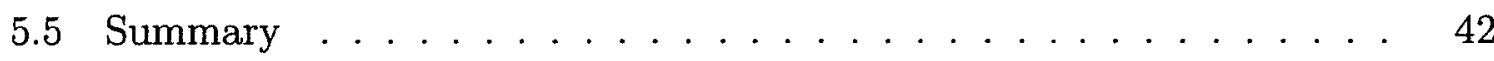

6 Study 44

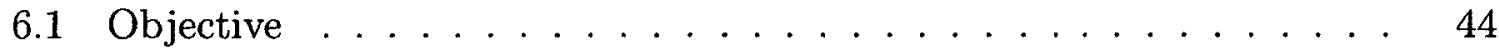

6.2 Description of participants . . . . . . . . . . . 45

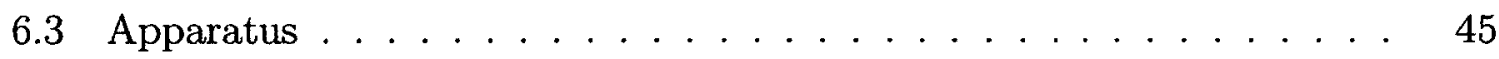

6.4 Materials ..................... 46 
6.5 Procedure .......................... 50

7 Results: hypotheses testing $\quad 53$

7.1 Hypothesis 1....................... 54

7.1.1 Downloads, Compliance, and Time . . . . . . . . . . 54

7.1.2 Advice confidence . . . . . . . . . . . . . . . 61

7.1 .3 The software category . . . . . . . . . . . 64

7.2 Hypothesis 2......................... 66

7.2.1 Downloads, Compliance, and Time . . . . . . . . . . . 67

7.2 .2 Advice confidence . . . . . . . . . . . . . . . 72

7.2.3 The software category ............... 75

7.3 Hypothesis 3.......................... 77

8 Results: perception and general discussion $\quad 82$

8.1 Questionnaire data ....................... 82

8.1.1 Pre-test questionnaire .............. 83

8.1.2 Post-test questionnaire . . . . . . . . . . . . 84

8.2 Observational data . . . . . . . . . . . . . . . 89

8.3 Interpretation . . . . . . . . . . . . . . 90

9 Conclusion $\quad 94$

$\begin{array}{ll}\text { A Ethics Application } & 97\end{array}$

B Informed consent form $\quad 110$

C Recruitment notice $\quad 113$

D Pre-test questionnaire $\quad 114$

$\begin{array}{ll}\text { E Pre-test questionnaire answers } & 117\end{array}$ 
F Post-test questionnaire

G Post-test questionnaire answers

H The website

128

List of References

128 


\section{List of Tables}

2 Software categories . . . . . . . . . . . . . . . . 48

3 Sample of software used in study and attributes (there were 41 in total) 49

4 Advice . . . . . . . . . . . . . . . . . . . . 50

$5 \quad$ All Downloads . . . . . . . . . . . . . . . . 55

6 ANOVA of all downloads for Facebook, General and Alex. . . . . . 56

$7 \quad$ Advice list (need to change this caption) $\ldots \ldots \ldots \ldots$

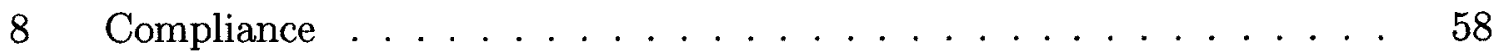

9 Compliance for Facebook, General and Alex. . . . . . . . . . . 58

10 Descriptive statistics for time $(\mathrm{sec}) \ldots \ldots \ldots$

11 ANOVA of time to make a decision for Facebook, General and Alex. . 60

12 ANOVA of confidence level $\mathrm{N}$ and number of downloads for Facebook, General and Alex. . . . . . . . . . . . . . . . 63

13 ANOVA of confidence level $\mathrm{Y}$ and number of downloads for Facebook, General and Alex. . . . . . . . . . . . . . . 63

14 Descriptive statistics for number of downloads of software in each category . . . . . . . . . . . . . . . . 66

15 Two-way ANOVA of number of downloads (advisor*category) . . . 67

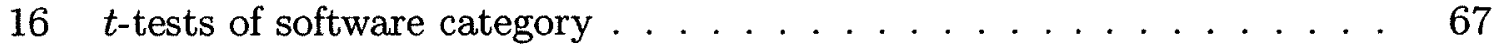

17 All Downloads . . . . . . . . . . . . . . . . . . . . . 69

18 ANOVA of all downloads for CISA, Symansoft and Alex. . . . . . . 69 
19 Compliance . . . . . . . . . . . . . . . . . . . . . . 69

20 Compliance for CISA, Symansoft and Alex. . . . . . . . . . 70

21 Descriptive statistics for time $(\mathrm{sec}) \ldots \ldots \ldots \ldots \ldots \ldots$

22 ANOVA of time to make a decision for CISA, Symansoft and Alex. . 72

23 ANOVA of confidence level N and number of downloads for Symansoft, CISA and Alex. . . . . . . . . . . . . . . 74

24 ANOVA of confidence level $Y$ and number of downloads for Symansoft, CISA and Alex. . . . . . . . . . . . . . . 74

25 Descriptive statistics for number of downloads of software in each category ........................... 76

26 Two-way ANOVA of number of downloads (advisor*ategory) . . . 77

$27 t$-tests of software category . . . . . . . . . . 77

28 Descriptive statistics for number of downloads of software . . . . . . 80

$29 t$-tests of Alternative vs No Alternative for advice MY . . . . . . . 81 


\section{List of Figures}

1 Diagram of people's social connections and trust relationship . . . . . 28

2 ONWatch framework diagram . . . . . . . . . . . . . . . . 29

3 ONWatch extension architecture . . . . . . . . . . . . . . 37

4 ONWatch extension icon: a life preserver indicating help . . . . . . 38

5 ONWatch extension flowchart .................... 38

6 ONWatch website: login page ................ 40

7 ONWatch website: requesting application review (step 2) . . . . . 40

8 ONWatch website: app list $($ step $3 \mathrm{~A}) \ldots \ldots 41$

9 ONWatch website: application being reviewed (step 3 B) . . . . . . 41

10 ONWatch website: application reviewed (step $3 \mathrm{C}$ ) . . . . . . . 41

11 ONWatch extension: seeing the piece of advice (step 4). The icons show the source of advice with a figure of a person, a colored indication of the advice, and a black circle with the word "why" indicating the reason. . . . . . . . . . . . . . . . . . . 42

12 Screenshot of study website . . . . . . . . . . . . 47

13 Screenshot of ONWatch: the advice . . . . . . . . . . . 48

14 All Downloads . . . . . . . . . . . . . . . . 55

15 Compliance Level . . . . . . . . . . . . . . . . . 59

16 Average decision time for each Scenario . . . . . . . . . . . . 60

17 Confidence Level . . . . . . . . . . . . . . . . . . 62 
18 Downloads in category . . . . . . . . . . . . . . 65

19 All Downloads . . . . . . . . . . . . . . . . . . . . . . . 68

20 Compliance Level . . . . . . . . . . . . . . . . . . . 70

21 Average decision time for each Scenario . . . . . . . . . . 71

22 Confidence Level . . . . . . . . . . . . . . . . . . 73

23 Downloads in category . . . . . . . . . . . . . . . 75

24 Alternative Comparison for advice MY . . . . . . . . . . 78

25 Alternative Comparison for advice $\mathrm{MN} \ldots \ldots \ldots$

26 Alternative Comparison for advice $\mathrm{N} \ldots \ldots . \ldots 79$

27 Pre-test Questions _. . . . . . . . . . . . . . . . . 85

28 Post-test Questions . . . . . . . . . . . . . . . . . . . 87

29 Post-test Questions . . . . . . . . . . . . . . . . . . . . . . 88

30 Pretest Questions . . . . . . . . . . . . . . . . . . . . . 118

31 Pretest Questions . . . . . . . . . . . . . . . . . . . . . . 119

32 Post-test Questions . . . . . . . . . . . . . . . . . . . 126

33 Post-test Questions . . . . . . . . . . . . . . . . . 127

34 ONWatch website: login page . . . . . . . . . . . . 128

35 ONWatch website: home page . . . . . . . . . . . . . . 128

36 ONWatch website: logout page . . . . . . . . . . . . . . . . 129

37 ONWatch website: sign up page . . . . . . . . . . . . . . . 129

38 ONWatch website: group page . . . . . . . . . . . . . . . . . 129

39 ONWatch website: create a group page . . . . . . . . . . . . 130

40 ONWatch website: edit group information page . . . . . . . . . 130

41 ONWatch website: profile page . . . . . . . . . . . . 130

42 ONWatch website: edit profile page . . . . . . . . . . . 131

43 ONWatch website: applications page . . . . . . . . . . 131

44 ONWatch website: adding new application page . . . . . . . . 132 
45 ONWatch website: application information page . . . . . . . . 132

46 ONWatch website: captain's view of the application page . . . . . 133

47 ONWatch website: captain writing the advice . . . . . . . 133

48 ONWatch study: page showed when participant was practicing using the system . . . . . . . . . . . . . . . . . . 134

49 ONWatch study: page displayed when participants were in the actual study. The participant would read the scenario, and then click the button to see the application . . . . . . . . . . . . 135 


\section{List of Acronyms}

\section{Acronyms Definition}

\begin{tabular}{ll}
\hline \hline API & Application Programming Interface \\
CAPTCHA & Completely Automated Public Turing test \\
& to tell Computers and Humans Apart \\
CISA & Canadian Internet Security Advisor \\
CSS & Cascading Style Sheets \\
DoS & Denial-Of-Service \\
EULA & End-user license agreement \\
HTML & HyperText Markup Language \\
JAS & Judge-Advisor System \\
JSON & JavaScript Object Notation \\
MN & Maybe No (bad software, 70\% confidence) \\
&
\end{tabular}




\begin{tabular}{ll} 
NI & No Information \\
OSN & Online Social Network \\
PHP & Hypertext Preprocessor \\
SbN & Socialbot Network \\
URL & Uniform Resource Locator \\
WOT & Web of Trust \\
Y & Yes (good software, 100\% confidence) \\
\hline
\end{tabular}




\section{Chapter 1}

\section{Introduction}

\subsection{Overview}

Malicious software is a significant threat to Internet security. Malicious software (malware) is designed to compromise a computer or network, and can be installed on one's machine without their consent or knowledge. If malware is installed in the victim's computer, the attacker can perform malicious activities, including having access to the user's files. The strategy of attack is often through deceiving people into clicking on links or downloading malicious software that is posing as useful software. Identifying malicious software can be a daunting task for ordinary users.

People, obviously, do not purposefully download malware to their devices, so attackers must use techniques to mislead users into downloading it unknowingly. In this work we intend to help people making better software security decisions by supporting decision-making about the security of software, using advice from trusted people in their social network. We define better security decision to mean decreasing the amount of malware downloads relative to useful software.

Inspired by the Neighborhood Watch program [1] (we will discuss more about it in subsequent sections), we believe that a few people taking care of the computer security of an online "neighborhood" can, overall, improve security. Additionally, we 
explore the idea of social networking to support advice. We believe that if people had advice easily available to them and more understandable, perhaps they would be more inclined to use the advice and lower their chances of being deceived into downloading malware.

In this work, we study how our current social networks can improve computer security by providing security advice. In order to do that, we compare the advice coming from a trusted person to the advice coming from other more general social networks, such as Facebook or from general people on the internet (whom the users did not necessarily know). We also compare it with the advice coming from authorities. We focus on the effect of the source of security advice on how people behave. We did not conduct field work on the actual security advice people receive via social networks, but this might be an important topic for future work.

\subsection{Contributions}

The primary contributions of this work are:

- The idea of social networking supporting computer security advice was explored.

- A framework was designed and implemented to leverage the discussed idea of users getting advice from trusted people when they face a decision of whether to download a piece of software or not to their computer.

- An empirical study was conducted with approximately 60 participants to answer the question: "can social networks help improving computer security?"

- Both a priori and post-hoc statistical analysis were conducted to interpret the results obtained in the study. 


\subsection{Organization}

A brief synopsis of the structure of the thesis document is as follows.

The first three chapters are introductory in nature. Chapter 2 reviews the literature relevant to this project and chapter 3 consists of the problem statement, which provides a concise conception of what this work is.

Chapter 4 describes the solution framework designed for the problem described in the previous chapter. This framework is an abstract design of the project. Chapter 5 gives a more detailed overview of the system built, including the technology used, and explanation of how the system works. Chapter 6 discusses the hypotheses that were made and the methodology used for the study. Chapter 7 presents the detailed analysis and results of the study that are related to the hypotheses stated in chapter 6 , and chapter 8 presents the questionnaire answers and a broader discussion of the results. Finally, chapter 9 gives a summary of the research and contributions of this thesis and identifies some limitations. It also discusses opportunities for future research. 


\section{Chapter 2}

\section{Literature Review}

The proposed research draws from several areas of study. This chapter gives relevant background information about each of these areas. The chapter begins with an overview of deception, which is one strategy used in computer attacks and it is an important problem that we are trying to help avoiding with the project developed in this work. In the next section, Social Networks and how they are usually seen as a weakness for computer security is discussed. The following section discusses reputation systems and how they encourage trustworthy behavior in online communities. Finally, previous work on how people make decisions provides insight about what influences people during the decision-making process.

\section{$2.1 \quad$ Deception}

The success of numerous attacks on computer systems can be linked to the security experts not understanding the psychology of the computer users they mean to protect [2]. In many instances the weakest point in the system's defences is the human, and the security engineer often fails to understand how real users would react to maliciously crafted stimuli.

Malicious software, known as malware, is designed to harm a computer or network, 
and can be installed on the victim's machine without their knowledge. This is often accomplished through deceptive links or downloads posing as something people might be interested in. A recent example of this situation was a Trojan Horse that posed as a legitimate Flash Player installer. If this malicious software was downloaded by an inattentive user, it would be capable of disabling updates to the default Mac OS X anti-malware protection system, potentially leaving the system open to the manual installation of other malware without any system warnings [3] [4].

Stajano et al. [2] examine a variety of scams in order to be able to understand and describe general principles the behavioural patterns of victims follow, and that deceivers have learnt to exploit. They believe that by better understating those patterns, experts will be able help users protect themselves from deceptive attacks. They were able to identify seven principles followed by the behavioural patterns of the victims of scams based on their research. Those principles follow.

The dishonesty principle: Anything illegal people do will be used against them by the fraudster, making it harder for them to seek help once they realize they have been tricked.

The deception principle: Things and people are not what they seem. Hustlers know how to manipulate people to make them believe in something that is not true.

The need and greed principle: People's needs and desires make them vulnerable. Once hustlers know what one really wants, they can easily manipulate them.

The Distraction principle: While one is distracted by what retains their interest, hustlers can do anything to the distracted person, which will go unnoticed.

The social compliance principle: Society trains people not to question authority. Hustlers exploit this fact to make people do what they want. 
The Herd principle: Users will make decisions regarding interacting with a given system based on the actions and opinions of their friends, family, and co-workers, among others.

The time principle: This principle assumes that when people are under time pressure to make an important decision, they use a different decision strategy. Hustlers will take advantage of this vulnerability of the victim to steer them towards a strategy involving less reasoning.

\subsection{Social Networks}

In recent years, the popularity of online social networks (OSNs) has greatly increased. The online communities created by OSNs are a fast growing phenomenon on the web empowered by new ways of social interaction among people from around the globe. As of June of 2012, Facebook [5] has more than 950 million people using the service in a given month [6], which represents 29 percent more users than one year before.

OSNs are useful for keeping in touch with friends, research collaboration, making connections, sharing interests, joining groups, and so on. Some OSNs are used for communication, photo and video sharing, and entertainment, such as Facebook, MySpace [7], and Orkut [8], while others are used for professional contacts, such as LinkedIn [9], where users can extend business connections.

OSNs have the ideal properties to become attack platforms, such as a very large and highly distributed user base, clusters of users sharing the same social interests, developing trust relationships, and seeking access to the same resources and platform openness for deploying malicious applications that lure users to install them [10].

Therefore, it is becoming increasingly easy even for an average user to exploit social media for malicious purposes. Organizations and governments are finding it difficult to accurately detect, identify, predict, and prevent the malicious exploitation 
of social media [11]. Possible malicious and illegal activities using these platforms are DoS attacks, privacy violations, disk compromise, and malware propagation.

Social Networks provide a way of spreading unsolicited communications, such as e-mail from spammers. Zinman et al. [12] address this problem by developing a research prototype that categorizes senders into broader categories than spam or not spam using features unique to OSNs, and they are able to find profiles that mimic ordinary users but which are actually commercial and usually undesirable entities. They argue that only the user will be able to define if a certain profile is actually spam or not, but the design of OSNs and their associated services can speed this evaluation through digestion and presentation of information that would otherwise be hidden.

Another challenge brought with the OSNs is the transcendence of cyber threats into real life, which causes socio-psychological problems. Chandramouli et al. [11] argue that technology and lack of policies are the causes of this problem, and outline some possible changes to improve this issue. One of their contributions is that they identify deceptive behavior as one indicator of hostile intent and they discuss methods to detect deception from text data generated in the context of social media communications.

A study by Irani et al. [13] measured the size of a user's online social footprint, and how easy it is to reconstruct it. This research revealed that a user with one social network exposes an average of 4.3 personal information fields. For users with over 8 social networks, this average increases to 8.25 fields. They also found that more than $40 \%$ of an individual's social footprint can be reconstructed by using a single pseudonym (assuming the attacker guesses the most popular pseudonym), and an attacker can reconstruct $10 \%$ to $35 \%$ of an individual's social footprint by using the person's name. This study shows that targeted attacks on individuals are possible using techniques based on social networking pseudonyms. 
Makridakis et al. [10] introduce some proof-of-concept attacks based on Facebook applications that aim to launch DoS attacks against third parties, fetching remote files from a victim's machine, and harvesting sensitive personal information of users.

Bostmasf et al. [14] argue that OSNs present some vulnerabilities that make it easy for a large-scale infiltration of socialbots, which are computer programs that control OSN accounts and mimic real users. Those types of attacks are leveraged by four current existing OSN vulnerabilities: ineffective CAPTCHAs, ease to fully automate the account creation process, crawlable social graphs (making it possible to reconstruct the social graph of an OSN), and exploitable platforms and APIs. In this work, they design and built a Socialbot Network $(\mathrm{SbN})$ : a group of adaptive socialbots that are orchestrated in a command-and-control fashion. After operating for 8 weeks collecting data related to users' behavior on Facebook, they were able to show that OSNs can be infiltrated with a success rate of up to $80 \%$, and depending on users' privacy settings, a successful infiltration can result in privacy breaches where even more users' data are exposed when compared to a purely public access. Finally, they also demonstrated that, in practice, OSN security defences, such as the Facebook Immune System, are not effective in detecting or stopping a large-scale infiltration as it occurs.

A study by Nagle et al. [15] evaluated the percentage of a sample Facebook population willing to befriend an unknown user or adversary. They designed different profiles and sent friendship requests to a sample of Facebook users. Their results showed an acceptance of $19 \%$ when there was no mutual friends between the person being requested friendship and the fake profile. On the other hand, they accomplished a $55 \%$ acceptance rate when there was at least one mutual friend between the test profile and the target profile. This means that while most users in their sample did not share sensitive information when asked by an adversary, more users were willing to divulge personal details to an adversary if there is a mutual friend connected to 
the adversary and the user.

\subsection{Reputation-based systems}

In much of our everyday lives, trusting decisions are made, be it directly or indirectly. Take the simple example of purchasing an item from a shop. We may choose to buy a certain brand because we have found it to be trustworthy in the past or it has a reputation for being widely trustworthy.

Prior to the Internet, vendors provided references, Better Business Bureaus tallied complaints, and past personal experience and person-to-person gossip told people on whom they could rely and on whom they could not. Internet services operate on a vastly larger scale than Main Street and permit virtually anonymous interactions. Nevertheless, reputations still play a major role.

A reputation system collects, distributes, and aggregates feedback about participants' past behavior. Though few producers or consumers of the ratings know one another, these systems help people decide whom to trust, encourage trustworthy behavior, and deter participation by those who are unskilled or dishonest [16].

The concept of reputation is closely linked to that of trustworthiness, but it is evident that there is a clear and important difference. This will be discussed in the following paragraphs.

Manifestations of trust are easy to recognise because we experience and rely on it everyday, but at the same time trust is quite challenging to define because it manifests itself in many different forms.

Gambetta's definition of trust is the following:

"Trust (or, symmetrically, distrust) is a particular level of the subjective probability with which an agent assesses that another agent or group of agents will perform a particular action, both before he can monitor 
such action (or independently of his capacity ever to be able to monitor it) and in a context in which it affects his own action" [17].

Jøsang et al. go further and enhance the definition of trust by introducing a vagueness in the definition, making it become more general. This second definition is as follows:

"Trust is the extent to which one party is willing to depend on something or somebody in a given situation with a feeling of relative security, even though negative consequences are possible" [18].

This broader concept includes several aspects of trust, which are: dependence on the trusted entity or party, the reliability of the trusted entity, utility in the sense that positive utility will result from a positive outcome and negative utility will result from a negative outcome, and finally a certain risk attitude in the sense that the trusting party is willing to accept. Moreover, trust is a subjective phenomenon that is based on various factors, some of which carry more weight than others.

Abdul-Rahman et al. [19] summarize trust characteristics as follows:

- Trust is not an objective property of an entity but a subjective degree of belief about entities.

- A trusting action is taken despite uncertainty of outcome but in anticipation of a positive outcome.

- Trust is dynamic and non-monotonic. This means that additional evidence or experience at a later time may increase or decrease our degree of trust in another entity or party.

- A trusting action may not follow the rules of rational choice theory. An entity may have reasons beyond the cognitive evaluation of risk and utility a trust 
decision may be made "in terms of here and now" instead of pondering on future outcome.

Reputation, on the other hand, is an expectation about something or somebody's behaviour based on information about or observations of its past behaviour [19]. It can be considered as a collective measure of reliability based on the rating from members of a community.

Resnick et al. [16] state that there are three properties that reputations systems must have in order to operate effectively. Those are:

- Capture and distribute ratings about current interactions (such information must be visible in the future).

- Use of feedback to guide decisions about current interactions.

- Long-lived entities (difficult for entity to change identity) to inspire an expectation of future interaction.

While trust systems produce a score that reflects the relying party's subjective view of an entity's trustworthiness, reputation systems produce an entity's (public) reputation score as seen by the whole community. Moreover, trust systems usually take subjective and general measures of (reliability) trust as input, whereas information or ratings about specific (and objective) events, such as transactions, are used as input in reputation systems. Finally, there are systems that incorporate elements of reputation systems and trust systems.

The form of exchange of reputation and rating scores between the participants depends on the architecture of the network of a particular system. The most common types are either centralised or distributed networks [18]. In the absence of a central component, the reputation system is distributed to the entities themselves. Each entity runs a local instance of the reputation system, where those instances 
may cooperate by exchanging recommendations [20]. There is still little commercial and scientific work on distributed reputation systems to date [21], and many of the existing ones consist of components inspired by peer-to-peer systems [22]. Centralised reputation systems feature a central authority that collects the ratings and recommendations, and uses them to derive a reputation score for every entity. Moreover, all the scores are publicly available. Furthermore, each score is given by other entities or members who have had direct experience with that party.

Some of the most well known online reputation systems use a centralised network and the computation is based on the summation or average of ratings. Some examples are:

eBay: it is an Internet auction site and one of the earliest and best known Internet reputation systems. It gathers ratings $(+1,0$ or -1$)$ and comments from buyers and sellers about each other after a transaction has taken place. According to a study of eBay's reputation system by Paul Resnick et al. [23], highly ranked sellers can charge about 8 percent more than sellers with no reputation for identical items.

Amazon: it is an American multinational electronic commerce site and it is the world's largest online retailer [24]. Amazon allows one to five star ratings submitted by previous buyers. Buyers are also allowed to leave comments on the products. Shoppers can read all reviews, and they also are presented with the average of all ratings [25].

Epinions: it is a consumer reviews platform on the Internet. It does not decide what content to post and what not to post, therefore it is an unbiased platform [26]. Interested people can sign up for an account for free. To provide a review, members need to write a minimum of 20 words and that review needs to pass Epinions' automated language check. They can also provide a qualitative 
rating related to a certain aspect of a product, such as ease of use, durability, and so on, and the quantitative ratings range from 1 to 5 . Each product also has an overall star rating, which is calculated based on average product rating, with extra weight given to high quality reviews, number of reviews about the product and recency of reviews about the product. Additionally, other members can rate reviews as Not Helpful, Somewhat Helpful, Helpful, and Very Helpful. Finally, Epinions charges product manufacturers and online shops by the number of clicks consumers generate as a result of reading about their products on Epinions' website, and reviewers earn Eroyalties credits for writing reviews. At the time of writing, Eroyalties credits are redeemable in U.S. dollars.

PageRank: is a link analysis algorithm, developed by Google founders Larry Page and Sergey Brin and represents a way of ranking the best search results based on a page's reputation. Simplistically, the theory is that the most important pages on the Internet are the pages with the most links leading to them. It does that by assigning a numerical weighting to each element of a hyperlinked set of documents, such as the World Wide Web, to measure its relative importance within the set. It also looks at the importance of the page that contains the link. A page has high rank if the sum of the ranks of its backlinks is high. This covers both the case when a page has many backlinks and when a page has a few highly ranked backlinks [27].

\subsection{Decision Making}

People routinely have to make decisions and they often rely on advice from others. Therefore, in order to model such decision-making structures, the topics regarding advice-giving and advice-taking have been widely researched. Important decisions are rarely made by one person alone [28], and even for less important decisions people 
also look for advice. People look for advice on decisions such as which movie to see, so they might read critics' review, or a new college graduate is likely to consult their parents and peers about which job offer to accept.

In most of the research about decision-making and advice taking, the structure considered is the judge-advisor system ("JAS"). In this structure there are two important roles:

The judge: this term refers to the decision-maker, which is the person who receives the advice and makes the final judgement.

The advisor: this term refers to the source of advice, information or recommendation to the judge.

Most studies have conceived of "advice" in terms of a recommendation, from the advisor, favoring a particular option. Several studies examined how the judge's trust in the advisor influences the acceptance of the advice.

Sniezek et al. studied the influence of trust, confidence, and expertise in JudgeAdvisor Systems in two experiments with Judge-Advisor pairs [29]. Their research examined trust as the judge's attitude of relying on and using advice provided by the advisor during the decision task and as an expectancy about one's partner's behavior. Confidence, in their research, is the strength with which a person believes that a specific statement or decision is the best possible and they believe that high advisor confidence can act as a cue to expertise and therefore influence the judge to accept the advice. Their experiments confirmed the importance of trust in the relationship of the judge and advisor in the acceptance of advice. Additionally, it confirmed the importance of cues to expertise, like confidence, in building trust especially when other information about the person is not available.

Van Swol et al. [30] studied advice utilization and the acceptance of expert advice. 
Their study took into account five different factors that could influence a judge's acceptance of advice: judge's trust in the advisor, advisor confidence, advisor accuracy, judge's prior relationship with the advisor, and judge's power to set payment to the advisor. They hypothesized that judges' lower expertise would increase their uncertainty in the task, thus creating the need to trust the expert advisor as a means to reduce this uncertainty. Their results showed that when the judge did match the advisor's advice, the judge had higher confidence, suggesting a reduction in uncertainty. They also examined differences in trust with high and low expertise participants without the factor of role (advisor and judge), and confirmed that low-expertise participants had higher trust. Also, their results suggested that the judges' higher trust in the experiments made by Sniezek et. al [29] was probably a factor of their lower expertise. Advisor confidence was the only significant factor in their studies that predicted the judge matching the advisor's advice. That suggests that expressions of high confidence by the advisors increase the acceptance of advice. Even when participants communicate freely face-to-face, written expressions of confidence were the best predictors of advice acceptance.

Some studies examined how the task difficulty and the egocentric discounting influences the acceptance of the advice. Yaniv et al. [31] studied decision making and advice taking being influenced by two factors: egocentric discounting of another's advice or options and reputation formation for advisors. Advice discounting is attributed to the notion that decision makers have access to their internal reasons for holding their own opinion, but not to the advisors' internal reasons. Reputation formation is related to the negativity effect in impression formation and to the trust asymmetry principle. In their research, the term reputation is used to describe what the decision maker learns online about the advisor through a series of estimation episodes and the ensuing feedback. Therefore, it is what a decision maker learns 
about an advisor through experience. They suggest that positive and negative information about reputation gathered across a series of episodes have a differential impact on the resulting weighting policy. Additionally, they suggest that advice-discounting results from decision makers' differential access to the underlying justifications for each opinion. Also, they have suggested that a reputation for being a good advisor is more easily lost than gained. The major conclusion of their study regarding the weighting policies is that decision makers tend to discount advisory estimates egocentrically. They found that the respondents' weighting policies were sensitive to the quality of the advice. Also, they found that the weighting policy is rapidly updated following changes in quality of the advice and there was a pattern in the results that showed that reputation, indeed, is more easily lost than gained.

Research by Gino et al. [32] examined the impact of task difficulty on people's willingness to use advice. They performed two experiments in which they varied the difficulty of the task and measured how people weigh others' advice. In one of the experiments, participants were obliged to get advice and then left with the option of how to use it, while in the other study participants had the option of getting advice. Their results showed indeed that people tend to overweight advice on difficult tasks and underweight advice on easy tasks. Moreover, it showed that on difficult tasks people use advice significantly more than one would expect based on the confidence they expressed in their opinions prior to receiving the advice. This way, in the difficult condition, their own opinions were less worthy, while in the easy condition, participants were more confident in the value of their own judgement and were more willing to dismiss the advice of another person.

Other findings related to advice acceptance were as follows:

Sniezek et al. [33] suggest the possibility of social pressure not to reject freely offered advice: such advice, if rejected, may not be proffered again in the future. Also, research suggests that advice is perceived as more helpful and discounted less 
if proffered by an expert source [34] and that expert advice is more influential than novice advice is. In addition, judges use information and explanations about their advisors' forecasting strategies as a way to infer advice quality. Yet, judges' inferences of quality may not always be correct [35].

Budesco et al. [36] assume that a judge combines the advisors' opinions by weighting them according to the amount of information underlying them, and the judge's confidence increases as a function of a variety of factors that reduce the variance of the aggregate. Their results showed that, contrary to the model's prediction, the judge's confidence is not sensitive to the inter-cue correlation. The best predictors of the judge's confidence are the perceived predictability of the event, the level of agreement among the advisors, and the advisors' self-reports of confidence (as already reported by $[30])$.

Research performed by Bonaccio [37] examined the judge's perceived usefulness of the advice, their expected satisfaction with the advisor, their trust in the advisor, and their own post-advice confidence. Their studies showed that advisor expertise and advisor intentions are most important in predicting judge's evaluations of advisors. Moreover, judges prefer advisors who are simultaneously experts and well-intentioned. Finally, they recommend that advisors who wish to be influential should strive to build a reputation highlighting the fact that they are experts and have their judges' best interests at heart.

Van Swol [38] focuses on the distinction between intellective and judgmental tasks and argues that people are more likely to accept advice on intellective tasks where the true answer is already known. She argues that this is because people seek out accuracy in answering intellective problems and an advisor may be able to demonstrate the correctness of their advice. By contrast, in judgemental tasks, where the true outcome or answer is not known at the time of the judgement, the degree of trust placed in the advisor is more important for the acceptance of the proffered advice. If the 
advisor is perceived as having similar values to oneself, then trust increases, and so does the acceptance of advice. On the other hand, in intellective tasks, high advisor confidence tends to lead to increasing trust in advice. Van Swol argues that, in judgemental forecasting tasks, advisors are likely to differ in their advice, and thus a potentially useful cue which may be used to differentiate between advisors is the degree to which an advisor shares the values of the client. In her empirical study, she found that advisors spontaneously provided additional information in a task where the advice was focussed on which movie the client would find most enjoyable. She argues that this unstructured material probably helps establish common values, and thus increases the level of trust in the proffered advice.

\subsection{Related Work}

In this section we report two related works which are technical approaches to improving computer security by providing advice in online communities.

\subsubsection{Web of Trust}

Web of Trust (WOT) [39] is a system that employs the wisdom of crowds to improve web security. The service was launched in 2006 and works by advising the users which websites they can trust based on other users' experiences. It operates on the principle that a collective decision by ordinary users, when harnessed wisely, can yield good outcomes.

It takes the form of a centralized database and a browser add-on, working with the majority of browsers (Internet Explorer, Firefox, Google Chrome, Safari and Opera). WOT collects users' experiences by having them rate websites regarding four categories:

Trustworthiness: this indicates whether a website can be trusted, if it is safe to use 
or even if it delivers what it promises. A poor rating may indicate, for instance, Internet scams, identity theft risks, credit card fraud, phishing, or that the site's content is not trustworthy.

Vendor reliability: this tells whether the site is safe for buying and selling or for business transactions in general. A poor rating indicates a possible scam or a bad shopping experience.

Privacy: this category indicates whether the site has a privacy policy that protects a person's personal identity and data. A poor rating indicates concern that user's data may be sold to third parties, be stored indefinitely or be turned over to law enforcement without a warrant, and so on.

Child safety: this tells whether a site contains adult content, violence, vulgar or hateful language, or content that encourages dangerous or illegal activities.

For each category, the user can either rate the website as excellent, good, unsatisfactory, poor or very poor. It also shows a confidence indicator, which suggests the amount of supporting evidence for that specific category. After gathering a required minimal confidence level, WOT publishes the aggregate rating, applying Bayesian inference to weigh user inputs differently based on the reliability of individual contributors, judging from their past rating behaviors. There are two views of the reviews, a more concise one called rating window, and a more detailed one in their website, which is called scorecard. In the more detailed view, besides the ratings, it is also possible to leave comments regarding a website and share it with the community.

\subsubsection{Work of Chia et al.}

Chia et al. [40] designed and implemented a prototype system on the Nokia N810 tablet to show risk signals from a personalized community when installing applications 
in the tablet and to deter unsafe actions by slowing the user down with habituationbreaking mechanisms such as user clicking-through warnings.

In this work, they identify that the two currently prevalent methods to identify inappropriate software are certification of "good" software by platform vendors and flagging of "bad" software by anti-virus vendors or other global entities, which are both centralized. They believe that those centralized means of signalling appropriateness are ineffective and can lead to habituation (user clicking-through warnings) or disputes (users discovering that certified software is inappropriate).

Their design is based on the fact that they consider a trustworthy installation process to be one that helps users to avoid installing inappropriate application. This means that besides providing risk signals that are perceived reliable and relevant, their design takes into account the risk of habituation, which undermines the efficacy of many security mechanisms involving end-users. Additionally, it incorporates mechanisms to gather and utilize feedbacks from the user's personalized community, which are friends and experts whom individual users trust in providing valuable inputs about software appropriateness.

The first part of their research intended to evaluate the potential of a personalized community in providing relevant and helpful signals. They found that information during installation, such as EULA, privacy policy and disclaimer notices, is mostly ignored. Additionally, they found that security vendors, experts and friends are important sources for information on digital risks. Moreover, $65 \%$ of the subjects in their research regarded the first-hand experience by friends and family members as important. In comparison, fewer subjects considered the experience from members of an online community to be important, suggesting that users regard inputs from friends and family members to be more relevant than those from an online community. They also found that when users know about digital risks, they are motivated to inform friends or family rather than the online community and that, in general, users consider 
reviews from trusted sources to be helpful.

After the implementation of their prototype installer developed on the Nokia N810 tablet, they conducted an evaluation of their tool to investigate the strength of opinion given by friends compared to opinion given by online community members. Their most significant result was that opinions by friends are stronger than those by online community. They found that warnings by friends overruled positive feedbacks by the online community, but the opposite was not true. The response towards habituation-breaking mechanisms implemented in their tool was mixed. They note that habituation-breaking mechanisms are designed to trade off some level of convenience for safer user actions, and may be hard to satisfy all users, therefore that result was not surprising. Finally, they had a very positive feedback on social rating for software appropriateness integrated with the installation process.

\subsection{Summary}

We believe that often people are deceived into downloading malicious software posing as something they might be interested in. We have reviewed the literature on human behaviour that underlies deception and how people deal with deception. Also we reviewed the literature on social networks that is related to computer security, and how they are often associated with the concept of being bad for security. Additionally, we reviewed literature that suggested that people rarely make decisions alone and they usually ask for advice when facing difficult situations. Our work suggests a technical approach for the problem of people downloading malware to their computers, and we use the background literature to show if a solution can be based on people exchanging security advice in a social network where people trust a specific known person.

The technical work in this area is not very broad. We reviewed the Web of Trust and another system developed by Chia et al. [40]. 


\section{Chapter 3}

\section{Problem Statement}

People in general are not computer security experts. They do not know about the many threats that exist when they download new software to their computers, or when they do not update the installed software in their computer, or even when they browse the web.

For ordinary users it is commonplace to have trusted friends, whom they ask for advice for various problems, ranging from illnesses, to computer issues. Moreover, they have different friends for different kinds of issues, which is a typical behaviour of social networking. This study investigates this aspect of social networks to see if it can improve computer security.

To better understand the reasoning behind this idea, the next sections will describe the considered threat model, the trade-offs between productivity and security, and the role that advice can play to improve security.

\subsection{Threat model}

Malicious software (malware) is any software that gives some control of a user's com-

puter to the malware creator, enabling them to do whatever they want. Malware can be found in many forms, such as viruses, worms, trojan horses, adware, spyware, 
and others. The damage it causes can vary, and in some cases it can give away full control of the infected machine. Often the victim will not notice that their computer has been infected, enabling the malware creator to perform further malicious actions. Those could range from damaging or deleting important files from the hard drive, to acquiring personal information, such as personal passwords, credit card numbers, email addresses, bank account information, and so on. Most malware requires the user, influenced by subterfuge, to initiate its installation.

There are several ways to gain access to a computer in order to deliver a malicious outcome (payload), which are called attack vectors. The attack vectors could be via email attachments, web pages, pop-up windows, instant messages, and so forth. In this work we are interested in the use of deceptive software as a vector of attack, and a payload such as trojan horses. In this form of attack, the user might be attempting to download useful software for work, for instance, and the attacker could deceive that user into (unknowingly) downloading a malicious application. The user thinks that application will help him, but it actually contains malware.

We believe that people do not purposefully download malware to their machines. Therefore, in this work we aim to improve security by reducing the number of malicious downloads.

\subsection{Security/productivity trade-off}

In order to be productive, people need to download applications that will help them accomplish the tasks that they need the computer for. In order to be safe, people must be careful when they download those applications from the Internet. As mentioned before, people do not purposefully download malware to their machines. They are usually trying to download software that they need, but they might be misled into downloading malicious software or just poorly designed software that will allow 
attackers to gain control of their machines.

People could, for instance, just avoid downloading all software, and they would then be secure from those kinds of threats, or they could just not connect to the Internet or even not bother buying a computer. Those are not practical solutions. Therefore, there is a trade-off between being secure from Internet security threats and productivity. By productivity we mean being able to accomplish whichever task people intend to do with their computer.

We believe that if people could be more aware of what is bad and what is good software, they would also be more secure. At the same time, people do not have enough education nor time for that. According to Cormac Herley [41], people consider security advice a burden, and they are reluctant to expend effort: in the face of dire descriptions of the threat landscape and repeated warnings, they do the minimum possible. Moreover, security tasks are cumbersome and seldom usable.

If people had advice easily available to them and more understandable, perhaps they would be more inclined to use the advice and lower their chances of being attacked.

\subsection{The role of advice}

People seek advice when making decisions ranging from the mundane (e.g., reading reviews in the newspaper before deciding on which movie to see or restaurant to go), to important issues (e.g., consulting with family and friends about taking a new job). Even when people have access to plentiful information they often lack the ability to make sense of it. Hence, again, they rely on the advice of trusted friends, colleagues, or advisors. Moreover, we believe that for several subjects people have different advisors which they trust for a particular subject. For example: a person might have a brother who is a physician, so they might double check with that brother the advice given by 
their family doctor or even just ask for advice before going to a clinic; people trust their neighbour with the key of their house when they go on a trip.

Having that in mind, we raised the question: can social networks improve computer security? We believe that most people are not computer security experts and will have a trusted person (a friend, a family member, etc) who helps them when they have problems or questions regarding their computers. Hence, we suggest that one way in which social networks could improve security is that people could get advice from those trusted friends.

We define better security decision to mean decreasing the amount of malware download relative to useful software. Therefore, instead of people just downloading every application that appears to be useful to them or not downloading anything to be more secure, people might follow the advice regarding downloading or not that particular application from a more knowledgeable person. They would, then, likely make better security decisions.

Having said that, one way that we can measure better security decisions is by the degree of compliance with the given advice. By measuring compliance, we are measuring the effect of the advice. We believe that this is a good measure because the program that the decision of downloading is at stake might be actually good or bad, but this varies independently of the advice. Additionally, what we think is important for this work is how well people follow the advice from their trusted person. Therefore, measuring the compliance will give us a good idea of that behaviour. Assessing the quality of the advice itself is out of the scope of this work.

There are several aspects of social networks that could be explored. In this work, we have decided to compare the advice coming from a trusted person to the advice coming from other more general social networks, such as Facebook or from general people on the Internet (whom the users do not necessarily know). We also compare it with the advice coming from authorities. 
There is another aspect that we explore in this work, which is also related to making better security decisions. When advising people not to download something, it might help to present them with alternative software to help them accomplish their task. We strongly believe that when people are told not to do something that they are inclined to do, they would likely be more compliant if they have an alternative.

Therefore, we believe that if people have understandable advice easily available to them, they would be inclined to use the advice, reducing their chances of putting their computers at security risk. This way, we study how our current social networks can improve computer security by providing security advice.

In summary, we believe that people would be inclined to use computer security advice to reduce the risks they're exposed to, as long as the advice is both understandable, easily available to them and coming from a trusted source. Therefore, we would like to study how current social networks can improve computer security by promoting the exchange of computer security advice. 


\section{Chapter 4}

\section{Solution framework}

\subsection{Overview}

We have designed a framework for advice exchange that we believe will help improve computer security. This chapter gives an explanation of this framework, and details the ideas supporting the choices made in the design.

In several countries, including Canada, the United States, Australia, and others, there is a program called Neighborhood Watch in which an organized group of citizens work on prevention of crime and vandalism in a neighborhood [42] [43] . This program works based on the fact that when citizens take positive steps to secure their own property and neighbors learn how to report suspicious activity around their homes, the number of occurence of several offences decrease dramatically. The neighbourhood watch is made up of small groups of volunteer residents in towns and cities around the country, and the members look out for signs of crime in their own neighbourhoods, and share that information with each other and local police [44].

Our model is inspired by the Neighborhood Watch program. We believe that a few people taking care of the computer security of an online "neighborhood" can, overall, improve security. More details about our framework design will be described in future sections. 


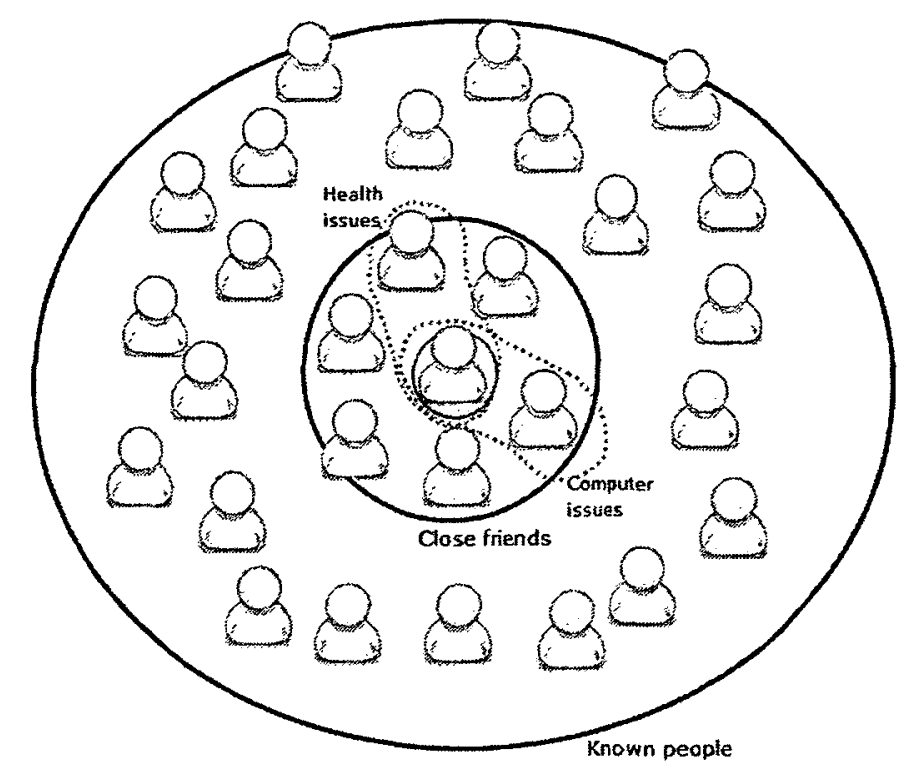

Figure 1: Diagram of people's social connections and trust relationship

Another important factor in our design is that we believe that people have trusted friends, family members or trusted acquaintances for specific issues. For example, one might have a cousin that he trusts for subjects related to health care, and a colleague that he trusts for parenting issues. Therefore, in general, people have trusted connections for each type of issue. Figure 1 illustrates these connections. Similarly, we believe that people will have trusted connections for computer related problems. In our framework, we want to take advantage of these powerful trust connections for computer security advice exchange. We decided to focus specifically on advice regarding software downloads. By doing that, we are trying to help people make better decisions when they are thinking about downloading software to their computers. There are several risks involved when downloading software to a machine, such as downloading trojan horses. We believe that often people are not aware of the danger, and if advice was provided to them in an easy and understandable fashion by a trustworthy person, they would likely follow the advice.

The following section will describe in more details the structure of the framework developed based on the ideas explained above. 


\subsection{Structure}

This section explains the structure of the framework designed in this work. Figure 2 shows a diagram of the designed framework.

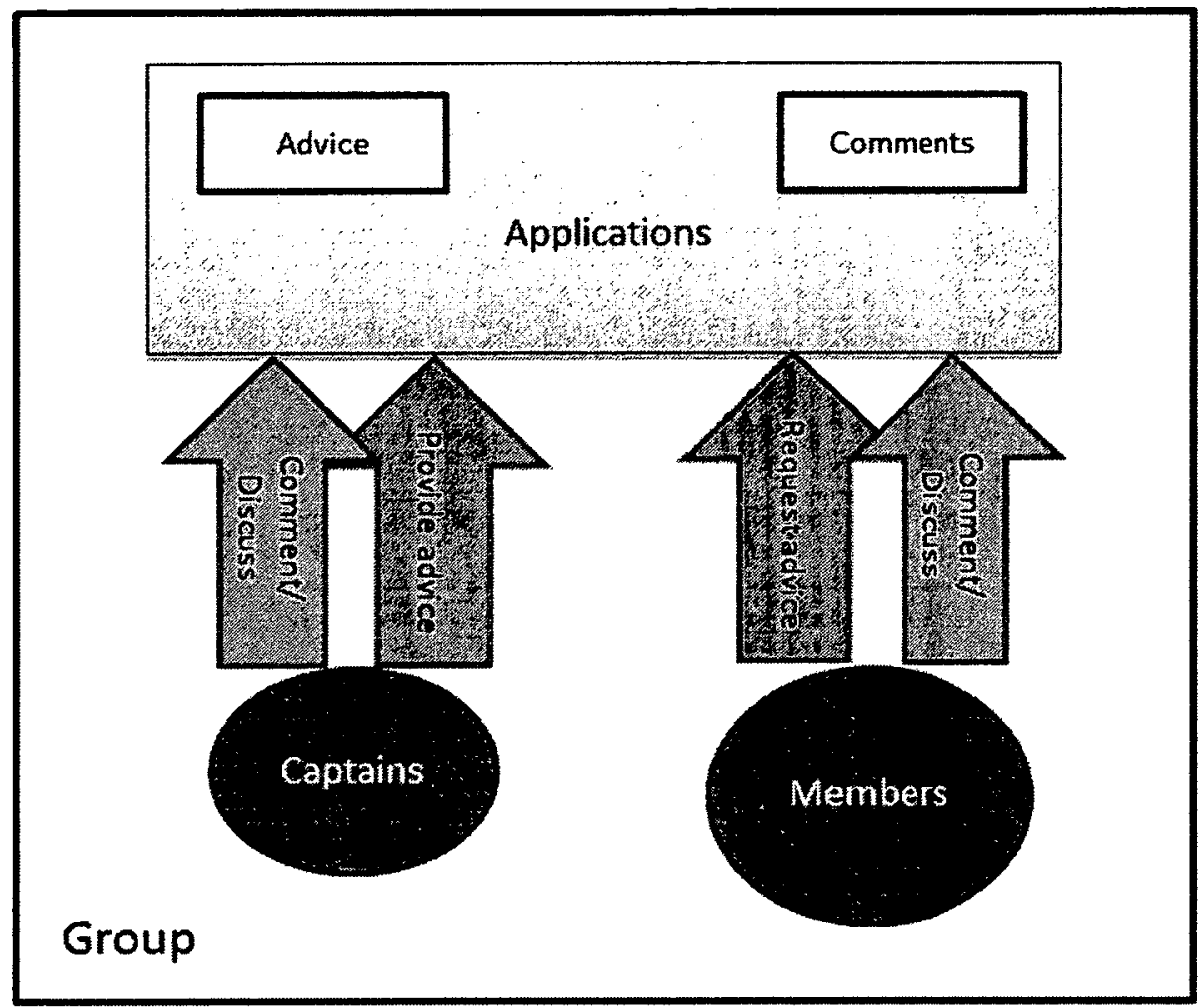

Figure 2: ONWatch framework diagram

\subsubsection{Advice}

The main focus of this framework is the advice. The objective of the framework is to facilitate the exchange of advice between the advisor and the person that is seeking advice.

In this framework, we considered the "kairos" [ancient Greek word meaning the right or opportune moment] factor. Kairos is the principle of presenting the message at the opportune moment [45]. B.J. Fogg studies persuasive technology, which is 
technology that is designed to change attitudes or behaviors of the users through persuasion and social influence, and he says that kairos can play an important role when we are trying to persuade people. Therefore, since we want to design a framework that will influence people to follow the advice and behave more safely when using their computers, we believe that using the kairos principle can help us achieving our objective.

When people are about to download software, they are usually on the download web page, which usually contains information about that program, including its name. That's the moment in which our framework would provide the user with the advice. The user has had a chance to explore the website, and read the information they want when they get to this point. So, the advice should be presented on the download page, before the user makes the decision to download.

The advice should contain a minimum set of information that will be able to help the user to make a decision. We suggest that the minimum information of a piece of advice for this framework is:

1. The name of the advisor.

2. The advice, in a concise manner.

3. The reason behind the advisor's decision.

Other interesting information that could also be available in a piece of advice is the confidence level that the advisor has in that advice. As previously discussed in chapter 2 , the greater the confidence showed by the advisor, the more it will improve the person's likelihood in accepting that advice. Moreover, advisors who express higher confidence are more influencial [30].

Finally, in case there is no advice for a certain application, the user should be able to ask for advice in a similar way that they are able to see the advice. 


\subsubsection{Viewing the information}

Besides the advice, the users should also be able to see more information about each application. So, in this framework, there should be a place to see all the information about the applications and the members of a group. Users will be able to comment and discuss about an application and the advice given.

It should also be possible for the users to edit information about applications, and to provide advice about the applications (see subsection 4.2.5).

\subsubsection{Small Groups}

The groups should have no more than 30 people. We suggest that a group of at most 30 people is the right size for people to know each other and have real (and trusted) bonds. Therefore, this is probably the largest number of people who would have a strong enough relationship for the system to be effective.

Despite the advances in communication technology over the years, our social network structure has largely stayed the same [46]. Moreover, these days, although we are able to connect to hundreds of people, we still have a small number of close friends. Therefore, planning small groups has advantage over bigger groups. Consequently, it will be easier for people that know each other to trust the advice, thus, the advice will have a greater impact in changing behavior.

Additionally, our idea is that only people in a trust relationship join this groups, and therefore we do not protect against malicious advice being propagated within the group. We also trust that people in the group make their best effort to only give advice if they feel that the advice is good. The issue of having bad advice being propagated in a group is out of the scope of this work. 


\subsubsection{Group Members}

In our framework, there are two types of membership to a group. A group member is the regular user, a member from a "neighborhood", that can see and ask for advice. They can also comment and discuss about the advice given, but they cannot necessarily give advice.

\subsubsection{Captains}

In the real Neighborhood Watch program in Ottawa there are two important roles: the Watch Members and the Block Captain [1]. The Watch Members are the backbone of the Neighbourhood Watch program. Their duty is to look after their own best interests and those of their neighbours. They also must remain alert to the occurrence of any suspicious activity and report it promptly to the police, then to their Coordinator. The Block Captain is principally responsible for monitoring a set of approximately ten homes within a Watch and to inform residents of breakings and enterings or other threatening activities that have occurred in the area.

In our framework, we designate as "captain" the member responsible for providing advice. They are people that are interested in technology, and they have knowledge or interest in researching about malicious applications. There should not be more captains than $25 \%$ of the size of the group. We also believe that people will volunteer to be captain because research shows that people make considerable sacrifices for the benefit of their group [46] [47].

The captains of this group might not have understanding of all types of applications that there might be (such as games, utility, and so on), but they should be able to find useful information about the security of software despite their own interest in that type of software. The responsibility of captains should be taken seriously, as others in the group will expect trustworthy advice. In actual practice, issues of 
liability and redress might arise: such issues are beyond the scope of the current work.

The captain also chooses other captains and can invite more people to the group.

\subsubsection{Group Owner}

The group owner can be either a captain or a regular member. The group owner chooses the group name, they can choose the captains, and they can invite more members to the group and they can pass the ownership to another member.

\subsection{Conclusion}

We have outlined at an abstract level a way for social network principles to help people make better security decisions, and we have designed and implemented a tool to support this. With a tool like this we speculate that people will use it often and it will help in reducing the number of downloads of malicious applications. Moreover, this work is especially taking focus on whether the captain's advice would likely have effect on reducing the number of downloads of malicious applications.

We have built this tool and we are going to test this proposal. The following chapters will describe the implementation and the study in more details.

To summarize, our solution framework:

- Facilitates people into organizing in small groups.

- Facilitates people into providing advice about software.

- Enables designation of trusted people in groups as advice givers.

- Facilitates the advice being given in an opportune moment. 


\section{Chapter 5}

\section{System Implementation}

The previous chapter described the framework that we believe will help improving computer security. In this chapter we describe an implementation of that model. We called the system ONWatch (Online Neighborhood Watch).

\subsection{Technology}

The framework was implemented in the form of a website and an extension for the Google Chrome browser. In the website, the user would be able to see all the available information about their group, and manage that information. The Chrome browser extension was developed in order to make the advice available to the user in a program download page.

The website was built with PHP version 5.3.2 and JavaScript, the JQuery library and CSS were employed on the front-end development. Aptana Studio 3 was used as the development environment and a MySQL database was used to store all the information. This is the most lightweight solution that would allow us to explore the effectiveness of the system.

The Chrome browser extension is a program that can enhance the browser's functionality, and it is developed using HTML, JavaScript and CSS. 
In the next subsections each of the mentioned pieces of this project will be explained in more detail.

\subsection{Main website}

A website was developed in order to make available to each user all the information on their group, such as members, applications, advice, and so on.

A list of the pages available to the user is as follows:

Home page: it is the user's starting point. In this page they can create a new account, they can $\log$ in if they are already registered. If they are member type captain, they will have available a list of applications that need review.

Group Info page: this page displays the name of the group, all the members from a group, their email addresses (in the form of links) and an icon that is associated with a type of membership. They can send an email message to any user by clicking on the email link. If they are the group owner or a captain, they can also invite new members from that page, and they can edit the membership type of each member.

Apps List page: from this page the user can manage the applications. If they are regular members, they can see a list of all the applications, they can comment, and they can add an application to the list so the captain can review it. If the member is a captain, they can edit information (give advice) about any application. The advice contains the following information: the name of the application, the status (or the advice), the URL of the download page of that software and the reason for the advice. The status (or the advice) is a dropdown menu, and the available options are: good, maybe good, bad, maybe bad and waiting for review. 
My Profile page: this page shows more details about the user, such as their name, last name, username, email address, membership type and group name. They can also edit that information, except for the name of the group and membership type. They can also remove themselves from the group.

Logout button: there is also available a button so the user can log out from the website.

A use case for the system is presented on section 5.4, as well as a set of screenshots.

\subsection{Extension}

In order for a user be able to see the advice without leaving the download web page of an application, we have developed a Chrome browser extension, called the ONWatch extension. This extension is capable of retrieving the advice associated with the program that the user is considering and displaying it to the user as part of the body of the website.

Extensions are small software programs that can modify and enhance the functionality of the Chrome browser. They are written using web technologies, such as HTML and JavaScript. They have little (such as an icon) or no user interface [48]. The drawback of using this approach is that it will only work on the Google Chrome browser, but other browser extensions could be developed.

An extension is a compressed package of files such as HTML, CSS, and JavaScript files, images, and any other resource necessary that adds functionality to the Google Chrome browser. Extensions can use any of the APIs provided by the browser, from XMLHttpRequest to JSON to HTML5. They can interact with web pages or servers using content scripts or cross-origin XMLHttpRequests. This is unlike ordinary web pages applications, which are restricted for security reasons. 


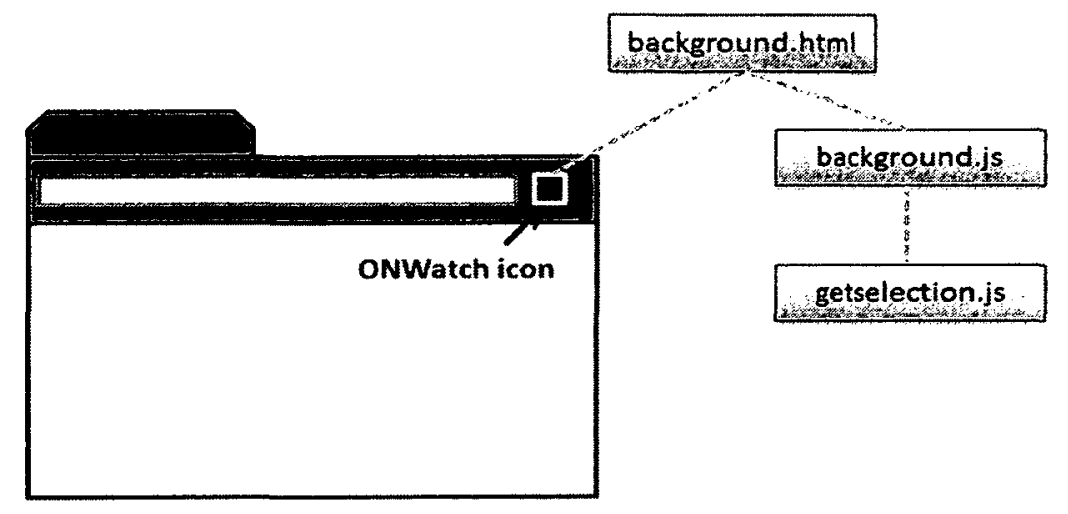

Figure 3: ONWatch extension architecture

An extension must have at least two files: a manifest file ( which gives information about the extension, such as the most important files and the capabilities that the extension might use), and an HTML file (called the background page and which holds the main logic of the extension). If the extension needs to interact with web pages, it may also contain a content script that acts as a regular JavaScript program in the loaded page.

The extension developed in this project contains the default HTML and manifest files, and it also contains two other JavaScript files and image files representing the extension icon (also called browser action) and images used when displaying the UI to the user.

The HTML file, called background.html declares a script (background.js) that adds a listener to the browser action, which, in turn, fires another script (getselection.js) when the user clicks on the browser action. Figure 3 shows the architecture diagram of the extension working.

In order the make the extension work, all the files must be packaged as a signed ZIP compressed archive with the file extension crx. Then, from the Google Chrome browser, the user can install the extension. Once installed, a button with the ONWatch extension icon (figure 4) appears beside the browser's address bar.

To use the extension, the user must be on the software download page, then 


\section{6}

Figure 4: ONWatch extension icon: a life preserver indicating help

highlight the name of the software they want to download and click the ONWatch extension. Once they do that, if the user is not logged in, a message displayed on the screen beside the highlighted name tells them to $\log$ in in order for them to see the advice. If they are logged in, the advice is displayed on the screen beside the highlighted name. Figure 5 shows a diagram that describes how the extension works.

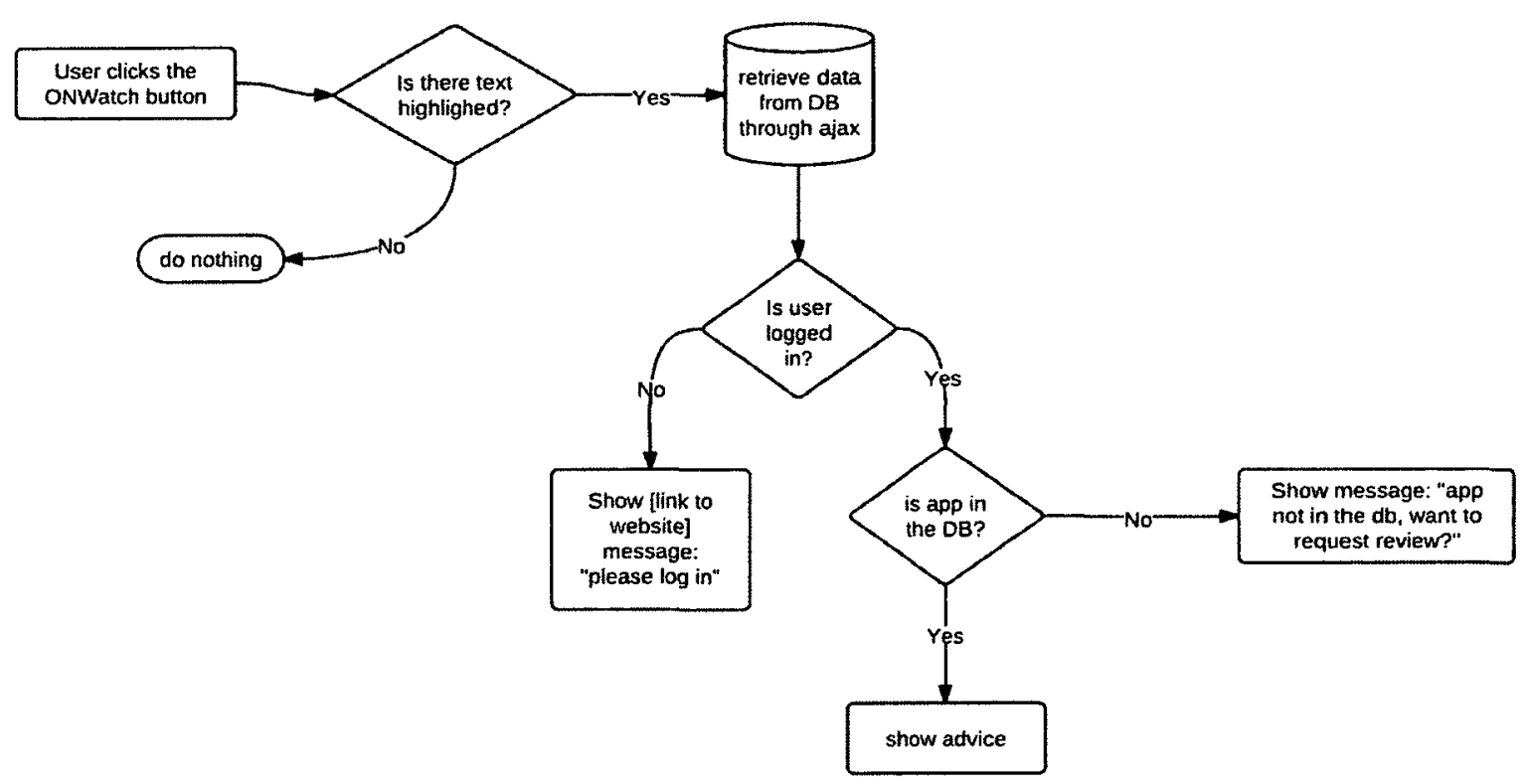

Figure 5: ONWatch extension flowchart

The extension, using Ajax, sends a request to the server running the ONWatch application containing information about the URL being visited and the name of the application. Data is then retrieved using the XMLHttpRequest object. That object holds information such as whether the user is logged in and the advice. The advice object has the following information:

Advisor: the person or entity providing this piece of advice. 
Advice: either good, maybe good, bad, maybe bad or waiting for review.

Reason for advice: advisor's argument that explains why they gave the advice above.

Alternative (optional): another piece of software that has similar functionality but with better security.

If the user clicks outside the box where the advice is being displayed, the advice disappears. If the user wants to see the advice again, they just need to highlight the name of the software again and click the ONWatch button.

As we mentioned, for our research project, the information sent to the server in order to retrieve the advice comprises only of the URL and the highlighted name of the software. In the server this information is used to match the data in the database in order to verify if the application is there and if there is advice regarding that application. Ideally, in order to have a more robust solution that could be able to identify software version and authenticity, we could have some authoritative description and verification of a piece of software. The authoritative description would include a precise name, version number and other information that describes that particular piece of software. This could be in the form of a digital signature that can be checked against the actual application that is signed by the creator. This way, an authoritative proof of validity could be a signed certificate and ONWatch should, ideally, be able to verify that signature.

We decided to use a simpler method because this work is a proof of concept and it is out of the scope of this thesis to study whether this method is efficient or to investigate other solutions to this problem.

The extension presents the information contained in the advice object in an organized fashion, and each piece of information (such as Advisor, Advice, and so on) has an icon for easy identification by the user. 


\subsection{Use case}

This subsection demonstrates some of the functionality of the entire application by describing a scenario in which a regular user uses the ONWatch system to get advice and the captain provides de advice for a particular application.

The basic flow of events is as follows:

1. User logs in to the website.

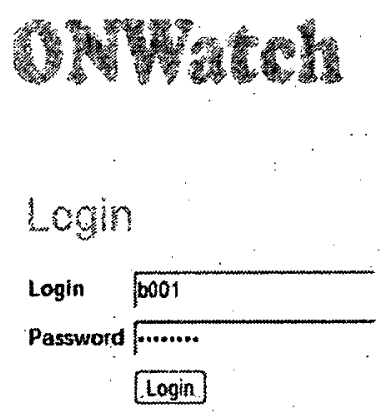

Dont have an account yet? Create new accolint

Figure 6: ONWatch website: login page

2. User requests advice about software.

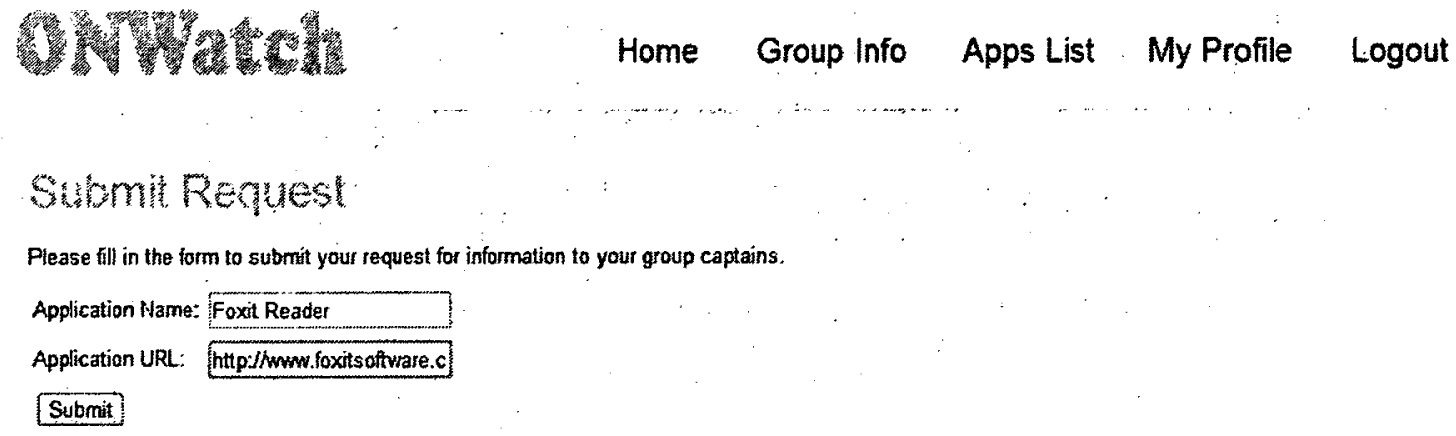

Figure 7: ONWatch website: requesting application review (step 2) 


\section{Captain reviews the request.}

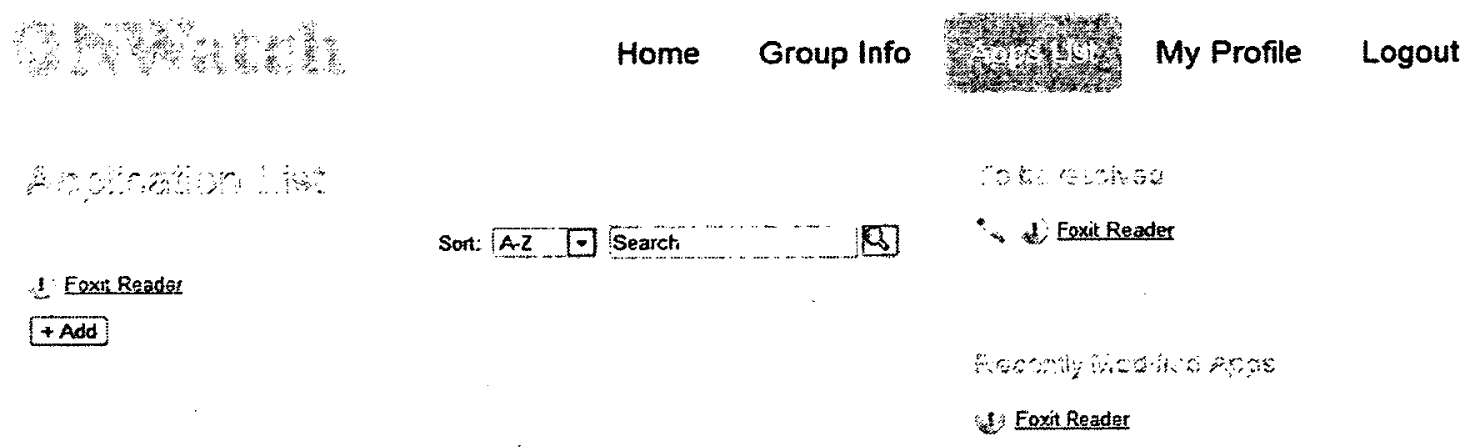

Figure 8: ONWatch website: app list (step $3 \mathrm{~A}$ )

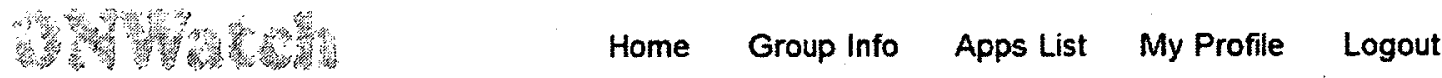

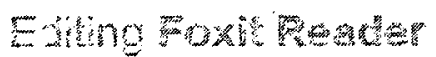

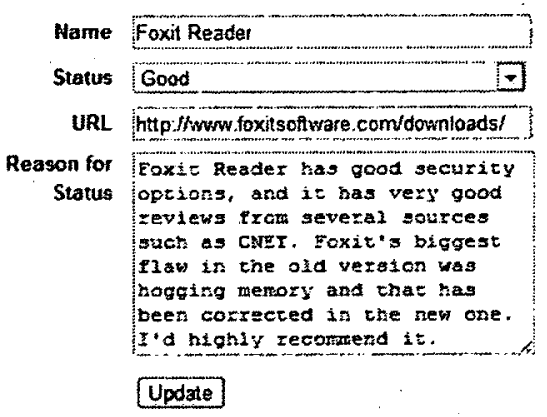

Figure 9: ONWatch website: application being reviewed (step $3 \mathrm{~B}$ )

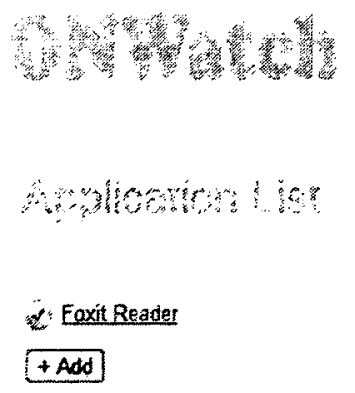

$$
\text { Home Group Info }
$$

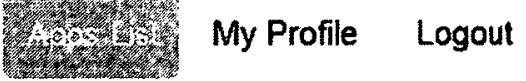$$
\cdots, \sec x \cos ^{2}
$$$$
\text { Son: A-Z } \square \text { Search }
$$

$$
\text { Eoxit Reader }
$$

Figure 10: ONWatch website: application reviewed (step $3 \mathrm{C}$ ) 
4. User uses ONWatch extension to see the advice.

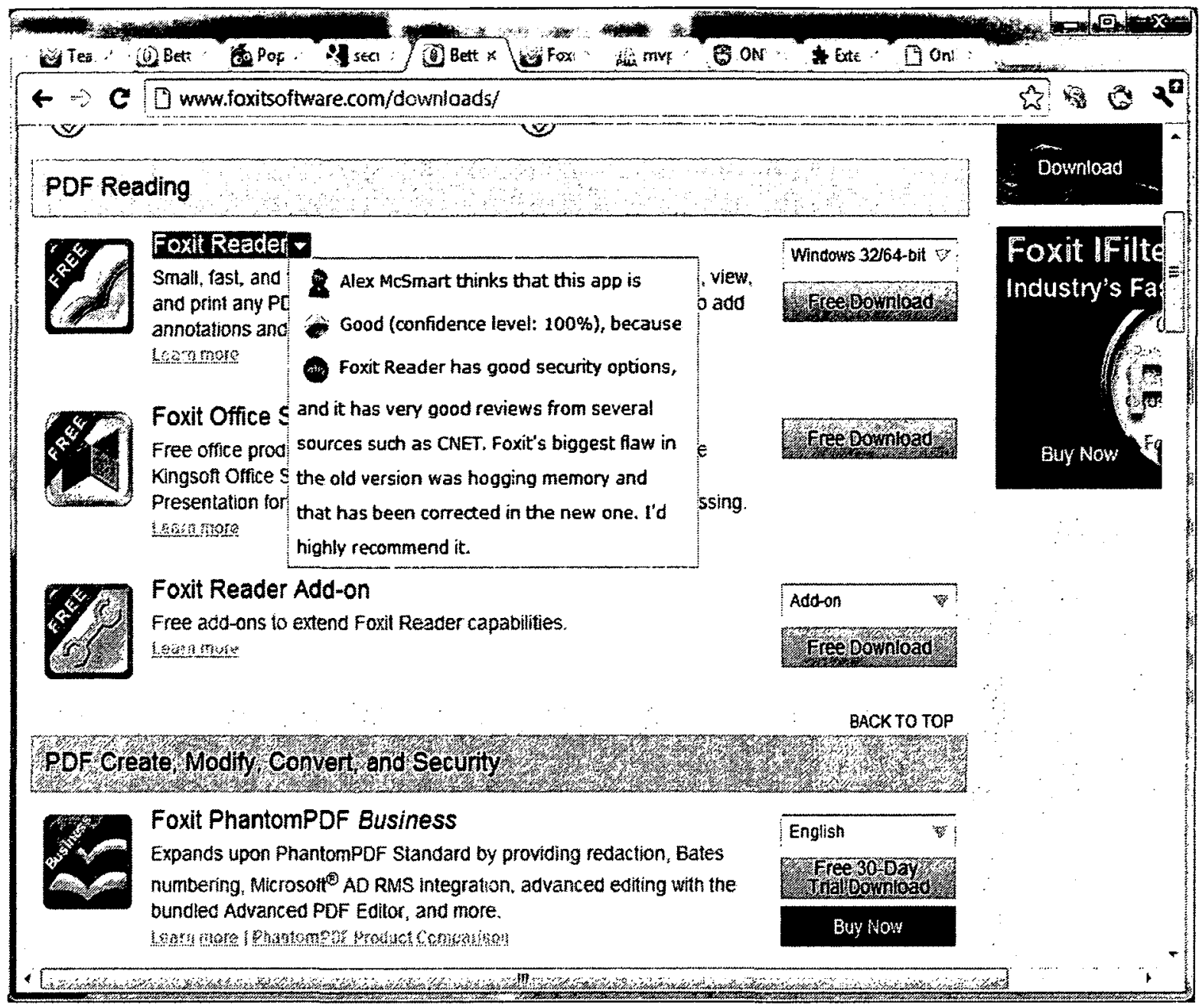

Figure 11: ONWatch extension: seeing the piece of advice (step 4). The icons show the source of advice with a figure of a person, a colored indication of the advice, and a black circle with the word "why" indicating the reason.

\subsection{Summary}

As we mentioned in the previous chapter, we designed a solution framework and in this chapter we have described our implementation. The framework was implemented to:

- Facilitate people into organizing in small groups. We have made this possible by 
building a website where people could create their groups, and it would provide information about each member of the group.

- Enable the designation of trusted people in groups as advice givers (captain). The system built allows the creator of the group or another captain to designate other captains in the group.

- Facilitate people into providing advice about software. This functionality is also available through the website, where the advisors have a specific web page with all the applications and their status visible and editable.

- Facilitate the advice being given in an opportune moment. We have built an extension for Google Chrome browser that provides the advice to the user on the download page of the software.

In order to have a better understanding of the usefulness of the system, there are several ways in which the system could be tested. We have conducted a study that is described in chapter 6 . This study will investigate some of the key aspects of this system that are related to advice taking. 


\section{Chapter 6}

\section{Study}

\subsection{Objective}

For this thesis research, a study was conducted in order to investigate the research question: can social networks improve computer security? The independent variable was the source of advice to the participant, and there were five models: the "captain" model, a "friends from a social network" model, a "general people from the Internet" model, an "unpaid authority" model, and a "paid authority" model. Each of these models only differs in the source of the advice, and we explain each source in more detail below. Three hypotheses were made:

H1: The captain model will lead to a better security decision than friends and general models.

H2: The captain model will lead to similarly good security decisions as the authorities models.

H3: Presenting alternatives will improve security.

Participants completed tasks related to deciding whether to download a certain application or not, given advice. We measured the number of downloads, the time 
taken to make a decision, the compliance with the advice and which application was being downloaded. Those are the dependent variables of the study. We believe that those metrics are easily available and they will give us a better understanding of the participants behaviour. In future sections a more detailed explanation will be given for each metric.

\subsection{Description of participants}

The participants in this study were recruited mainly around the university campus, via posters spread throughout the campus, as well as word-of-mouth. They were required to be over 18 years old and needed to feel comfortable with using a personal computer through a mouse and a graphical user interface. Using students as participants does limit the demographics, but their age and experience is very relevant for the risks involved in software downloads. Specific issues such as training in security and experience with malware were addressed in our pre-test questionnaire (see section 8.1.1). They were compensated for their time in the form of a ten-dollar gift card from a popular coffee shop chain. The participants were recruited for the study through posters spread throughout the campus, as well as word-of-mouth.

\subsection{Apparatus}

The study took place solely in the HotSoft Lab, at Carleton University (in the HCI Building). The apparatus used in the study consisted of an ordinary desktop computer

running Windows 7. During the study, the participants made use of a speciallydesigned website which was hosted online, and accessed using the Google Chrome web browser. Also used in the study was our extension (ONWatch) for Google Chrome, which was created for the study and was previously installed in the browser. Finally, 
a number of questionnaires were administered to the participants, all of them using the LimeSurvey application.

\subsection{Materials}

In accordance with the requirements of the Carleton University's Research Ethics Board (approved ethics form can be seen in appendix A), the participants were presented with a consent form and asked to sign it. Additionally, the study also included two questionnaires as part of the material. A pre-test questionnaire provided us with information about the participants, including demographic information. We also presented the participants with a post-test questionnaire.

To administer the experiment, a website and an extension for Google Chrome (ONWatch) were created (figure 12 and figure 13, respectively). The website consisted of text that described the scenario that the participant would have to consider. It would provide the participant with background information regarding the motivation behind downloading an application or not. Following the scenario text there would be the description of the software and an image that would relate to it. Finally, there would be two buttons to allow the participant to communicate whether they would download the referred application or if they would skip it.

The website would present each participant with a total of 41 different scenarios with their respective application, being 33 belonging to the actual study while the first eight were part of an initial practice set.

The 33 programs used in the study consisted of 11 existing programs that were commercially available at the time of the study and 22 fictitious programs. The fictitious programs were created with names and functionality that would resemble other existing programs that were commercially available at the time of the study. The programs were categorized in three distinct groups: Well-known programs, Utility 


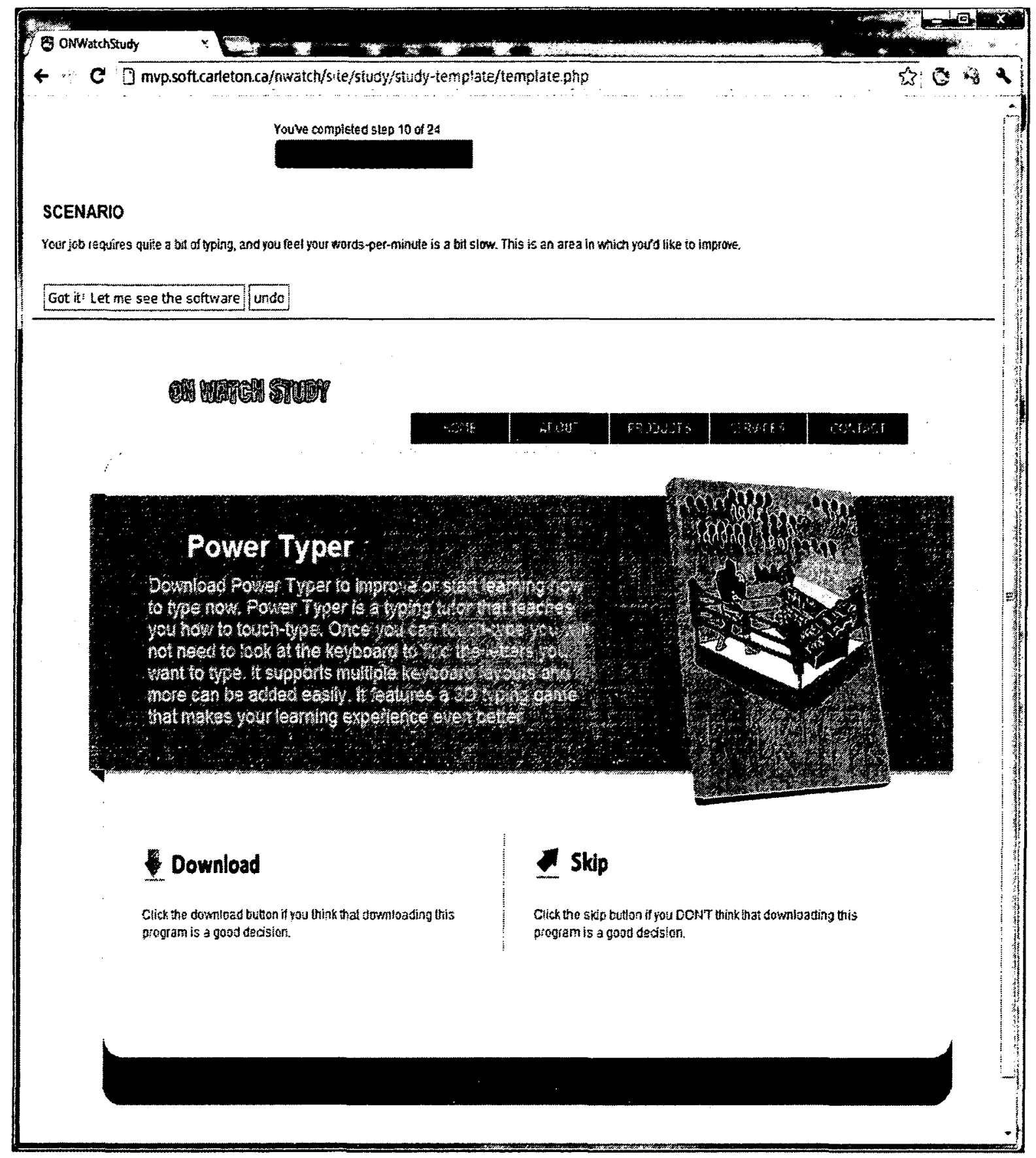

Figure 12: Screenshot of study website 


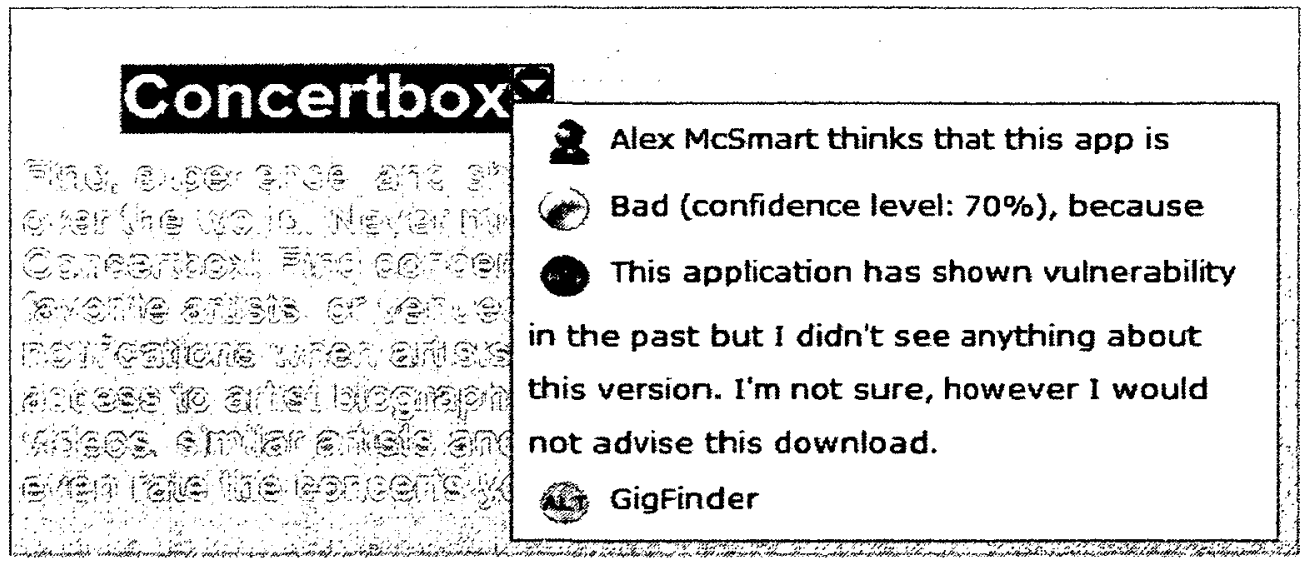

Figure 13: Screenshot of ONWatch: the advice

programs and Entertainment (Fun) programs (see definition in table 2). These groups were used for analysis, but not identified to the participant. Each program was associated with a set of attributes: a scenario, a name, a description, an image and a related advice. Table 3 shows 3 examples of applications and their attributes used in this study. The scenario would consist of the description of a hypothetical situation. The participants would have to consider what would have been their course of action were they faced with that scenario. Every scenario would lead the participant into the position where they would need to download the suggested program.

Table 2: Software categories

\begin{tabular}{ll}
\hline Fun & Software that is used for entertainment. \\
Utility & Software that has a practical use. \\
Well known & Software that is well known by the community \\
\hline
\end{tabular}

ONWatch (the Google Chrome extension) provided the participant with security advice about the application in question. Participants were randomly assigned to one of five conditions, each of which contained a different advisor. The advice consisted of a security assessment about the program (bad software or good software), a confidence level of the advice given (either $100 \%$ or $70 \%$ ), the reasoning behind the given 
Table 3: Sample of software used in study and attributes (there were 41 in total)

\begin{tabular}{|c|c|}
\hline Software Name & Attributes \\
\hline Concertbox & $\begin{array}{l}\text { Description: Find, experience, and share live music events from } \\
\text { all over the world. Never miss another concert with Concertbox! } \\
\text { Find concerts based on your location, favorite artists, or venues. } \\
\text { Use the watchlist to get notifications when artists play near you. } \\
\text { It provides easy access to artist biographies, artist pictures and } \\
\text { music videos, similar artists and more! In Concertbox, you can } \\
\text { rate the concerts you attended. } \\
\text { Scenario: You enjoy going to concert with your friends. You } \\
\text { want an application to tell you when your favorites artists are } \\
\text { on tour. } \\
\text { Advice: This application has shown vulnerability in the past but } \\
\text { I didn't see anything about this version. I'm not sure, however } \\
\text { I would not advise this download. }\end{array}$ \\
\hline Dropbox & $\begin{array}{l}\text { Description: Dropbox is a free service that lets you bring all your } \\
\text { photos, docs, and videos anywhere. This means that any file you } \\
\text { save to your Dropbox will automatically save to all your comput- } \\
\text { ers, phones and even the Dropbox website. Dropbox also makes } \\
\text { it super easy to share with others, whether you're a student or } \\
\text { professional, parent or grandparent. } \\
\text { Scenario: You have a few files that you want to sync between } \\
\text { your school computer and your PC at home. } \\
\text { Advice: Sorry, but your advisor has not provided any information } \\
\text { about it yet. }\end{array}$ \\
\hline Photo Organizer & $\begin{array}{l}\text { Description: Photo Organizer is a free program for every step } \\
\text { in the process of managing and sharing pictures. It offers easy } \\
\text { downloading from a camera or scanner and let's you stay orga- } \\
\text { nized with Sort Pictures so you can quickly find a picture. You } \\
\text { can also describe and tag your pictures, and even geotag your } \\
\text { photos and then pin it to a map to show where you too those } \\
\text { pictures. } \\
\text { Scenario: Over the years, youve accumulated what seems like } \\
\text { thousands of photos. You finally have found time to do some- } \\
\text { thing about them, but it is no easy task. A program that could } \\
\text { ease your workload would be nice, especially if it could limit the } \\
\text { clutter-factor in the future. } \\
\text { Advice: This application had shown vulnerability in the past. I } \\
\text { know that some of them were fixed, but I don't know if all. I'm } \\
\text { not sure about the security of this product so I would advise you } \\
\text { to avoid this download. }\end{array}$ \\
\hline
\end{tabular}


assessment and, for some scenarios, a suggested alternative application. For each of the three categories described above, three out of 11 applications were presented as alternatives to other applications. Therefore, each category contained five applications with no alternatives, three applications that had alternatives and the three alternatives, totalling 11 . In summary, the 11 applications in each category would contain one of the following options for advice:

Table 4: Advice

\begin{tabular}{llll}
\hline 1. & Good Software & $100 \%$ & no alternative \\
2. & Good Software & $70 \%$ & no alternative \\
3. & Bad Software & $100 \%$ & no alternative \\
4. & Bad Software & $70 \%$ & no alternative \\
5. & No Information & not applicable & not applicable \\
6. & Good Software & $70 \%$ & had alternative \\
7. & Bad Software & $100 \%$ & had alternative \\
8. & Bad Software & $70 \%$ & had alternative \\
\hline
\end{tabular}

Whenever there was a piece of advice that would suggest an alternative, the advice for the alternative would always be "Good Software" with $100 \%$ confidence level.

We chose the two levels $100 \%$ and $70 \%$ because we wanted to see the difference that it would make in the participants' decision if one type of advice showed complete confidence while the other was not completely confident.

\subsection{Procedure}

The study took place in the HotSoft Lab, and the duration was approximately one hour for each participant. A total of 60 people participated in the study, but only the data from 50 participants were used in the analysis due to the fact that some were 
pre-study participants and others did not seem to fully understand the task. All the sessions occurred during the month of June.

Participants were randomly assigned to one of five conditions, where their advisor varied by condition. Before they started the study, they were asked to read and sign the informed consent form. They were then asked to fill out the first questionnaire.

After the questionnaire, they were introduced to the task by completing a brief training exercise. During this part, they were able to familiarize themselves with the location of the content and using ONWatch. They were also told which advisor would be providing them with advice about downloading the application.

For those people that were in the captain condition, they were told to pretend that the advice was coming from their good friend who they trust for computer issues. The name of the advisor in this case was Alex McSmart, and such choice was made because Alex is applicable to either male or female and also sounded intelligent. Therefore, it would make it easier for the participants to pretend that Alex was their good "tech savvy" friend. When they felt confident that they understood the task, they would click a button to start the actual study. For participants that were in the paid authority condition, they were told that would receive advice from Symansoft, which is a security company and that the advice is a paid service, and they could assume that the fee had already been paid. For participants that were in the unpaid authority condition, they were told that would receive advice from CISA (Canadian Internet Security Advisor), which is a government organization that performs research in computer security subjects and it was a free service. Finally, for participants in the general people from the Internet condition, they were told that they would receive advice from other users from around the world and they did not know them necessarily. We did not specify precisely how many people were giving the advice, because we presumed people would be familiar with advice and review sites from the Internet. In practice, people might be likely to take more seriously advice 
agreed to by a larger number of people. This issue should be explored in future work. The participants had to make 24 decisions in total, and all participants were presented with the same set of situations. A situation is defined as a pair of a scenario and application. Thus, the user had to read the scenario description and then read the program description. They had the option of reading the advice from their advisor and would finally make a decision to either download the program or skip it. As soon as they made their decision and selected the desired button, they would be presented with the next situation. Some pieces of advice, as mentioned before, could suggest to the participant an alternative program. In those cases, they would have to choose to download either one of the two options, or to skip both.

Mouse clicks performed by the participants during the study were logged and saved in a database. That allowed us to measure how long they took to make decisions, what was their decision, and so on.

When they were done, they were presented with the last questionnaire (posttest). Finally they received their payment for participating in the study, which was a ten-dollar gift card from a popular coffee shop chain.

The following chapter will report the results obtained from this study. 


\section{Chapter 7}

\section{Results: hypotheses testing}

The study, described in Chapter 6, was carried out as planned. The recruitment took place over a one month period, for one hour each participant. More than 50 people were recruited, although we decided to use the data of 50 participants for the analysis, since some participants did not seem to fully understand the test. For instance, the participants received the following instruction: "please pretend those are real situations you are facing. Therefore, if the scenario says something such as you really like puzzles, please pretend that you like puzzles even though in real life you might not". At the end of the study, a couple of participants seemed to have skipped most of the software in the Fun category. When they were asked why, they responded that it was because they do not like games, or do not watch movies. So we inferred that they did not understand the test, and we did not use their data.

This chapter reports the results. The parameters used in the analysis were number of downloads, compliance, and time taken to make a decision. Each parameter will be explained in the next sections. All statistical analysis was carried out with the $\mathrm{R}$ package for statistical programming [49]. The study was conducted on the premises of three hypotheses to be tested. Each of these hypotheses and the applicable results are described in the three sections of this chapter. In summary, we found little support for hypothesis 1 and hypothesis 2 but strong support for hypothesis 3 . 


\subsection{Hypothesis 1}

This section presents a summary of the data associated with Hypothesis 1. After data is presented and analysed, a conclusion will be reached as to whether this hypothesis is supported or not.

H1: The captain model will lead to better security decisions than the friends from social network model and the general people from the Internet model.

For the extent of this report, each model involved in this section will be referred to as follows:

Captain model:

Alex

Friends from social network model:

Facebook

General people from the Internet model: General

\subsubsection{Downloads, Compliance, and Time}

The total number of downloads performed by each member, the compliance with the advice and the time taken to make each decision are explored in order to help the understanding of people's behaviour when making a decision.

\section{a) Downloads}

Table 5 shows descriptive statistics for the number of downloads. Figure 14 shows box plots containing information about the total number of downloads. Box plots were chosen to illustrate the distribution of data because they can be a convenient way of presenting data. They show the median as the black bar in the centre, the 2nd and 3rd quartiles as the bottom and top edges of the box, and the 1st and 4th quartiles as whiskers extending from the box. The notches indicate $95 \%$ confidence intervals around the median. In the cases where the confidence intervals fall outside 


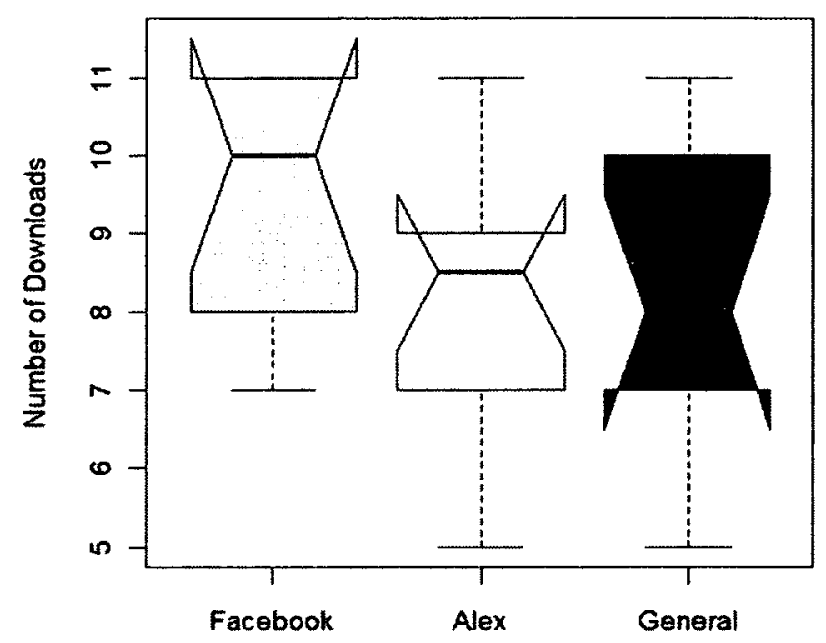

Figure 14: All Downloads

of the 2 nd or 3rd quartiles, the notches extend beyond the box. There can also be outliers, which are the points that appear to deviate markedly from other members of the sample in which it occurs.

Table 5: All Downloads

\begin{tabular}{lccccccc}
\hline & Median & Mean & Min & Max & SD & Skewness & Kurtosis \\
\hline Facebook & 10.0 & 9.5 & 7 & 11 & 1.6 & -0.5 & -1.6 \\
Alex & 8.5 & 8.2 & 5 & 11 & 1.8 & -0.3 & -1.1 \\
General & 8.0 & 8.1 & 5 & 11 & 1.9 & -0.0 & -1.4 \\
\hline
\end{tabular}

No strong conclusion can be drawn just by looking at figure 14, but it is interesting to see that, overall, there are more people in Facebook choosing to download applications than people in Alex, while people in General present very similar behavior to people in Alex condition. Table 5 also shows that people in Alex and General have a very similar mean number of downloads, while for Facebook the mean is slightly 
higher. Also, it shows that everyone in Facebook chose to download at least 7 applications, while people in the other two conditions had a lower minimum total number of downloads value of 5 .

The normality of the sample was assessed by examining the skewness and kurtosis of the distribution. When the skewness and kurtosis values were in the interval $[-3.00,3.00]$ we assumed that the sample was normal. Since in all three cases the skewness value and the kurtosis value are in that range, a one-way ANOVA was conducted to test the equality of the three means. Table 6 shows the result of this test. Analysis of variance (ANOVA) is a procedure used to test the equality of three or more means at one time by using variances. It assumes that the samples are independent, that the errors are normally distributed and that the variance is equal between groups. In this and all analysis below, we use an alpha value of 0.05 for significance to ensure independence of data. The data for each participant is aggregated by the independent variable (the group the participant belongs to).

Table 6: ANOVA of all downloads for Facebook, General and Alex.

\begin{tabular}{lccccc}
\hline & df & SS & MS & F & $p$ \\
\hline Advisor & 2 & 12.2 & 6.1 & 1.89 & 0.17 \\
Residuals & 27 & 87.0 & 3.2 & & \\
\hline
\end{tabular}

No significant differences in total number of downloads between the three conditions were seen $(F(2,27)=1.89, p=0.17)$. Although this is a clue indicating that participants did not present different behavior depending on their advisors, this can not be a definite conclusion yet.

\section{b) Compliance}

Next the compliance level is analysed for each condition.

We tried to estimate how compliant each participant were with the advice by the following formula: 


$$
C(x)=A d v(x)-A c t(x)
$$

where

$$
\operatorname{Adv}(x)= \begin{cases}2, & \text { if } x=\mathrm{Y} \\ 1, & \text { if } x=\mathrm{MY} \\ 0, & \text { if } x=\mathrm{NI} \\ -1, & \text { if } x=\mathrm{MN} \\ -2, & \text { if } x=\mathrm{N}\end{cases}
$$

and

$$
\operatorname{Act}(x)= \begin{cases}2, & \text { if } x=\text { Download } \\ -2, & \text { if } x=\text { Skip }\end{cases}
$$

In this formula, the compliance varies linearly with the advice and the action. For the advice meaning, please refer to table 7 .

Table 7: Advice list (need to change this caption)

\begin{tabular}{ll}
\hline Good software (100\% confident). & Y (yes) \\
Good software ( $70 \%$ confident). & MY (maybe yes) \\
No information about this software yet. & NI (no information) \\
Bad software ( $70 \%$ confident). & MN (maybe no) \\
Bad software (100\% confident). & N (no) \\
\hline
\end{tabular}

It is interesting to note that the more positive $\mathrm{C}(\mathrm{x})$ is, the more cautious (more skips) the participant is. The more negative, the more risky (more downloads) the participant is. 
Table 8: Compliance

\begin{tabular}{lccccccc}
\hline & Median & Mean & Min & Max & SD & Skewness & Kurtosis \\
\hline Facebook & -0.7 & -0.5 & -0.9 & 0.1 & 0.4 & 0.5 & -1.6 \\
Alex & -0.3 & -0.2 & -0.9 & 0.7 & 0.5 & 0.3 & -1.1 \\
General & -0.1 & -0.2 & -0.9 & 0.7 & 0.5 & 0.04 & -1.4 \\
\hline
\end{tabular}

Table 8 shows descriptive statistics for the compliance. Since skewness and kurtosis statistics are in the interval $[-3.00,3.00]$, we decided that all three samples were normal (as explained previously). Figure 15 shows box plots containing information about the compliance of members in each condition analysed in this section. It shows that people in Facebook are the least compliant, and they tend to be more risky: they have clicked download more often. General and Alex are similarly compliant, although people in the General condition tended to be the most cautious. Table 9 shows the results of an ANOVA conducted with those three samples. The results showed no significant difference between those groups $(F(2,27)=1.89, p=0.17)$.

Table 9: Compliance for Facebook, General and Alex.

\begin{tabular}{lccccc}
\hline & df & SS & MS & F & $p$ \\
\hline Advisor & 2 & 0.9 & 0.4 & 1.89 & 0.17 \\
Residuals & 27 & 6 & 0.2 & & \\
\hline
\end{tabular}

\section{c) Time}

Finally, another interesting aspect to this analysis is the time to make a decision. We have calculated the time taken to make a decision for each scenario and the result can be seen in the figure 16 and it is summarized in table 10 .

In this case, for all three conditions the skewness value and the kurtosis value are less than 3. Therefore, a one-way ANOVA was conducted.

The tests, with results that can be seen in table 11, showed no significant difference 


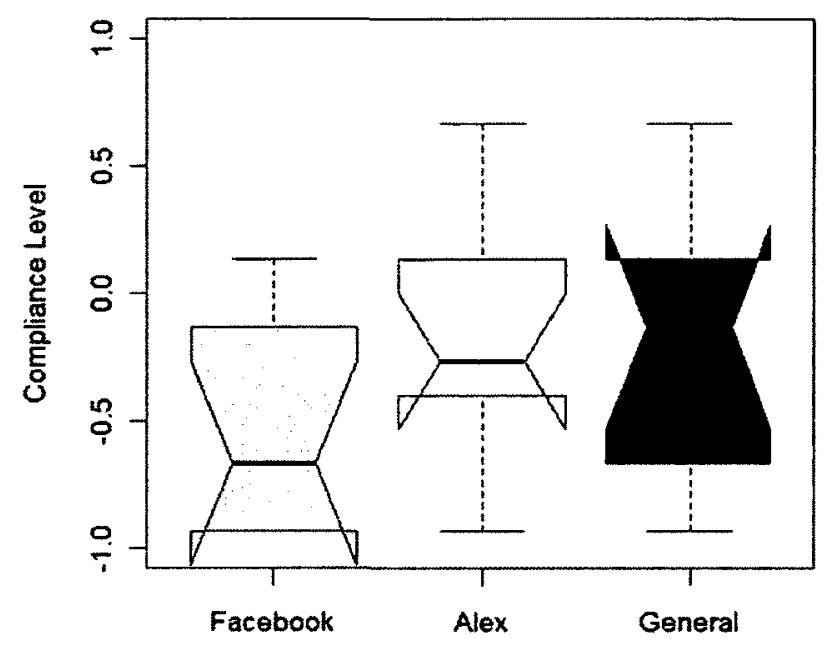

Figure 15: Compliance Level

Table 10: Descriptive statistics for time (sec)

\begin{tabular}{lccccccc}
\hline & Median & Mean & Min & Max & SD & Skewness & Kurtosis \\
\hline Facebook & 33.6 & 35.4 & 11.9 & 55.3 & 13.3 & -0.1 & -1.2 \\
Alex & 32.4 & 32.6 & 14.3 & 51.8 & 11.9 & 0.2 & -1.2 \\
General & 23.1 & 24.6 & 16.4 & 38.8 & 7.4 & 0.6 & -1.1 \\
\hline
\end{tabular}

in the time taken to make a decision between all three conditions $(F(2,27)=2.52, p=$ 0.09). Nevertheless, it is interesting to note that the time taken to make a decision by the participants in Facebook and Alex were both greater than the participants in General. For the latter, people in average were 10.8 seconds (30\%) faster than in Facebook condition and 8 seconds (25\%) faster than people in Alex condition. It is also interesting to note that in the General condition people were $10.8 \mathrm{~s}$ faster than Facebook, which is $50 \%$ of their average time. We would think that people make quick decisions when they know about something, therefore they don't need to spend time thinking about it. But figure 15 shows that people in the General condition were 
Table 11: ANOVA of time to make a decision for Facebook, General and Alex.

\begin{tabular}{lccccc}
\hline & df & SS & MS & F & $p$ \\
\hline Advisor & 2 & 625.1 & 312.6 & 2.52 & 0.09 \\
Residuals & 27 & 3353.7 & 124.2 & & \\
\hline
\end{tabular}

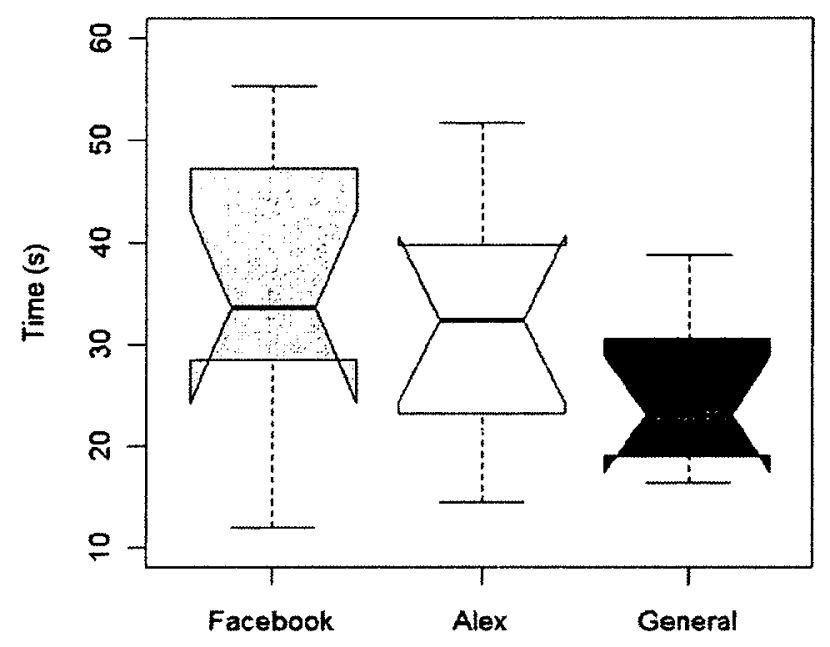

Figure 16: Average decision time for each Scenario

actually very compliant with the advice. So we speculate that they would check the advice and immediately follow that advice. That is a very surprising result, since our hypothesis was that people would trust a specific friend (Alex) better than general people from the Internet.

We hypothesized that people in the Alex condition would make better software decisions than people in Facebook and General conditions. The results showed that, although people were slightly less compliant in the Facebook condition, no evidence of differences between those three groups was found. Therefore, we found little or no support for hypothesis 1 . 


\subsubsection{Advice confidence}

In this section we explore the effect of advice confidence on the user decisions. Past research has found that factors such as advisor confidence is a significant factor affecting advice matching [30]. Therefore we investigate the role played by the advisor's confidence in this study.

We have explored the differences between the number of downloads depending on the confidence level stated by the advisor. As mentioned previously, for each advice "Good Software (Y)" and "Bad Software (N)" there was a corresponding less confident advice: "Good Software with $70 \%$ confidence (MY)" and "Bad Software with $70 \%$ confidence (MN)". Besides those four types of advice, there was a fifth one, which actually represented the absence of advice (NI). Table 7 shows a summary of the advice and the abbreviation used for each of them.

Figure 17 depicts box plots of the number of downloads for each type of advice received by the participants. The figure actually contains three graphs, each corresponding to the data for the three conditions analysed in hypothesis 1 (Facebook, General and Alex).

Figure 17 suggests that a participant's decisions were influenced by their advisor's confidence in the advice: the number of downloads decreased when the advisor suggested a download (MY) but did not guarantee complete confidence in the advice, and the number of downloads increased when advisors were not confident about the advice to not download (MN).

Table 12 and table 13 show the results of a two-way ANOVA that tests the significance of the main effect for two independent variables: the group each participant is in, and the advice given. It is very similar to the one-way ANOVA test. However, in addition to the main effect, the interaction effect across different independent variables is also evaluated. 


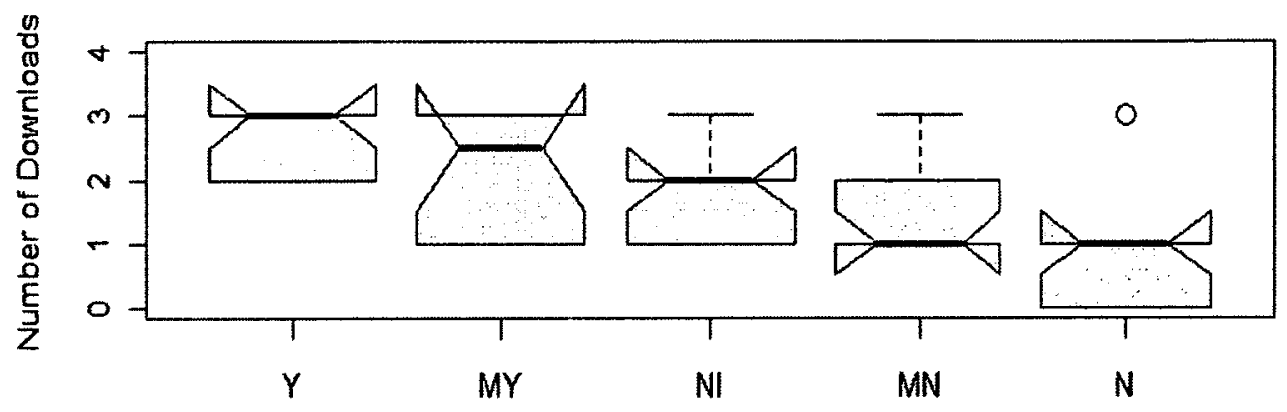

Facebook
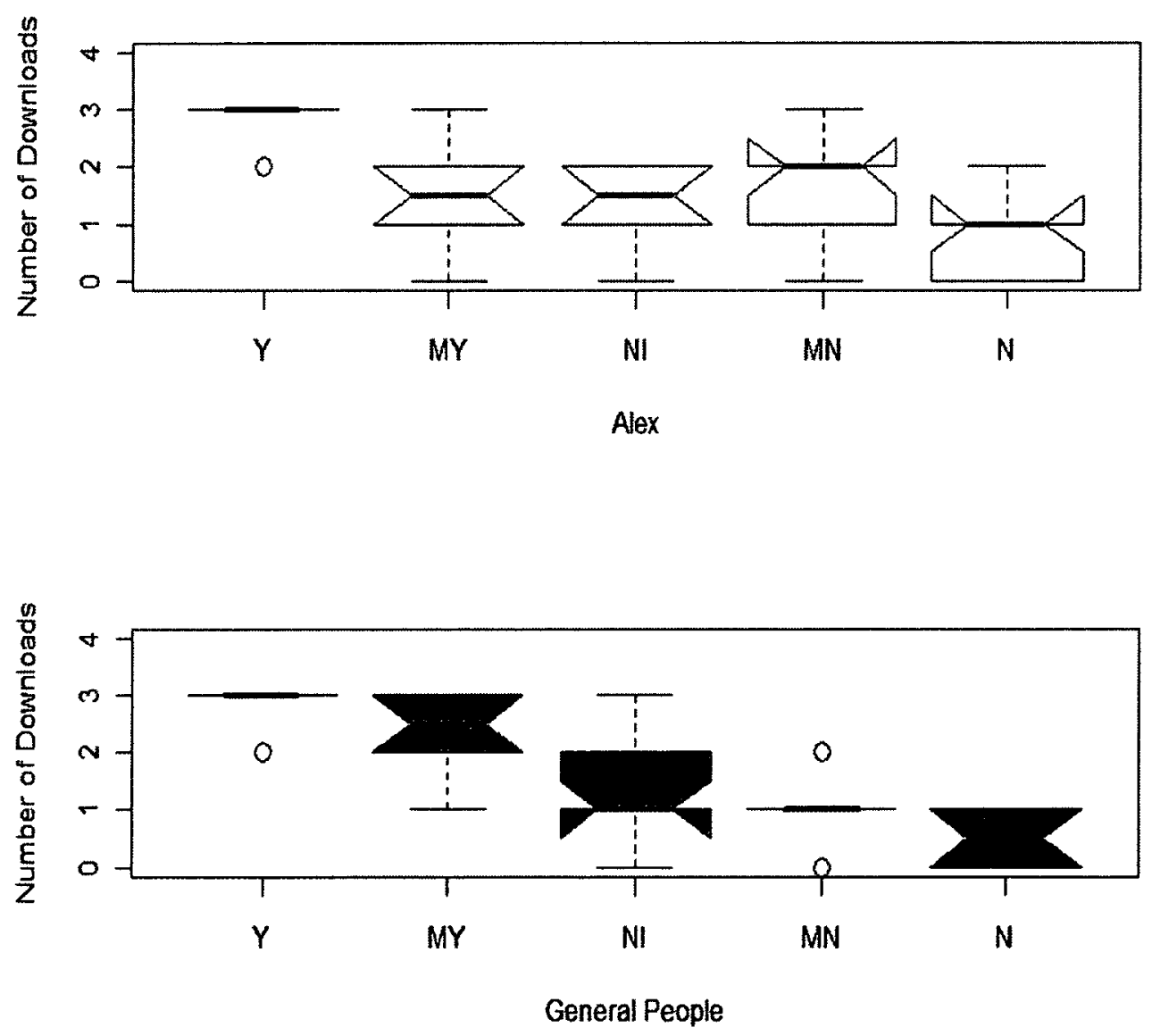

Figure 17: Confidence Level 
Table 12: ANOVA of confidence level $N$ and number of downloads for Facebook, General and Alex.

\begin{tabular}{lccccc}
\hline & df & SS & MS & F & $p$ \\
\hline Advisor & 2 & 3.9 & 2 & 3.1 & 0.053 \\
Advice & 1 & 6.7 & 6.7 & 11 & 0.002 \\
Advisor:Advice & 2 & 0.8 & 0.4 & 0.66 & 0.52 \\
Residuals & 54 & 34 & 0.6 & & \\
\hline
\end{tabular}

Table 13: ANOVA of confidence level $\mathrm{Y}$ and number of downloads for Facebook, General and Alex.

\begin{tabular}{lccccc}
\hline & df & SS & MS & F & $p$ \\
\hline Advisor & 2 & 1.6 & 0.8 & 1.8 & 0.18 \\
Advice & 1 & 8.8 & 8.8 & 20 & $<.001$ \\
Advisor:Advice & 2 & 2.1 & 1.1 & 2.4 & 0.1 \\
Residuals & 54 & 24 & 0.4 & & \\
\hline
\end{tabular}

Those tables show that there are no significant mean differences between our groups for the independent variable advisor, which is the condition the participants are in. However, the results show that there is a correlation between the number of downloads and the advice confidence in both cases: "good software" $(F(1,54)=$ $20, p=0.002)$ and "bad software" $(F(1,54)=11, p<.001)$. Finally, the last line of table 12 and table 13 shows the group*advice interaction and that there is no statistically significant interaction between them and the dependent variable number of downloads $(F(2,54)=0.66, p=0.52)$ and $F(2,54)=2.4, p=0.1)$

We were in fact expecting a difference in the number of downloads when the advisor showed different levels of confidence in their advice, and the results met our expectations. It is also interesting to note that, when we plot a graph such as figure 17 , there is (roughly) a decreasing line drawn by the average medians of each 
box. Also, it is relevant to note that people in Facebook and in General behaved more closely to what we were expecting, while people in the Alex condition behaved surprisingly, choosing to download more applications in general when the advice was not to download with confidence of $70 \%$, compared to when the advice was to download with confidence of $70 \%$. There is no obvious reason why people are being more cautious when they are being advised to download than when they are being advised not to download, even when the confidence of the advisor is not $100 \%$.

\subsubsection{The software category}

We also evaluated if there would be a difference in the number of downloads depending on the category of the software. As we talked about previously, we came up with different applications that would fit in one of three categories (FUN, UTILITY and WELL KNOWN).

Figure 18 shows the number of downloads per category of software. People in all three conditions have downloaded more software in the WELL KNOWN category than any of the other two categories.

The figure shows that in this experiment, people in the Facebook and General conditions have very similar behaviour, while people in Alex condition have a slightly higher download number in the WeLl KNOWN category. This suggests that people do not rely on advice or the tool (we observed during the lab sessions that sometimes participants would not even look at the advice) if they previously know the software. It is worth noting that the maximum number of downloads each participant can have is 5 , meaning that in all three cases $25 \%$ of the people chose to download all the well known software presented to them.

Table 14 shows that the skewness value and the kurtosis value are in the interval $[-3.00,3.00]$. Therefore, a two-way ANOVA was conducted to test whether there are any significant differences between the means of those groups. The results from this 


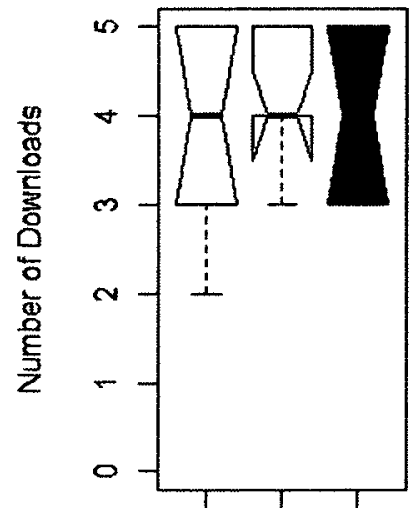

a) Well known

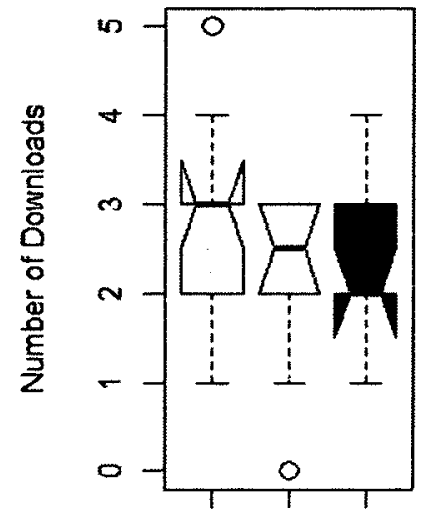

b) Fun

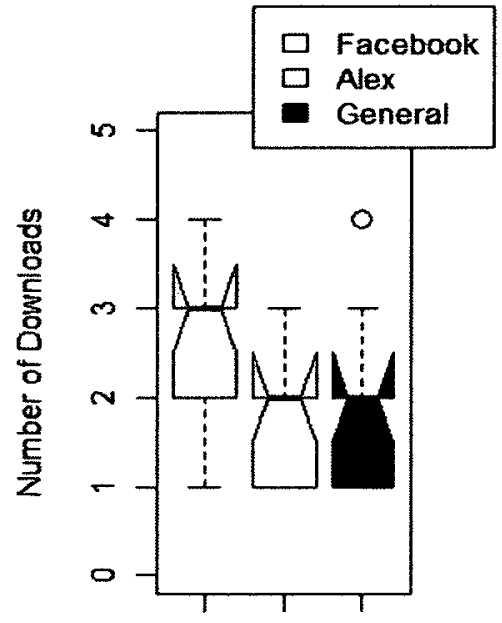

c) Utility

Figure 18: Downloads in category

test can be observed in table 15 .

No significant differences in the number of downloads $(F(2,81)=2, p=0.1)$ were found among the three groups. Additionally, no difference in the interaction advisor*category $(F(4,81)=2, p=0.4)$ was found either. Nonetheless, the test showed significant differences in the number of downloads in the categories $(F(2,81)=$ $32, p<.001)$.

Table 16 shows a pairwise comparison between each software category, resulting from a t-test. A t-test, like ANOVA, assesses whether the means of two groups are statistically different from each other. The WELL KNOWN category is statistically different from both other two categories, nonetheless no difference was found between the FUN and UTILITY categories.

Research on decision making shows that decision-makers often do not accept advice even if it might be beneficial, when they feel they can rely on their own judgement 
Table 14: Descriptive statistics for number of downloads of software in each category

\begin{tabular}{|c|c|c|c|c|c|c|c|}
\hline \multicolumn{8}{|c|}{ WELL KNOWN } \\
\hline & Median & Mean & Min & Max & $\mathrm{SD}$ & Skewness & Kurtosis \\
\hline Facebook & 4.0 & 3.9 & 2 & 5 & 1.0 & -0.4 & -1.1 \\
\hline Alex & 4.0 & 4.1 & 3 & 5 & 0.7 & -0.1 & -1.3 \\
\hline General & 4.0 & 4.0 & 3 & 5 & 0.9 & 0.0 & -2.0 \\
\hline \multicolumn{8}{|c|}{ FUN } \\
\hline & Median & Mean & Min & Max & $\mathrm{SD}$ & Skewness & Kurtosis \\
\hline Facebook & 3.0 & 2.9 & 1 & 5 & 1.1 & 0.2 & -0.6 \\
\hline Alex & 2.5 & 2.2 & 0 & 3 & 1.0 & -0.9 & -0.6 \\
\hline General & 2.0 & 2.2 & 1 & 4 & 0.9 & 0.4 & -0.8 \\
\hline \multicolumn{8}{|c|}{ UTILITY } \\
\hline & Median & Mean & Min & $\operatorname{Max}$ & $\mathrm{SD}$ & Skewness & Kurtosis \\
\hline Facebook & 3.0 & 2.7 & 1 & 4 & 1.1 & -0.5 & -1.2 \\
\hline Alex & 2.0 & 1.9 & 1 & 3 & 0.7 & 0.1 & -1.3 \\
\hline General & 2.0 & 1.9 & 1 & 4 & 1.0 & 0.8 & -0.6 \\
\hline
\end{tabular}

instead [38]. This might explain our results, because people tended to ignore the advice when they faced a familiar situation and trusted their own judgment whether it was safe or not to choose to download the well known software.

\subsection{Hypothesis 2}

Similarly to section 1, this section explores the data associated with the conditions in Hypothesis 2 and several tests are conducted in order understand if this hypothesis is supported or not.

H2: The captain model will lead to similarly good security decisions as the paid security authority model and the unpaid security authority model. 
Table 15: Two-way ANOVA of number of downloads (advisor*category)

\begin{tabular}{lccccc}
\hline & df & SS & MS & F & $p$ \\
\hline Advisor & 2 & 4 & 2 & 2 & 0.1 \\
Category & 2 & 59 & 29 & 32 & $<.001$ \\
Advisor:Category & 4 & 4 & 0.9 & 1 & 0.4 \\
Residuals & 81 & 74 & 0.9 & & \\
\hline
\end{tabular}

Table 16: $t$-tests of software category

\begin{tabular}{lrrr}
\hline & $t$ & $\mathrm{df}$ & $p$ \\
\hline Well Known vs. Fun & 6.3 & 56.3 & $<.001$ \\
Well Known vs. Utility & 7.6 & 57.1 & $<.001$ \\
Utility vs. Fun & 1 & 57.8 & 0.312 \\
\hline
\end{tabular}

Each model involved in this section will be referred as follows:

Captain model: $\quad$ Alex

Unpaid authority model: CISA

Paid authority model: Symansoft

\subsubsection{Downloads, Compliance, and Time}

In order to understand if there are significant differences between the Alex, CISA and Symansoft conditions, several tests are performed involving the number of downloads, the compliance with the advice and the time taken to make each decision by each member.

\section{a) Downloads}

Figure 19 illustrates the total downloads chosen by each condition in this hypothesis, while table 17 shows the descriptive statistics for that data. 


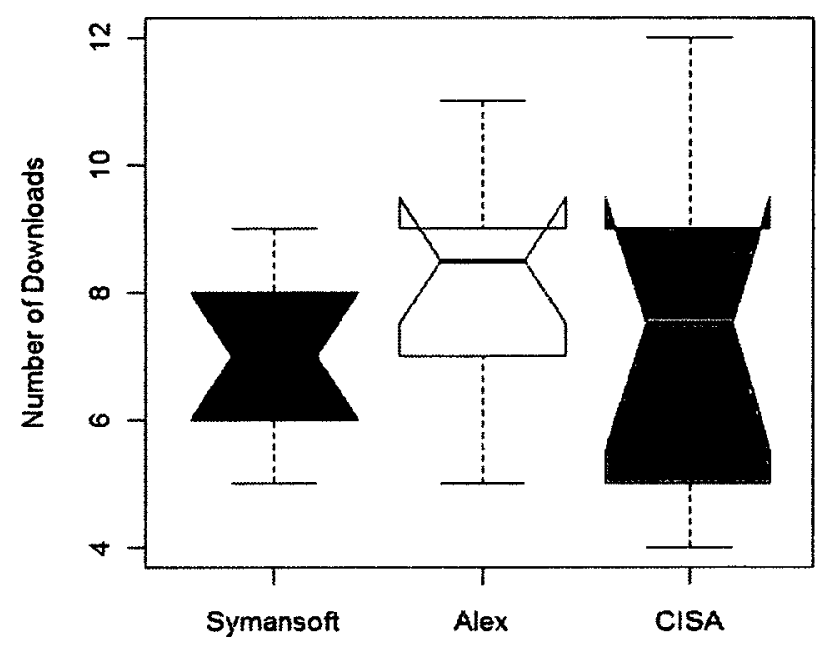

Figure 19: All Downloads

The mean number of downloads ranged between 7.1 in the Symansoft condition, and 8.2 in the Alex condition. The median number of downloads ranged between 7 in the Symansoft condition, and 8.5 in the Alex condition. The total number of available applications that people could choose to download was 15. Therefore, this result shows that, in average, participants chose to download half of the options available to them. The greatest number of downloads was 12 and it was performed by someone in the CISA condition. Moreover, figure 19 shows that people in Symansoft were the most cautious. The maximum number of downloads in that condition was 9, which is the number of donwloads performed by $75 \%$ of people in both Alex and CISA conditions.

Since skewness and kurtosis statistics are in the interval $[-3.00,3.00]$, we decided that all three samples were normal. Therefore, a one-way ANOVA was conducted to test the equality of the three means. Table 18 shows the result of this test.

No significant differences in the number of downloads among the three conditions 
Table 17: All Downloads

\begin{tabular}{lccccccc}
\hline & Median & Mean & Min & Max & SD & Skewness & Kurtosis \\
\hline Symansoft & 7.0 & 7.1 & 5 & 9 & 1.4 & -0.2 & -1.5 \\
Alex & 8.5 & 8.2 & 5 & 11 & 1.8 & -0.3 & -1.1 \\
CISA & 7.5 & 7.6 & 4 & 12 & 3.0 & 0.2 & -1.5 \\
\hline
\end{tabular}

Table 18: ANOVA of all downloads for CISA, Symansoft and Alex.

\begin{tabular}{lccccc}
\hline & df & SS & MS & F & $p$ \\
\hline Advisor & 2 & 6.1 & 3.0 & 0.6 & 0.5 \\
Residuals & 27 & 126.9 & 4.7 & & \\
\hline
\end{tabular}

were seen $(F(2,27)=0.65, p=0.532)$, indicating that there was no evidence that participants behaved differently depending on their source of advice.

b) Compliance

Table 19: Compliance

\begin{tabular}{lccccccc}
\hline & Median & Mean & Min & Max & SD & Skewness & Kurtosis \\
\hline Symansoft & 0.1 & 0.1 & -0.4 & 0.7 & 0.4 & 0.2 & -1.5 \\
Alex & -0.3 & -0.2 & -0.9 & 0.7 & 0.5 & 0.3 & -1.1 \\
CISA & 0 & -0.03 & -1.2 & 0.9 & 0.8 & -0.2 & -1.5 \\
\hline
\end{tabular}

Table 19 shows descriptive statistics for the compliance. Since skewness and kurtosis statistics are in the interval $[-3.00,3.00]$, we decided that all three samples were normal (as explained previously). Figure 15 shows boxplots for the compliance level in each condition. It shows that people in the Symansoft condition were the most cautious while people in the Alex condition were the most risky compared to the other two. Table 9 shows the results of an ANOVA conducted with those three samples. The results showed no significant difference between those groups 


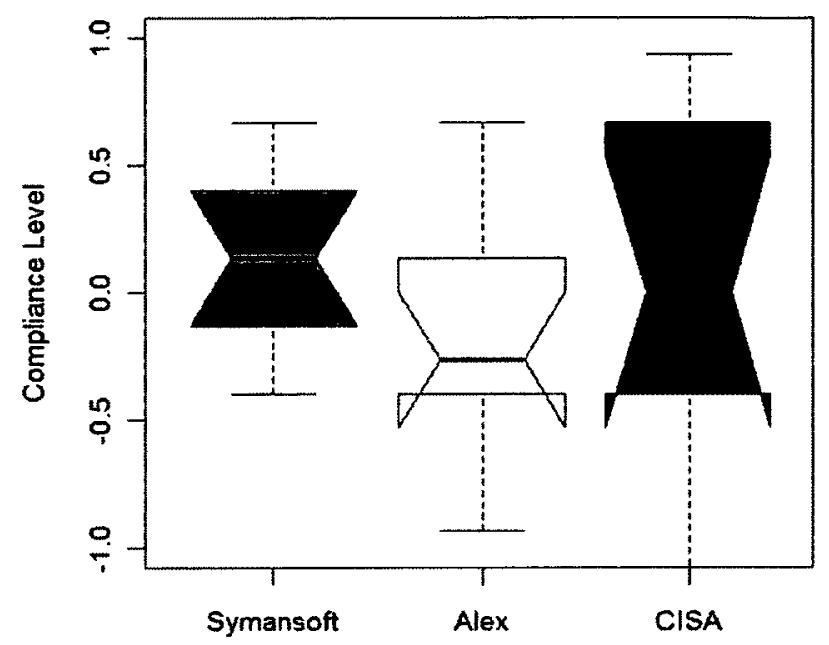

Figure 20: Compliance Level

$(F(2,27)=0.65, p=0.53)$.

Table 20: Compliance for CISA, Symansoft and Alex.

\begin{tabular}{lccccc}
\hline & df & SS & MS & F & $p$ \\
\hline Advisor & 2 & 0.4 & 0.2 & 0.65 & 0.53 \\
Residuals & 27 & 9 & 0.3 & & \\
\hline
\end{tabular}

\section{c) Time}

Lastly, figure 21 shows the boxplots of time in seconds taken by the participants to make a decision. The graphs for the Alex and CISA conditions look very similar, while people in the Symansoft condition made decisions slightly faster.

Table 21 shows the descriptive statistics of the time taken to make each decision for each condition. Mean time were similar and longest in the Alex (32.6 seconds) and CISA (33.3 seconds) conditions, and shortest in the Symansoft (28.5 seconds). The median login times were shorter in every condition. For all three conditions the 


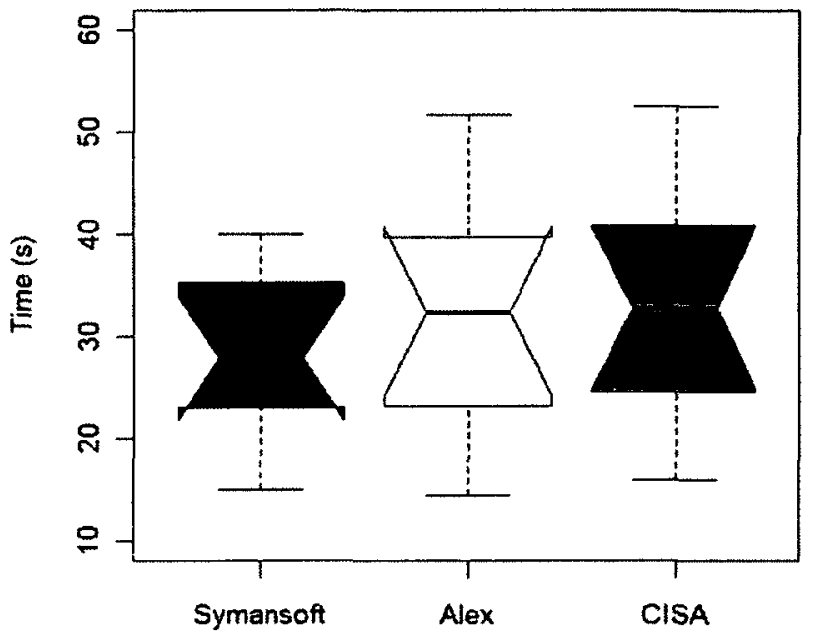

Figure 21: Average decision time for each Scenario

skewness value and the kurtosis value fall in the interval $[-3.00,3.00]$. Therefore, a one-way ANOVA was conducted to test if there was a significant difference among the three groups. Table 22 shows the results of this test.

Table 21: Descriptive statistics for time (sec)

\begin{tabular}{lccccccc}
\hline & Median & Mean & Min & Max & SD & Skewness & Kurtosis \\
\hline Symansoft & 27.9 & 28.5 & 15.0 & 40.0 & 8.5 & -0.1 & -1.5 \\
Alex & 32.4 & 32.6 & 14.3 & 51.8 & 11.9 & 0.2 & -1.2 \\
CISA & 32.7 & 33.3 & 15.9 & 52.6 & 11.9 & 0.3 & -1.3 \\
\hline
\end{tabular}

No significant differences in time $(F(2,27)=2.52, p=0.09)$ were found among the three study conditions.

All the tests made in this section showed that there is no differences among the Alex, Symansoft and CISA conditions, which leads us to suspect that hypothesis 2 is supported: the Alex conditions will lead to similarly good security decisions as 
Table 22: ANOVA of time to make a decision for CISA, Symansoft and Alex.

\begin{tabular}{lccccc}
\hline & df & SS & MS & F & $p$ \\
\hline Advisor & 2 & 136.0 & 68.0 & 0.6 & 0.56 \\
Residuals & 27 & 3180.9 & 117.8 & & \\
\hline
\end{tabular}

the other two authority conditions. This result, however, is not definitive. Since the number of participants in each condition was not really high, we can not confirm the results. More participants would be necessary for a more definitive result.

\subsubsection{Advice confidence}

The influence of advice confidence was also investigated in the conditions evaluated in this section. Figure 22 shows three graphs: one for each condition, each graph showing the boxplot of the number of downloads for each type of advice.

The figure shows that people's choice whether to download an application or not was influenced by the advice and the advisor's confidence in the advice. People followed the advice when the confidence demonstrated was higher. This means that, when the advice was positive (Y), most people chose to download all the applications. Some exceptions are in the CISA conditions, where some of the participants had a more cautious behaviour and, even with a confident and positive advice, they chose to skip one application. When the advice was negative (N), participants in CISA and Symansoft condition presented the same behaviour. For those pieces of advice, $50 \%$ of the participants in both conditions chose to download at most one application when the advisor did not demonstrate total confidence in the advice, and $50 \%$ of the participants chose not to download any application when the advice was negative with $100 \%$ confidence. 

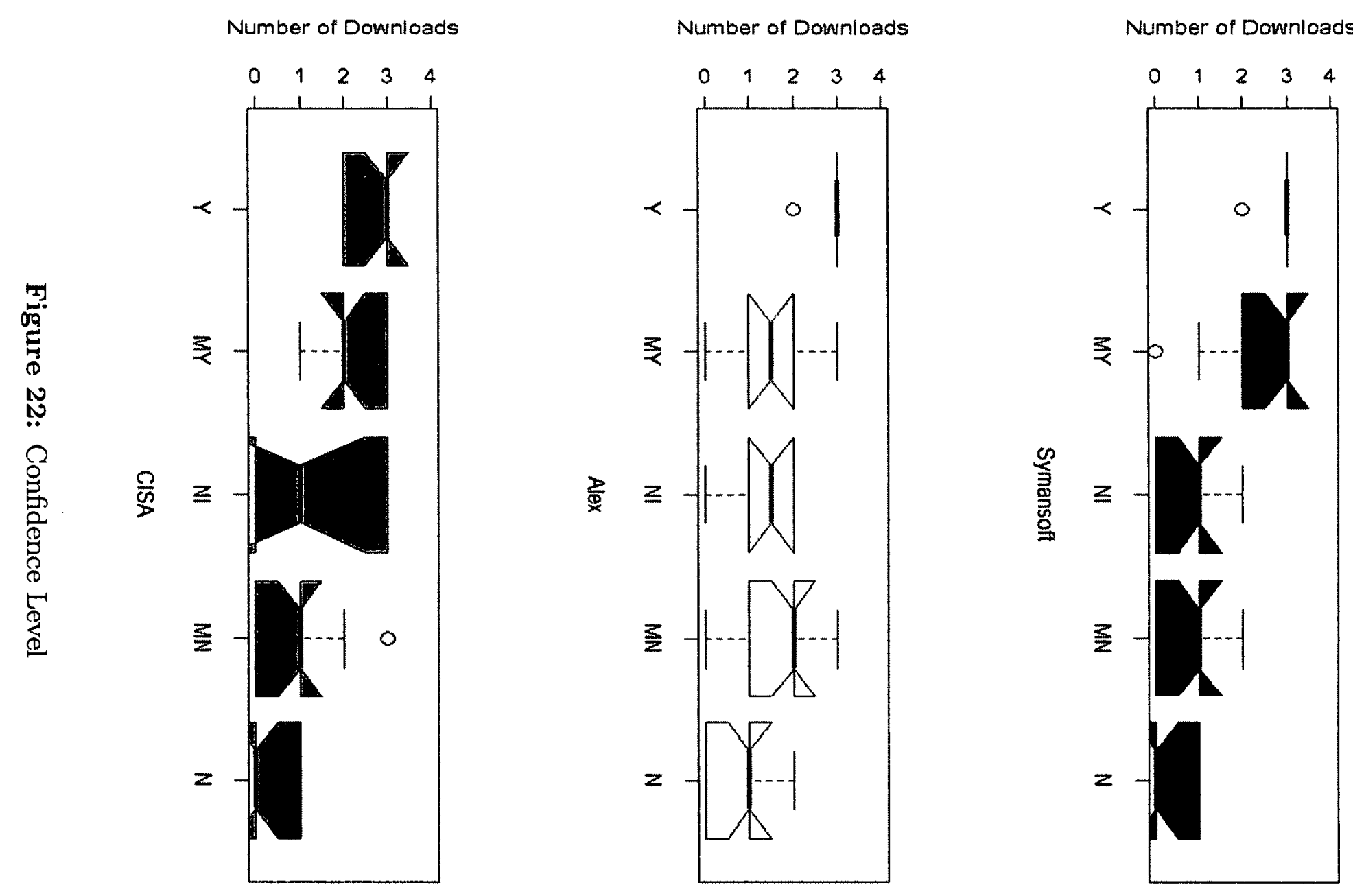
Table 23 and table 24 shows the results of a two-way ANOVA for the two independent variables that we are interested in: the group each participant belongs to and the type of advice received by the participant.

Table 23: ANOVA of confidence level $N$ and number of downloads for Symansoft, CISA and Alex.

\begin{tabular}{lccccc}
\hline & df & SS & MS & F & $p$ \\
\hline Advisor & 2 & 4.9 & 2.5 & 4.7 & 0.013 \\
Advice & 1 & 5.4 & 5.4 & 10 & 0.0021 \\
Advisor:Advice & 2 & 1.3 & 0.65 & 1.3 & 0.29 \\
Residuals & 54 & 28 & 0.52 & & \\
\hline
\end{tabular}

Table 24: ANOVA of confidence level $Y$ and number of downloads for Symansoft, CISA and Alex.

\begin{tabular}{lccccc}
\hline & df & SS & MS & F & $p$ \\
\hline Advisor & 2 & 0.93 & 0.47 & 0.88 & 0.42 \\
Advice & 1 & 8.8 & 8.8 & 17 & $<.001$ \\
Advisor:Advice & 2 & 2.1 & 1.1 & 2 & 0.14 \\
Residuals & 54 & 29 & 0.53 & & \\
\hline
\end{tabular}

As expected, the results show that there is a correlation between the number of downloads and the advice confidence in both cases: $\mathrm{Y}(F(1,54)=17, p=0.00015)$ and $\mathrm{N}(F(1,54)=10, p=0.0021)$. Also, a significant difference was found between the conditions when the advice was $\mathrm{N}(F(2,54)=4.7, p=0.013)$ but no significant difference was found when the advice was $\mathrm{Y}(F(2,54)=0.88, p=0.425)$. No significant differences in number of downloads for both types of advice were found in the interaction member*advice, $\mathrm{Y}(F(2,54)=2, p=0.14)$ and $\mathrm{N}(F(2,54)=1.3, p=0.29)$. 


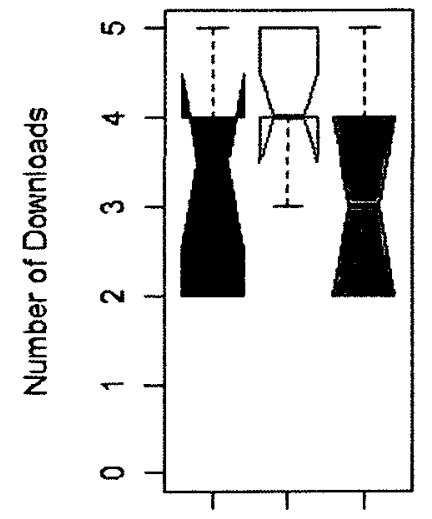

a) Well Known

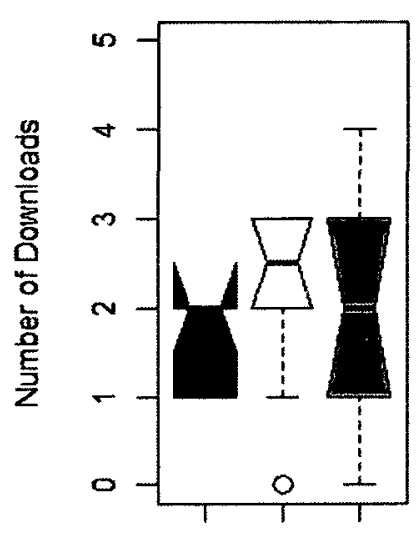

b) Fun

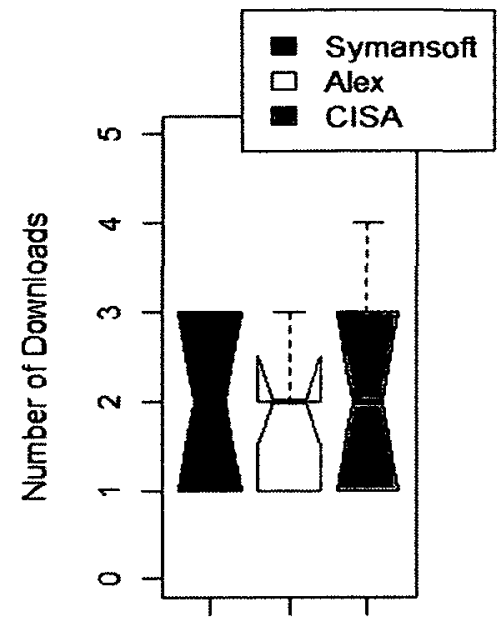

c) Utility

Figure 23: Downloads in category

\subsubsection{The software category}

In this subsection we explore the influence of the software category in the number of downloads in each condition. Figure 23 shows the number of downloads per category of software.

As expected, people in all conditions have downloaded more software in the WELL KNOwN category compared to the other two categories.

The median number of downloads for the WELL KNOWN category was 3.0, 3.5 and 4.5 (Symansoft, Alex and CISA conditions respectively). For the other two categories, the median number of downloads was 2.0 (except for the Alex condition in the FuN category, which was 2.5). The maximum number of downloads in the WELL KNOWN category was 5 for all three conditions, while for the other two it ranged from 2 to 4 . This clearly shows that people rarely trusted or used the advice for the software in the WELL KNOWN category. Moreover, the minimum number of downloads in the FUN category was 0 for the Alex and CISA conditions and 1 for the Symansoft. In 
the UTILITY category, the minimum number of downloads was 1.

Table 25: Descriptive statistics for number of downloads of software in each category

\begin{tabular}{|c|c|c|c|c|c|c|c|}
\hline \multicolumn{8}{|c|}{ WELL KNOWN } \\
\hline & Median & Mean & Min & $\operatorname{Max}$ & $\mathrm{SD}$ & Skewness & Kurtosis \\
\hline Symansoft & 3.5 & 3.3 & 2 & 5 & 1.3 & 0.1 & -1.8 \\
\hline Alex & 4.0 & 4.1 & 3 & 5 & 0.7 & -0.1 & -1.3 \\
\hline CISA & 3.0 & 3.3 & 2 & 5 & 1.2 & 0.2 & -1.6 \\
\hline \multicolumn{8}{|c|}{ FUN } \\
\hline & Median & Mean & $\operatorname{Min}$ & $\operatorname{Max}$ & $\mathrm{SD}$ & Skewness & Kurtosis \\
\hline Symansoft & 2.0 & 1.7 & 1 & 2 & 0.5 & -0.7 & -1.6 \\
\hline Alex & 2.5 & 2.2 & 0 & 3 & 1.0 & -0.9 & -0.6 \\
\hline CISA & 2.0 & 2.0 & 0 & 4 & 1.2 & 0.0 & -1.4 \\
\hline \multicolumn{8}{|c|}{ UTILITY } \\
\hline & Median & Mean & Min & $\operatorname{Max}$ & $\mathrm{SD}$ & Skewness & Kurtosis \\
\hline Symansoft & 2.0 & 2.1 & 1 & 3 & 0.9 & -0.2 & -1.8 \\
\hline Alex & 2.0 & 1.9 & 1 & 3 & 0.7 & 0.1 & -1.3 \\
\hline CISA & 2.0 & 2.3 & 1 & 4 & 1.2 & 0.2 & -1.6 \\
\hline
\end{tabular}

Because skewness and kurtosis statistics are in the interval $[-3.00,3.00]$, a two-way ANOVA was conducted in order to determine if there was any significant difference in the means of the independent variable analysed in this subsection.

Table 26 shows that no significant differences in the number of downloads $(F(2,81)=1, p=0.4)$ were found among the Symansoft, Alex and CISA conditions, even after applying any correction for post-hoc analysis. Furthermore, the test showed that there is no significant difference in the interaction advisor * category $(F(4,81)=1, p=0.4)$. However, a significant difference was found among the categories $(F(2,81)=24, p<.001)$.

A pairwise t-test was performed in order to determine which category is different 
Table 26: Two-way ANOVA of number of downloads (advisor*category)

\begin{tabular}{lccccc}
\hline & df & SS & MS & F & $p$ \\
\hline Advisor & 2 & 2 & 1 & 1 & 0.4 \\
Category & 2 & 47 & 24 & 24 & $<.001$ \\
Advisor:Category & 4 & 4 & 1 & 1 & 0.4 \\
Residuals & 81 & 81 & 1 & & \\
\hline
\end{tabular}

from the other. The results can be seen in table 27. No difference was found between the UTILITY and Fun categories, but a significant difference was found between the WELL KNOWN category and the other two categories.

Table 27: $t$-tests of software category

\begin{tabular}{lrrr}
\hline & $t$ & $\mathrm{df}$ & $p$ \\
\hline Well Known vs. Fun & 6 & 57.0 & $<.001$ \\
Well Known vs. Utility & 5.6 & 56.2 & $<.001$ \\
Utility vs. Fun & -0.55 & 57.9 & 0.586 \\
\hline
\end{tabular}

As discussed in subsection 7.1.3, the difference found in the results was not a surprise. People tend to overemphasize their own opinion relative to that of their advisor since they have access to their internal justifications for arriving at a particular decision and they are familiar with the situation. The other two categories only had applications that do not exist, so people could not be familiar with them. Therefore, it was likely that they would give a greater weight to their advisor's opinion.

\subsection{Hypothesis 3}

In this section, our last hypothesis and the data related to it is discussed. As previously cited: 


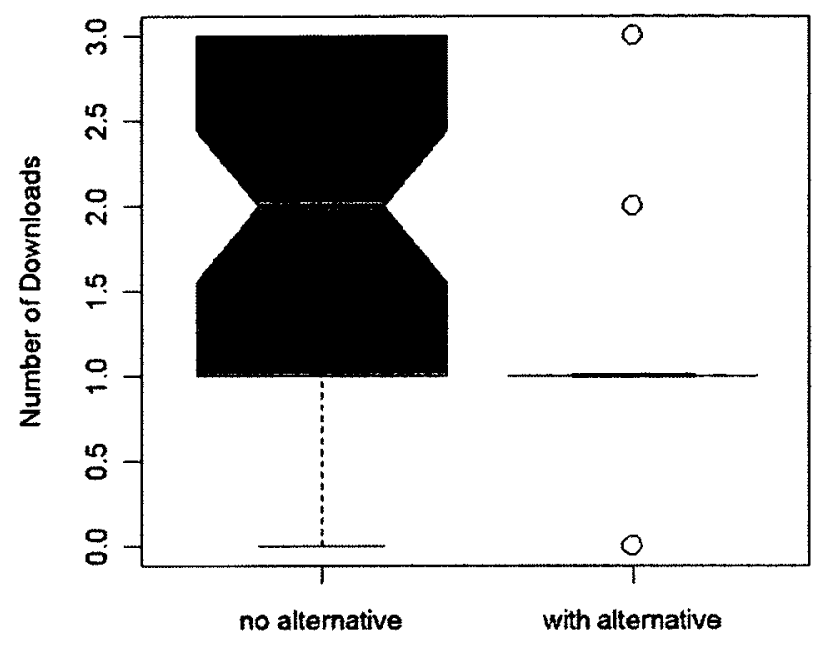

Figure 24: Alternative Comparison for advice MY

H3: Presenting alternatives will improve security.

In order to be able to see if our hypothesis was supported or not, every participant had 9 situations in which they were given a second option (alternate software) that they could choose from, in addition to the 9 presented without alternative. Those situations happened when the advice was either MY, MN or N (see table 7). Whenever an alternative was suggested, this alternative would come with an advice of type Y. These same type of advice would also show up to the participant but with no suggested alternative. Thus, we were able to compare the number of downloads for each type of advice when there was a suggested alternative or not.

Figure 24, figure 25 and figure 26 depict boxplots for each advice given, and compare the cases with or without an alternative application. Except for figure 26, each pair of boxes shows differences, and the number of downloads decreases when the advisor suggested an alternative. Moreover, the confidence interval of each box do not overlap with the other, suggesting distinct confidence intervals. 


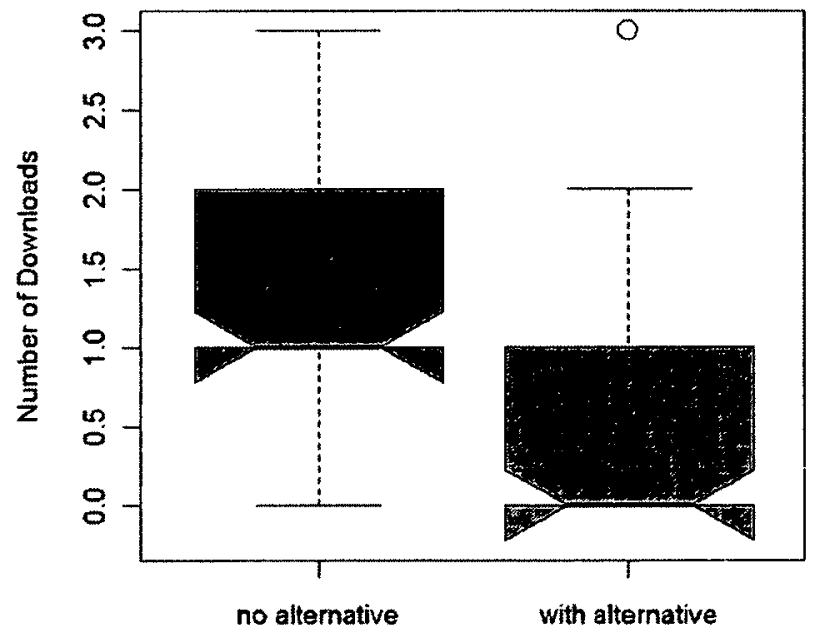

Figure 25: Alternative Comparison for advice MN

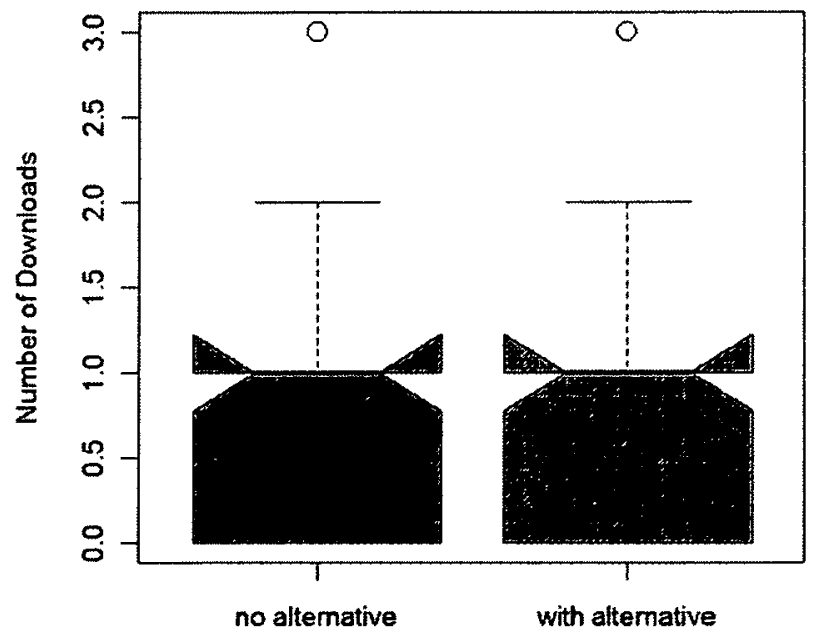

Figure 26: Alternative Comparison for advice N 
Table 28 shows the descriptive statistics for the number of downloads for each type of advice, both for when there was and when there wasn't an alternative. It is interesting to note that, for every type of advice, with an alternative or not, there were people choosing to download all three possible applications and people choosing to skip all of them ( $\min =0$ and $\max =3$ in all cases). The median value was always lower when there was an alternative, except when the advice was N. In that case, the median number of downloads was 1 for both. Moreover, $75 \%$ of the participants downloaded 1 or less. Additionally, the fact that the median value was 1 or higher for all the cases, except when the advice was MN with an alternative, is probably explained by by the downloads in the WELL KNOWN category. As discussed in the previous sections, people tended to disregard advice when they were familiar with the software and download it.

Table 28: Descriptive statistics for number of downloads of software

\begin{tabular}{clccccccc}
\hline Advice & & Median & Mean & Min & Max & SD & Skewness & Kurtosis \\
\hline \multirow{2}{*}{ MY } & No Alternative & 2 & 2 & 0 & 3 & 0.9 & -0.6 & -0.8 \\
& With Alternative & 1 & 1 & 0 & 3 & 0.8 & 0.7 & 0.2 \\
\hline \multirow{2}{*}{ MN } & No Alternative & 1 & 1 & 0 & 3 & 0.9 & 0.4 & -0.6 \\
& With Alternative & 0 & 0.6 & 0 & 3 & 0.8 & 1 & 0.08 \\
\hline \multirow{2}{*}{ N } & No Alternative & 1 & 0.6 & 0 & 3 & 0.7 & 1 & 2 \\
& With Alternative & 1 & 0.8 & 0 & 3 & 0.7 & 0.7 & 1 \\
\hline
\end{tabular}

Since the kurtosis value and the skewness value are in the interval $[-3.00,3.00]$, a t-test was conducted to determine if there was any significant difference in the means of the sample analysed in this section. Table 29 shoes a summary of the results of these tests.

A significant difference was found found for the advice $M Y$, when comparing with and without an alternative $(t(97.2)=5.5, p<.001)$. A significant difference was also 
Table 29: $t$-tests of Alternative vs No Alternative for advice MY

\begin{tabular}{clrrr}
\hline Advice & & $t$ & $\mathrm{df}$ & $p$ \\
\hline MY & Alternative vs. No Alternative & 5.5 & 97.2 & $<.001$ \\
MN & Alternative vs. No Alternative & 3.6 & 97.5 & $<.001$ \\
N & Alternative vs. No Alternative & -1 & 97.0 & 0.314 \\
\hline
\end{tabular}

found for the MN advice $(t(97.5)=3.6, p<.001)$. Finally, no significant difference was found when the advice was $\mathrm{N}(t(97)=-1, p=0.314)$.

From the obtained results, presenting an alternative to the user clearly improves security, if the suggested alternative is actually better software. The only case where no difference was found when an alternative was suggested was when the advice was N. That can be explained by the fact that people followed the advice, and did not download any software. The majority of the participants did choose to download an application when the advice was $\mathrm{N}$ (more than $50 \%$ of the participants downloaded 1 application or more), and most of those downloads were software that belonged to the WELL KNOWN category. 


\section{Chapter 8}

\section{Results: perception and general discussion}

This chapter reports results from the data collected during the study from observing the participants and questionnaires. We then discuss possible interpretations and implications.

\subsection{Questionnaire data}

During the study, the participants had to answer two questionnaires. The first one was presented before the study and asked some demographic questions and their general understanding about computer security (see appendix D). The second one was filled at the end, after the participants were done using our system (see appendix F). This questionnaire mainly asked questions about their experience using the system and also asked questions regarding their trust in the advisor and the advice.

Some questions required open ended text answers, but for most of the questions, participants were given a series of statements and asked to rank their agreement on a Likert scale from 1 to 10 , where 1 was "strongly disagree" and 10 was "strongly agree". 


\subsubsection{Pre-test questionnaire}

The participants' age in this study ranged from 18 to 43 years old. The median was 21 years old and the mean was 22.9 . There were 26 male participants and 24 females, and all of them were students. Moreover, 44 out of the 50 participants were undergraduate students.

There was a question asking if they had had some type of security training, and only 3 of all the participants answered that they had. One of them answered that his major in school was in network security and he's also working as a network technician. The other two mentioned that they had some short security training at work.

They were also asked how often they browsed the web, and 47 participants answered "daily", while 3 answered "several times a week".

An interesting result came from the question "have you ever downloaded bad software to your computer?". Twenty-three participants answered yes. It is interesting that some of them describe their experience as their computer becoming slow after they downloaded the malware. Also, most of them described that they got viruses when downloading torrents, shareware and kids' games. We also asked them if they had taken security courses, and only three had. Of course, they might have some other knowledge but we did not elicit that.

In summary, our participants were young adults who use the Internet regularly, and who are not security experts but have some experience and concern regarding malware.

A review of the most important results of the pre-questionnaire follow (figure 27). The answers to the other remaining questions may be seen in appendix E.

The majority of the participants use their computer for entertainment as well as work (see subfigure (b)). Less than 20 participants showed concern about having their computer compromised (answered 1 or 2), while 7 participants showed no concern 
(scale 9 or 10) (see subfigure (c)). Participants also generally believe that an antivirus program protects their computer from any malicious application (subfigure (d)), and most of them believe they know about the threats involved when downloading software to their computer (see subfigure (e)).

A surprising result came from the statement "I have a trusted person that always helps me with computer issues" (see subfigure(a)). The histogram is flat, and there is no trend in the answer. Overall, this study was based on our conviction that people had a trusted person that they would ask for advice about computer security and other issues. The participants' answers tell it differently. Perhaps some of the wording in the question might have confused the participants, such as "always helps me". Further study could investigate this issue, and determine if, in fact, people in general do not have a "captain".

Briefly, the other findings are: the participants strongly believe that they only download software that looks trustworthy, they mostly look at reviews before downloading software, and they are split whether they only download software made by a well known company.

\subsubsection{Post-test questionnaire}

In the post-test questionnaire, participants were asked a series of questions about their perceptions of usability, their trust in the advice, and in the system. The great majority of the questionnaire was made of statements where the participants had to rank their agreement on a Likert scale from 1 to 10 , like in the pre-test questionnaire. Figure 28 shows boxplots for some of the most interesting statements, and the other statements can be found in the appendix $\mathrm{G}$.

The results showed that amongst the different conditions, there was broad agreement in the fact that they thought it was easy to use the tool (a), with some potential exceptions in the Alex condition. We speculate that, since they were told to pretend it 


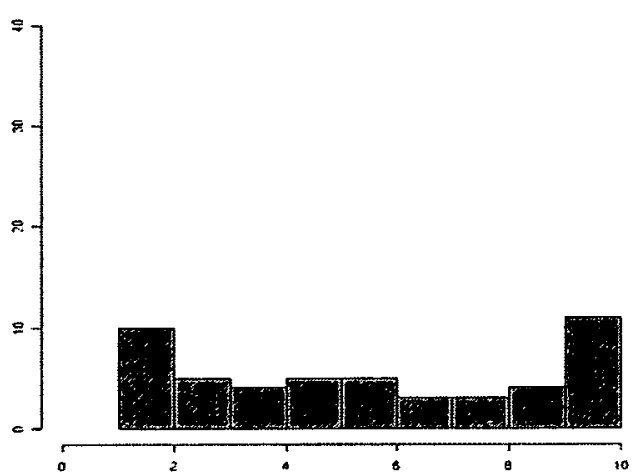

(a) I have a trusted person that always helps me with computer issues

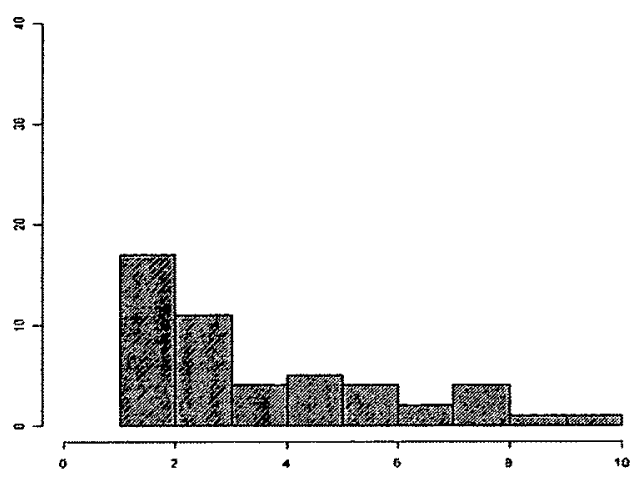

(c) I'm not worried about having my computer compromised

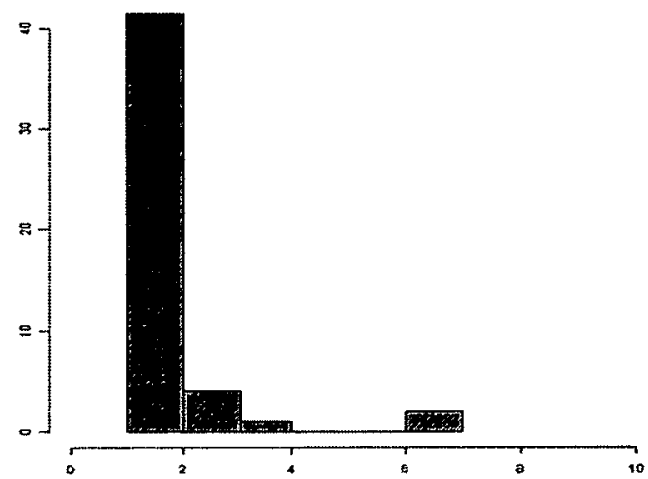

(b) I never use my computer for entertainment

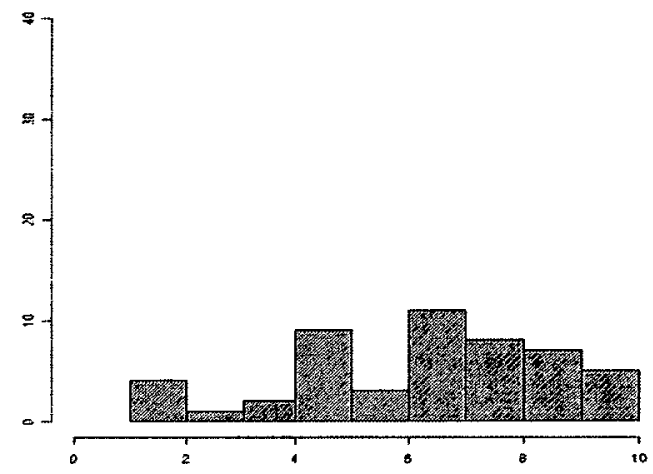

(d) I feel confident that an anti.virus program will protect my computer from any malicious application I may download

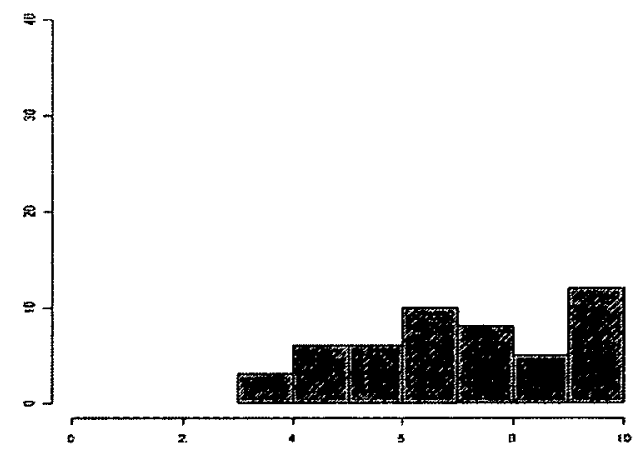

(e) I believe I know about the threats involved when downloading software to my computer

Figure 27: Pre-test Questions 
was their trustworthy friend that was giving them the advice, they found too difficult to imagine a friend whom they did not have. Statement (b) shows that the variance is very high for the CISA, Symansoft and Alex conditions, whereas participants had a stronger opinion on the dependability of the Facebook and the General People advice. In (c), participants in the CISA and General conditions are not willing to pay for advice, but the others are. It seems that we have influenced the decision, because once we put them in groups they became willing to pay for the advice. Finally, (d) shows that most participants trust the advice, with greater variance in Facebook and General conditions. This shows that there is an agreement that the advice coming from CISA, Symansoft or Alex are more trustworthy.

There was one set of questions that was slightly different for the participants depending on the condition they were in. These questions compared their trust in their advisor to the other possible advisors, which were briefly explained. This way, if a participant was in the Facebook condition, there would be 4 statements, each comparing the participant's trust in their friends from a social network to their trust in CISA, Alex, Symansoft and General People. Figure 29 shows box plots of this comparison. Each set of boxplots shows the trust participants have in their advisor (their condition) compared to the advisor mentioned in the graph label. Thus, for instance, if the graph says "Trust compared to Facebook", then each box shows the answers of participants when they were asked if they trusted their own condition's advisor better than Facebook.

Participants in the Symansoft condition were the ones that thought that their advisor is the most reliable compared to the other four. In all questions their median was near 8 , while the median was closer to 6 in most other cases. Also interesting is the fact that their highest answer occurred when comparing to CISA (graph (a), blue box). Moreover, when the other were asked if they trusted their source of advice better than Symansoft, the results showed that participants are not certain whether 
that is true or not (elongated boxes in (b), median around 5). Graph (c) also shows some uncertainty in participants' opinion with regards to the trust on their advisor compared to a trusted friend (Alex). In the other graphs the median is mostly greater than 6 , meaning that they would trust more their advisor than the one being asked about.

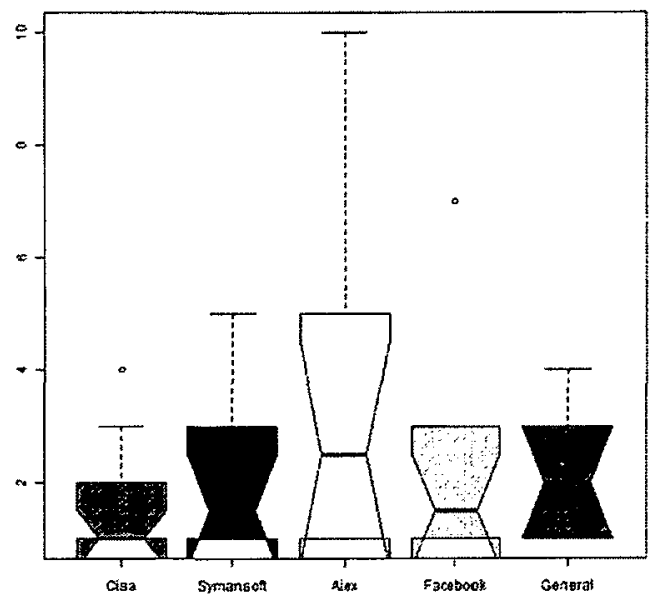

(a) It was hard to use the tool in order to see the advice.

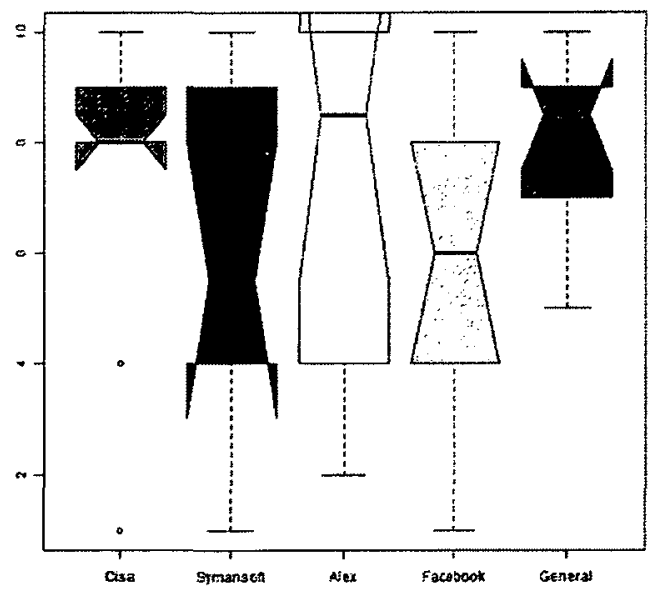

(c) I would NOT be willing to pay for an authority to give me advice about computer security.

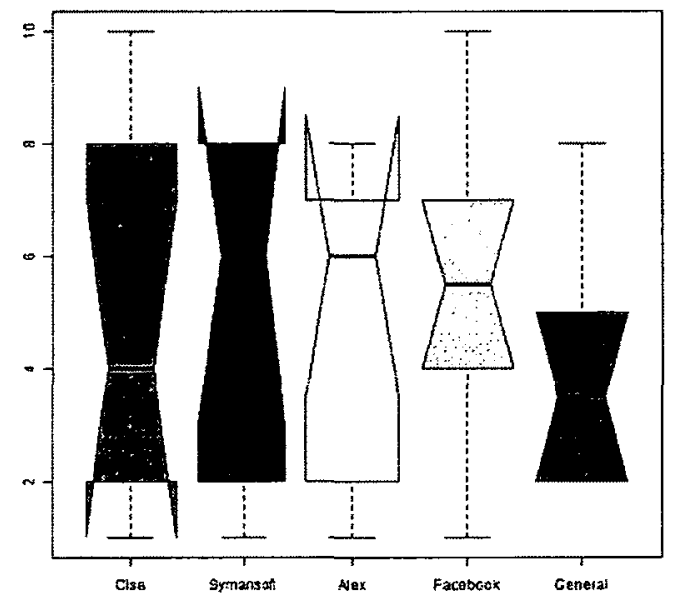

(b) I did not depend on the source of advice to choose my answer.

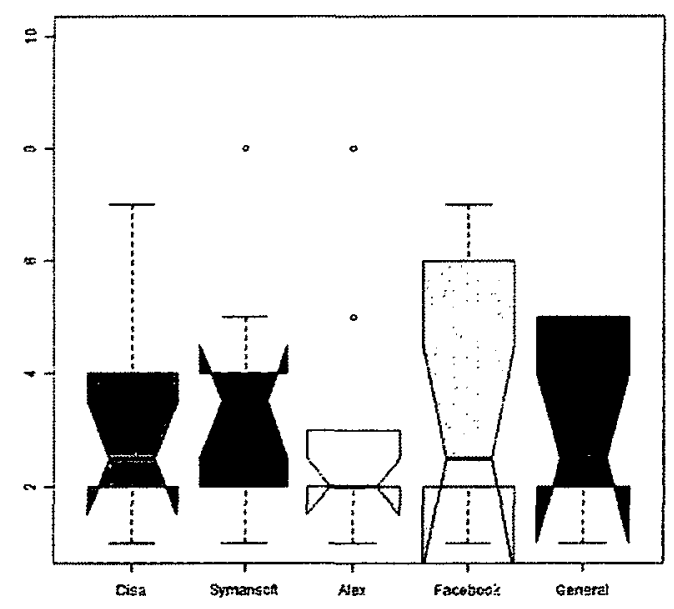

(d) I distrust the advice given.

Figure 28: Post-test Questions 


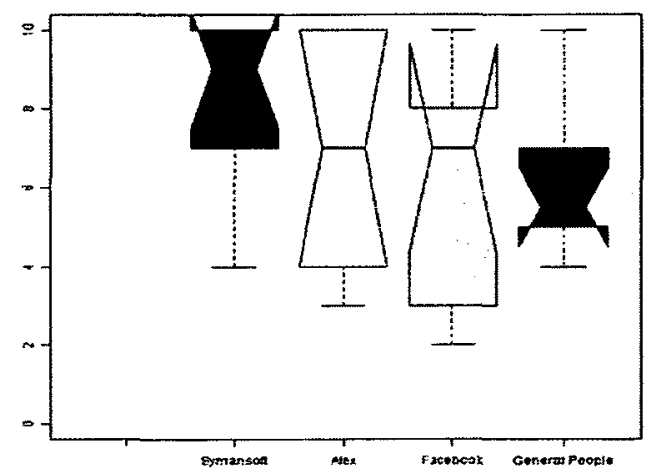

(a) Trust compared to CISA

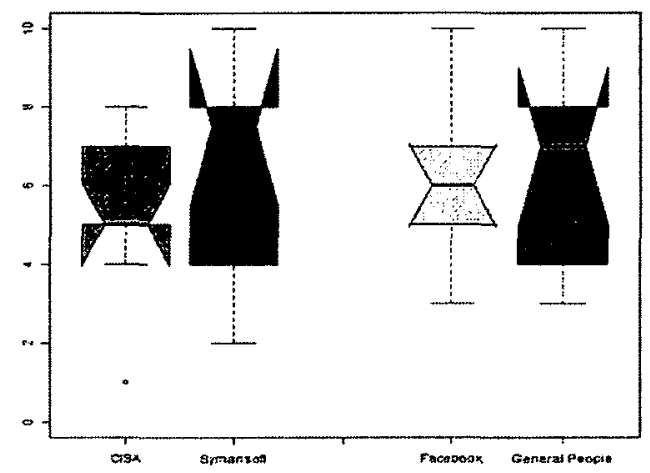

(c) Trust compared to Alex

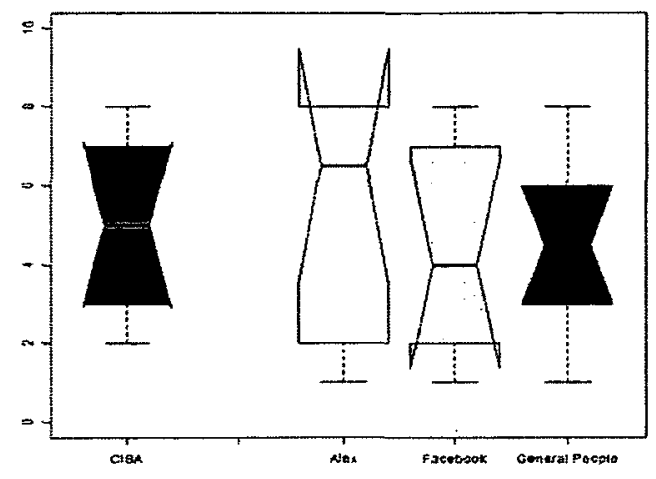

(b) Trust compared to Symansoft

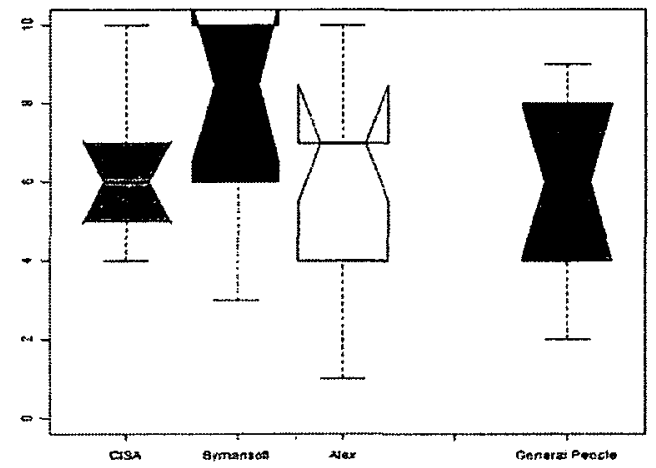

(d) Trust compared to Facebook

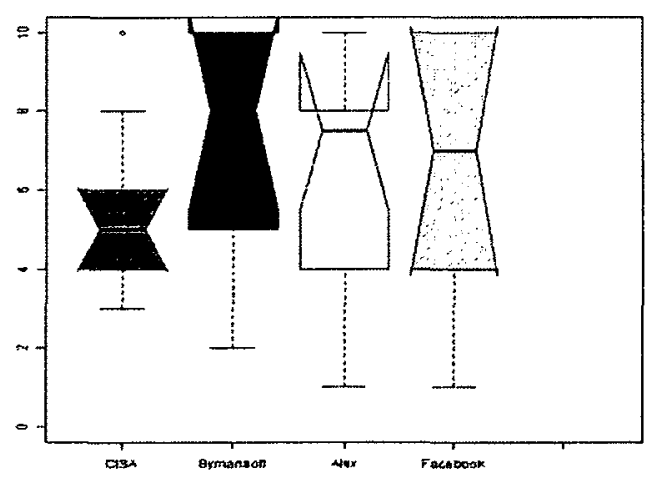

(e) Trust compared to General

Figure 29: Post-test Questions 


\subsection{Observational data}

Participants in general seemed to quickly understand their task and thought it was an enjoyable experience. When they were first introduced to the ONWatch tool, several participants demonstrated interest in the tool and asked if this tool would be available for them to use in their computer. Someone commented: "This software is amazing, I am glad it finally exists". One person even took note of the name of the tool and the research, so he could learn more about it after this thesis was ready. This leads us to believe that such tool could be successful after more research is done and a more robust tool is built. Some participants asked if they it would be possible to use a right-click of the mouse in order to trigger the extension because clicking the ONWatch icon was too cumbersome. We think that this is interesting to keep in mind for future improvements of the tool.

After being introduced to their advisor, more than two participants in the Facebook condition exclaimed: "Oh, I would not trust my friends from Facebook for such thing!". Additionally, one participant asked me if they would be able to know which friend in their Facebook network was giving them the advice. This suggests that this person, and probably others in this condition, would prefer a model such as the Alex condition (captain model). Another participant that was in the Symansoft condition mentioned that she would trust her brother better than Symansoft. She also added that she decided to download Microsoft Outlook even when Symansoft advised that it was a bad application but had the same advice come from her brother, she would have skipped it.

Finally, some interesting observations in participants' behaviour when deciding whether to download software were:

- Several participants would actually read the descriptions and use it to help them with their decision. Some participants, when they had an alternative, would 
choose the one with more features instead of the one with better advice. And others even asked if there was more information available to help them make the decision.

- Several participants mentioned that they trusted the advice because it was the only source of information they had about most of the applications, so it would be better than nothing.

- Someone mentioned that security was not the most important thing, but usability was also a big deal. So, when deciding between MS Word and Writer, if considering that MS Word would not cost him anything, he would choose MS Word even if security was not better than writer.

\subsection{Interpretation}

The study confirmed our hypothesis that presenting an alternative program will improve security. When participants are told not to download a piece of software, they will avoid that download more often if they are presented with an alternative application that will have similar functionality but better security. Usually, recommendation systems in websites such as Amazon, ebay, and others, include advice from users, which would tell if a given product or vendor is good or not, and incremented with some comments. The results of our study suggest that the decision could be improved if the advice would also include an alternative. Therefore, websites that include reviews by users could potentially provide a better security tool for its users by enabling reviewers to suggest alternative applications when they think it's appropriate. Hence, we believe it would be worthy to further study this subject to better explore the influence of suggested alternatives when advice is given and its implications. 
In this study we also explored the effect of a person receiving advice from a trusted friend and we compared it to other advisors. We didn't find significant evidence that the advice had a different effect based on who the advice was coming from. We suggest a few reasons why this might have happened. First, from the questionnaire answers we could see that approximately half of the participants did not have a trusted friend for computer issues. We initially thought most people would have one. The lack of a trusted friend for those issues might have prevented the participants from correctly assessing the test. Even though we had asked the participants to pretend that Alex $M c S m a r t$ was their trusted friend for computer issues, and they all have agreed that they were able to do that, we could see from the results of the questionnaire that some of them might not have been able to do that properly. Therefore, we were not able to create an ecologically valid context in this case. The way the experiment was designed, participants would be assigned to their condition (advisor) as soon as they signed the consent form. Had we asked the participants if they had a trusted friend before deciding which condition they would be given, we would have been able to collect more data involving people that were able to understand the role of Alex McSmart.

Another possible reason for that result is, since every participant in the study only had the advice and some additional information about the application to help them make the decision, it might have influenced their answers, making the results similar across the five conditions. Some participants tried clicking the study application website fake links such as "about" or "products", and some even asked the test conductor if there was any other information available about the applications. A participant commented that he usually looks online for information, such as reviews, when downloading software for his computer. Another participant said: "as I was unfamiliar with most of the programs featured in the study, and because I had no other authorities to whom I could appeal, I sought and trusted the advice On Watch gave 
me". Due to these facts, we believe that we might not have been able to create an ecologically valid situation in this case. Perhaps if the experiment had a different set up, the results when comparing the various sources of advice would have been more meaningful. For instance, instead of having the fifth condition "General people from the Internet", we could have embedded the advice from general people from the Internet for every application in addition to the one from their advisor. This way, we would have created a more realistic environment, where people are used to seeing reviews from general people, such as in Apple's App Store. From there we would have been able to determine which advice people would give more weight to: if their advisor's (one of the other four) or the general people's.

The results could also be explained by the fact that there was not enough people in each condition to provide valid results. Perhaps the best solution would have been to start the study with fewer conditions (maybe 3 conditions instead of 5 ). We would have had, thus, more participants and, therefore, more data for each condition, which would better describe their behaviour.

Finally, another possible explanation for our results could just be that people vary about their concern about security. When one participant was asked why they did not trust the advice for a given decision, the participant answered: "I didn't trust the advice because I have an adventurous outlook and like to try new apps when I don't think it would be too bad for my computer or at least try them out for a little bit to see if I like the "feel" of the app". Another participant commented that security is not the only concern he has when he is downloading software, but he also considers the usability of the program. This way, since people have different levels of concern about their computer security, it is difficult to assess the power of a security advice when we don't have knowledge of what it means to the participant. Further studies could investigate how concerned people are with security and their understanding of the subject. 
In the pre-test questionnaire, some people commented on their experience with downloading malware to their computers, but we did not specifically explore the effect of this result. Further studies could examine if people that were previously deceived into downloading malware are more cautious when downloading general software to their computers, or other effects that this could cause.

One very interesting result from the study was that advice is not very effective when it is related to well-known software. In every condition, the lower mean number of downloads in the well-known category was 3 , while in the other two categories the lower mean was 1.7. Furthermore, the lower minimum number of downloads in the well known category was 2 , while in the other two was 0 . As previously discussed, one possible reason that people fail to fully use advice in some cases is that people tend to be overconfident and overvalue their own initial judgements, combining advice with their own judgement, even when the advice was given by a more knowledgeable and experienced advisor [50]. Some comments participants made with regards to this issue were: "I know and use programs like Excel and would trust them to be safe despite the advice" and "because of my experience I knew some of the software and companies, so no need for advice". These results showed us that people have a poor understanding of the dangers even well-known programs can impose. Some of them might have harmful bugs in a particular version, and some malware is disguised as genuine software, and may come from an official company website. Further studies could investigate people's understanding of malware and why they trust well known software will not present danger to their computer's security. Also, one participant made a comment that included "... often limited nature of the advice...". That suggests that perhaps some users felt that the advice did not provide them with enough details about the reasoning for the advice. Therefore, further studies could investigate different advice formats, which people could rely on and feel satisfied with the explanation. 


\section{Chapter 9}

\section{Conclusion}

The Internet has become an integral part of people's lives, both personal and professional. Threats rise each year because too many people are unaware of the security risks involved when using the Internet. Malware is one significant threat to computer security, and it can be installed on one's machine without user's knowledge. In order to do that, attackers use techniques to deceive users into downloading malware unknowingly.

We believe that if people had understandable advice easily available to them when they are about to make a decision on whether to download software or not, they would be inclined to use the advice, reducing their chances of putting their computers at security risk. Therefore, the main objective of this research was to propose, implement and test a framework to support decision-making about the security of software, utilizing advice from trusted people in their social network, and to understand how our current social networks can improve computer security.

In the first three chapters we introduced the idea that was going to be developed in this work. In Chapter 2 we reviewed important literature that served as basis for the main idea of this thesis. In Chapter 3 we stated the problem that we are trying to solve, and the reasoning behind it. Chapter 4 and Chapter 5 described the design and implementation of the solution framework, while chapter 6 documented the 
study conducted to test the implemented system and the hypotheses made. Finally, Chapters 6,7 and 8 reported the results from the empirical study, providing a priori and post-hoc statistical analysis and interpretation of the results.

We wanted to study how our current social networks can improve computer security by providing security advice. Therefore, we ran an empirical study so we could compare the advice coming from a trusted person to the advice coming from other more general social networks, and the different advisors were the independent variables of the study. There were five in total: Alex McSmart (the trusted expert friend), friends from Facebook, general people from the Internet, Canadian Internet Security Advisor (CISA) and Symansoft. We didn't find much evidence that the advice had a different effect based on the advisor, but the study confirmed our hypothesis that presenting alternative software will improve security. This means that when people are told not to download a piece of software, they will likely avoid that download if they are presented with an alternative program that has similar functionality but better security.

Another interesting result from this study was that advice is not very effective when it is about well-known software. While most people followed the advice for software that was not well-known, the advice was often ignored when the participant knew the program (such as MS Excel).

Other approaches to this problem include Gatekeeper, which is a feature of Apple's desktop operating system (OS), Mac OS X 10.8. Gatekeeper restricts the OS to Mac App Store and Apple-signed applications by default (but users can opt out) [51]. This way, Apple is trying to protect user's Macs from malware and untrustworthy apps downloaded from the Internet.

Future work in this area could investigate people's understanding of malware and why they trust that well known software will not be dangerous to their computer's security. A controlled lab study could possibly explore the influence of alternatives 
suggested when advice is given and its implications. Additionally, future work could improve the experiment design to create a more ecologically valid context to try to obtain results that will present statistical differences among the conditions. Also, more people could be recruited in a future work to see if an increase in the sample will start showing differences in the results. 
Appendix A

\section{Ethics Application}


Carleton

UNVERSITY

Canada's Capital University
Research Ethics Board

510B Tory Building

Tel: $613-520-2517$

ethics@carleton.ca

\section{Graduate Student Research Ethics Protocol Form}

Office use only:

Project number:

Type of review:
Expedited
Date received:

REB Review Date:

\section{INSTRUCTIONS:}

Please complete the application form and sign the document. Incomplete forms will be returned.

Make 8 copies of the application including all appendices. Please staple the application forms and attachments.

Submit the original and copies to the Research Ethics Board (REB) coordinator located at $510 \mathrm{~B}$ Tory:

All applications are due the first Tuesday of each month except August when the REB does not meet.

Applications are due no later than $4: 00 \mathrm{pm}$

If you have questions please contact Leslie MacDonald-Hicks, REB Coordinator at $613520-2517$ or leslie macdonald-hicks@carleton.ca

\section{Section 1: Project Registration}

\subsection{Research Supervisor:}

Name: Ashraf Matrawy

Department/School: Systems and Computer Engineering

University E-mail Address: amatrawy@sce.carleton.ca

Name: Robert Biddle

Department/School/Centre: School of Computer Science

University E-mail Address: robert biddle@carleton.ca 


\subsection{Student Researcher Information:}

Name: Bruna Machado Freitas

Department/School: Systems and Computer Engineering

University E-mail Address: bfreitas@connect.carleton.ca

Status: X Master's programme $\quad \square$ Ph.D. programme

\subsection{Project Title:}

Social Networks and software security decisions

\subsection{Purpose of the research (one or two sentences):}

We would like to determine if social networks can improve people's software security decisions.

\subsection{Proposed Research Dates:}

Start date: April 1, 2012

Expected date of completion: December 31, 2012

1.6 Research funding: Is this project funded? $\mathbf{X}$ Yes $\quad \square$ No

Funding source and program

NSERC / ISSNET Strategic Research Network

Agency reference number (if applicable)

NETGP - $2006-340802$

Amount

$\$ 5,000,000.00$

Funding period

$2007-2013$

\section{7: Signatures:}

\section{Research Supervisor}

I have assisted with, read and approved the research ethics protocol. I will ensure that the student researcher conducts the research in accordance with the Tri-Council Policy Statement: Ethical Conduct for Research Involving Humans $2^{\text {nd }}$ edition, the Carleton University Policies and Procedures for the Ethical 
Conduct of Research and the conditions of clearance established by the Carleton University Research Ethics Board and agree to provide all necessary supervision to the student.

Signature

Date:

I have assisted with, read and approved the research ethics protocol. I will ensure that the student researcher conducts the research in accordance with the Tri-Council Policy Statement: Ethical Conduct for Research Involving Humans $2^{\text {nd }}$ edition, the Carleton University Policies and Procedures for the Ethical Conduct of Research and the conditions of clearance established by the Carleton University Research Ethics Board and agree to provide all necessary supervision to the student.

Signature

Date:

\section{Student Researcher}

I agree to conduct this research in accordance with the Tri-Council Policy Statement: Ethical Conduct for Research Involving Humans $2^{\text {nd }}$ edition, the Carleton University Policies and Procedures for the Ethical Conduct of Research and the conditions of clearance established by the Carleton University Research Ethics Board.

Signature

Date:

\section{Section 2: Research Project Information (Please complete each section below. Do not omit any section.)}

2.1 Description or a summary of the research project: (See guidelines. Limit 250 words.)

We are conducting a study of how people take advice on security matters and we have developed a tool called ONWatch to assist them in this process. The tool is intended to support users decide whether it's safe to download certain software from the Internet. It will do so by enabling the sharing of security advice from a trusted source. Although computer security is a concern for online users, many have difficulty making effective security decisions. We believe that people usually have their trusted sources of advice for computer security matters. We also believe that their sources of advice are often people within their circle of friends and that the advice of these "experts" is as powerful as advice from a Computer Security Authority. ONWatch is a platform that will facilitate the communication of security advice and present that information to the user both conveniently and timely (at the moment of an important decision).

The platform will present the user with 20-40 pairs of software security situations and related advice and the user will be given a choice as to accept or reject it. The advice will come from one of 5 different sources and each participant will be assigned to only one of those sources. 
The study is intended to verify that the security advice coming from trusted friends is as effective or more than advice coming from any of the other 4 sources.

\subsection{Methodology/Procedures:}

General Methodology: User testing will be conducted through one-on-one in-person sessions with the experimenter. During each session, the participant will use our online tool to make some decisions about software download and complete questionnaires providing their understanding of the risks involved when downloading files from the Internet and feedback about the tool itself.

Number of Sessions: One session lasting at most one hour.

Location: Sessions will take place at research facilities at Carleton at the HotSoft lab located in room $\mathrm{HCl}$ 2110.

\section{Data Collection:}

A computer will be provided by the experimenter for using the tool.

While we are testing a tool for improving computer security decisions, none of the participant's personal information, accounts, or credentials will be at risk.

The following data will be collected:

1. The participants' interaction with the tool will be logged by the system.

2. The experimenter will take notes on relevant comments made by participants during the session.

3. Participants will be asked to describe their general experience with the tool.

4. Participants will complete online questionnaires about their experience with the system and their understanding of the security threats when downloading files from the Internet.

\section{Detailed Methodology:}

1. Each participant will be greeted and asked to read and sign the consent form if they agree to participate in the study

2. The experimenter will explain that the purpose of the study is to evaluate different kinds of security advice.

3. The participant will

a) Complete two questionnaires: one initial questionnaire about computer security and a demographics questionnaire.

b) They will then use our system to make 20-40 decisions regarding software download.

c) complete a final questionnaire about their experience using the tool

4. The experimenter will debrief the participant about the session and answer any questions that the participant may have.

5. Participants will be compensated for their time at the end of the in-person session.

\subsection{Location(s) where the research will be conducted:}

$\mathbf{X}$ Carleton University

Region of Ottawa-Carleton

$\square$ Canada (please specify):

$\square$ Other (please specify): 
2.4 Additional reviews: (See guidelines)

$X$ None

$\square$ Yes, documentation attached

$\square$ Yes, documentation to follow

Name of other boards, committees or agencies: Provide the name, address and contact information/person for each board or committee.

\section{N/A}

2.5 Visa or research license required: $\square$ Yes $\mathbf{X}$ No

If Yes:

$\square$ Documentation attached

$\square$ Documentation to follow

\section{Section 3: Research Participants}

\subsection{Recruitment}

a) Describe how potential research participants will be identified and recruited.

Participants will be recruited through posters around. We may also send announcements on mailing lists such as today@Carleton and similar campus mailing lists. See Appendix for recruitment materials.

\section{b) Proposed number of participants in the study:}

c) Research population with special needs: $\mathbf{X}$ Not applicable

Describe steps to be taken to ensure that the needs of these research participants are respected and the collection of data method will ensure the safe and ethical conduct of the research.

\section{d) Vulnerable populations: $\mathbf{X}$ Not applicable}

Describe your knowledge, training and experience working with this population and what steps you will take to ensure the safe and ethical conduct of research with the identified population. 
3.2 Append the required recruitment documents. (See guidelines.)

\section{Section 4: Conflict of Interest/Power Relationships}

\subsection{Are potential research participants employees, clients or persons you have worked with in a professional or volunteer capacity (past or present)? $\square$ Yes $\quad$ No}

If YES, explain your relationship to or authority over the potential participants and what steps you will take to ensure that the participants' decision to take part in the research will not be influenced by their relationship to you.

\section{N/A}

\subsection{Are potential research participants, friends, relatives or students? $X$ Yes $\square$ No}

If YES, explain your relationship to or authority over the potential participants and what steps you will take to ensure that the participants' decision to take part in the research will not be influenced by their relationship to you.

Recruitment will not specifically target friends, relatives, or students with which we have an existing relationship. If such people volunteer, we will ensure that they receive the same compensation, instructions, and consent forms as other participants.

People closely associated with our research lab will be excluded from participating in the study to avoid any conflict of interest and avoid unduly influencing the results of the study.

\subsection{Do you or any members of the research team have any financial and/or commercialization} interest in the research results? $\square$ Yes $X$ No

If YES, explain in detail your interest.

N/A

4.4 Do you or any members of the research team have a volunteer or paid role with any organizations that is a part of this study? $\square$ Yes $X$ No

If YES, explain in detail your interest.

N/A

Section 5: Risks and Benefits

5.1 Minimal risk: 
$\mathbf{X}$ The risk to participants is minimal. (If you check this box provide an explanation below and then move to 5.3 )

Explain why the project should be assessed as minimal risk.

Risk is no more than ordinary computer usage.

5.2 Risks to participants: (Check all that apply)

Physical harm or discomfort. (This includes any bodily contact, application of equipment, management of any substance.)

Psychological/emotional harm. (This includes feeling demeaned, embarrassed worried or upset, discussing personal sensitive information.)

Social and/or economic harm. (This includes possible loss of status, privacy and/or reputation, disclosure of sensitive information by others, possible loss of income, threat to professional status including loss of job and possible retribution.)

Explain in detail all possible risks to research participants.

5.3 Managing risk: Describe what steps will be taken to reduce harm to participants.

Risk is minimal and is no different from regular usage of a computer

During the session, participants will be allowed to take breaks as needed, can skip questions in the questionnaires, and will be allowed to withdraw from the study at any point if they so choose. If a participant withdraws from the study, their data will be destroyed.

Data will be coded so that it is associated with a username that is not linked to the participant's identity. Results will be aggregated. In the event that a comment or observation is included from particular session, no identifying information will be included.

\subsection{Deception: Is there any deception involved in this research project? $\square$ Yes $\mathrm{X}$ No}

If YES, describe why participants will be deceived, how the deception will be carried out and how and when you will debrief participants.

N/A

\subsection{Are there any risks to you or the researcher team? $\square$ Yes $X$ No}

If YES, describe the steps that will be taken to ensure researcher safety. 
N/A

\subsection{What are the benefits of the research to the participants?}

Participants will learn about online computer security risks and increase their awareness of those risks.

5.7 If you are working with an agency or community group describe what benefits they may receive from this research. $\quad \mathbf{X}$ Not applicable

N/A

\section{Section 6: Compensation}

6.1 Will research participants receive compensation for their participation? $\square$ Yes $\square$ No If YES:

a) Describe the compensation (money, gift, transportation, childcare costs, etc.)

\section{Money}

b) What is the monetary value of the compensation?

\section{$\$ 10$ gift card (Tim Horton's or Starbucks)}

c) Explain how the compensation be distributed?

Participants will receive monetary compensation at the end of the in-person session. Participants will be compensated even if they choose to withdraw from the study.

\subsection{Will you or members of the research team provide time or assistance to the community participants?}

$\square$ Yes $\quad$ X No

If YES:

Describe the assistance that will be provided.

N/A

\section{Section 7 - Anonymity and Confidentiality}

7.1 Anonymity (treatment of the identity of participants) 
a) Will the identity of participants be known to the researcher(s) during the collection of information, data gathering or testing?
$\mathbf{X}$ Yes
$\square$ No

b) Will the identity of participants be revealed in any reports, papers, research articles, presentations, etc?
$\square$ Yes
$\mathbf{X}$ No

c) Will the identity of participants be known to other participants in the study?
$\square$ Yes
$\mathbf{X}$ No

d) Will the identity of participants be known to non-participants in the study? (Example: colleagues, family friends of the participants)
$\square$ Yes
$\mathbf{X}$ No

7.2 Confidentiality: (attribution of responses and data)

a) The responses/data collected will be anonymous and non-attributed to participants.
$\mathbf{X}$ Yes
$\square$ No

b) The data collected will be attributed to participants.
$\square$ Yes
$X$ No

If YES to $b$ ):

Will participants have the opportunity to request that certain responses remain non-attributed?

$\square$ Yes $\quad \square$ No

\subsection{Limitations on Anonymity and Confidentiality: (See guidelines)}

If researchers anticipate any conflict between the research project procedures and data gathering and the law please describe those potential conflicts in detail.

\section{N/A}

\section{Section 8: Informed Consent}

8.1 Informed consent process: Describe the procedures for obtaining informed consent for each part of the research project. If the researcher is seeking oral consent, explain why and the procedure that will be used to obtain consent.

A written consent form will be presented and explained to participants at the beginning of the session. Participants will have opportunity to read it and ask questions about it. If they agree to participate, they will be asked to sign and date the form. See Appendix for the Informed Consent 
form.

At the end of the session, participants will have opportunity to ask any questions they have about the research.

8.2 Participant withdrawal: Participants have the right to withdraw from a research project. Please explain the procedures for withdrawal from the research.

Participants have the right to withdraw without any explanation as to the reason for their withdrawal at any time during their session. Participants will receive their monetary compensation even if they withdraw from the study. Their data will be destroyed.

8.3 Append the required informed consent form (See guidelines). NOTE: All consent forms must be on Carleton University letterhead.

\section{Section 9: Data Collection, Storage and Dissemination}

\subsection{On-line survey section only:}

Is the host server company Canadian? $\mathbf{X}$ Yes $\square$ No

If NO, in what country will the host data be stored?

\section{N/A}

Describe the process for transferring the data from the host server to you and verification that the host server is no longer in possession of the data.

Our questionnaires are hosted on our own research servers, physically located in our research labs, using Limesurvey software. The system is password-protected and only researchers associated with the study will have access to the data.

\subsection{Audio or video recording:}

Will the research participants be audio recorded?

$\square$ Yes $\quad X$ No

Will the research participants be video recorded?

$\square$ Yes $\quad X$ No

Will the research participants be photographed?

$\square$ Yes $\quad X$ No 
If YES to any of the above, describe what steps will be taken to ensure the privacy and confidentiality of the participants. Explain if the recordings will be destroyed or archived for future research.

N/A

\subsection{Translation and transcription of data:}

Will the research project require the services of a translator? (Check No if researcher is translator)

$\square$ Yes $\quad$ No

If YES, describe what steps will be taken to ensure the privacy and confidentiality of the participants. Attach a copy of the confidentiality agreement for the translator.

\section{N/A}

Will the project require a transcription service? (Check No if researcher is the transcriber)

$\square$ Yes $\quad X$ No

If YES, describe what steps will be taken to ensure the privacy and confidentiality of the participants. Attach a copy of the confidentiality agreement for the transcription service.

\section{N/A}

9.4 Storage of data: Explain how the data will be stored during the course of the study. If the data will be used in future studies explain how it will be stored.

Data will be stored electronically on our servers with password protection. Access will be restricted to those researchers directly involved with the research.

The only personally identifiable information will be the signed paper consent forms. These will be kept in a locked filing cabinet and not associated with the electronic data.

9.5 Access to data: Explain who will have access to the data during the course of the study.

Only researchers directly involved with the study will have access to the data.

9.6 Disposition of data (after analysis and completion of report)

Data will be:

Returned to participants (Describe how the data will be retuned and by what date.) 
$\mathbf{X}$ Archived (Describe how the data will be stored; including the storage format)

Since this work is part of a larger research project, data may be kept for comparison with later prototypes/studies/surveys.

Data will be made anonymous.

Destroyed (Describe how the data will be destroyed and by what date. This includes all audio tapes, digital recordings, videos and photographs.)

9.7 Dissemination of data: (Check all that apply)
$\mathbf{X}$ Thesis
$\mathbf{X}$ Academic journals
X Book(s)
$\mathbf{X}$ Conferences
$\square$ Final report to organization

$\square$ Final report to participants, upon request

X Workshops

$\square$ Course research paper

$\mathbf{X}$ Classroom presentations/exercises 


\section{Appendix B}

\section{Informed consent form}

Title of research project: Social Networks and software security decisions

Date of ethics clearance: 23/Apr/2012

Ethics Clearance for the Collection of Data Expires: 31/May/2013

The purpose of the study is to evaluate how people take advice on security matters when using a tool called ONWatch to assist them in this process. The platform will present you with 20-40 pairs of software security situations and related advice. You will then be given a choice as to accept or reject the advice.

We are testing the impact of using the tool, not your performance. As a participant, you will use the tool on a computer and give feedback about your experience. You will also be asked to complete questionnaires giving your opinion and perception of the prototype. The session will take at most an hour. There will be no audio, video, or photographic recording.

There are no known risks associated with this study beyond ordinary computer use. You will not be required to use your own computer and none of your personal information will be accessed.

Data collected during your session will be associated anonymously and have no connection with any personally identifiable data. Data will be stored electronically on our research servers with password protection. Access will be restricted to those 
researchers directly involved with the study. Since this work is a part of a larger research project, anonymous data may be kept for comparison with later studies. The data will only be used for these purposes.

You may decline to answer any question and you may withdraw from the study at any point during the session. If you choose to withdraw, your data will be destroyed.

At the end of the session, you will receive $\$ 10$ gift card (Tim Hortons or Starbucks) as compensation for your time in participating in this study. You will receive compensation even if you withdraw from the study.

This project was reviewed and received ethics clearance by the Carleton University Research Ethics Board (REB). Contact information for the REB Chair follows:

Professor Antonio Gualtieri, Chair

Research Ethics Board

Carleton University Research Office

Carleton University

1125 Colonel By Drive

Ottawa, Ontario K1S 5B6

Tel: $613-520-2517$

E-mail: ethics@carleton.ca

The principal researchers involved in this research are: 
Bruna Freitas, Student Robert Biddle, Professor Ashraf Matrawy, Professor Systems and Computer School of Computer Sci- Systems and Computer Engineering Department ence Engineering Department

Carleton University

1125 Colonel By Drive

Ottawa, Ontario K1S 5B6

Tel: (613) 520-2600 ext 6317

bfreitas@connect.carleton.ca robert_biddle@carleton.ca

Carleton University

1125 Colonel By Drive Ottawa, Ontario K1S 5B6 6317
Tel: (613) $520-2600$ ext Tel 2901

amatrawy@sce.carleton.ca

I have read and understand the above terms of testing and I understand the conditions of my participation. My signature indicates that I agree to participate in this experiment.

Signature of participant:

Signature of researcher:

Date: 


\section{Appendix C}

\section{Recruitment notice}

Our research group at Carleton University is currently conducting a user study. We are conducting a study to evaluate how people take advice on security matters and we have developed a tool called ONWatch to assist them in this process. The tool is intended to support users decide whether its safe to download certain software from the Internet, by enabling the sharing of security advice from a trusted source. As a participant you will use the tool in a computer and give your feedback about your experience.

The session will take around 30 minutes. Participants will receive $\$ 10$ gift card (Tim Horton's). For more info, please email us at: securityadvicestudy@hotsoft.carleton.ca

To be eligible, participants should:

- Be over 18 years old

- Be comfortable with using a mouse and graphical user interface. 


\section{Appendix D}

\section{Pre-test questionnaire}

Welcome to the pre-test questionnaire. In this questionnaire, we'll be asking some brief demographics questions, as well as some questions regarding security on the internet. All data is confidential and is coded for anonymity. You are not obliged to answer any of the questions. If you have any questions, please ask the experimenter for clarification.

1. Please enter your username.

2. What is your age?

3. What is your gender?

4. Are you a student?

- Yes

- No

5. At what level are you studying?

- Undergraduate

- Masters 
- Ph.D

- Other

6. What year of study are you in?

7. In what academic program are you enrolled?

8. What is the highest level of education you have completed?

- University or college degree or equivalent

- Some university

- Intermediate between secondary level and university (e.g. technical training)

- high school

9. What is your field of expertise?

10. Do you have any formal training in computer security?

- Yes

- No

11. Please describe.

12. How would you rate yourself with respect to your level of competency with the internet (on a scale of 1 (novice) to 10 (expert)).

13. How often are you online (browsing the web, etc)?

- Daily

- Several times a week

- Once a week 
- Less than once a week

14. Have you ever downloaded any software online that caused some kind of harm to you or your computer?

- Yes

- No

15. Please describe.

Please rate the following statements on a scale of 1 to 10 , where 1 is strongly disagree and 10 is strongly agree.

16. I believe I know about the threats involved when downloading software to my computer.

17. I usually download software to my computer only if it looks trustworthy.

18. I look for reviews before I download software to my computer.

19. I have a trusted person that always helps me with computer issues.

20. I feel confident that an anti.virus program will protect my computer from any malicious application I may download.

21. I never download software unless it is made by a reputable company.

22. I never use my computer for entertainment.

23. I only use my computer for work or school.

24. I am not worried about having my computer compromised. 
Appendix E

Pre-test questionnaire answers 


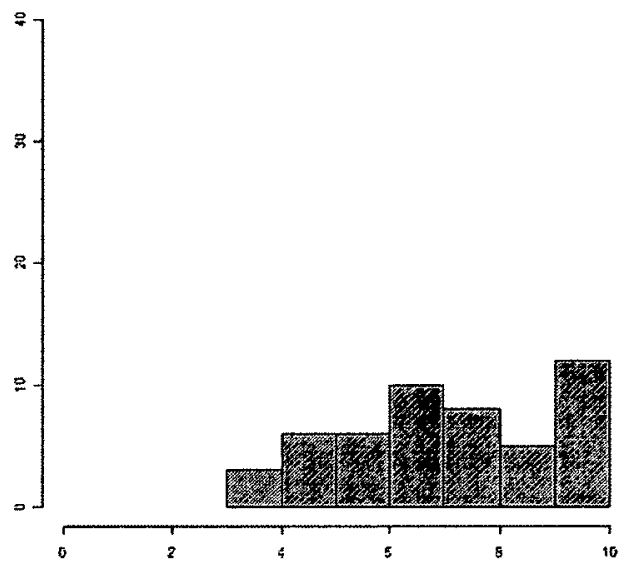

(a) I believe I know about the threats involved when downloading software to my computer

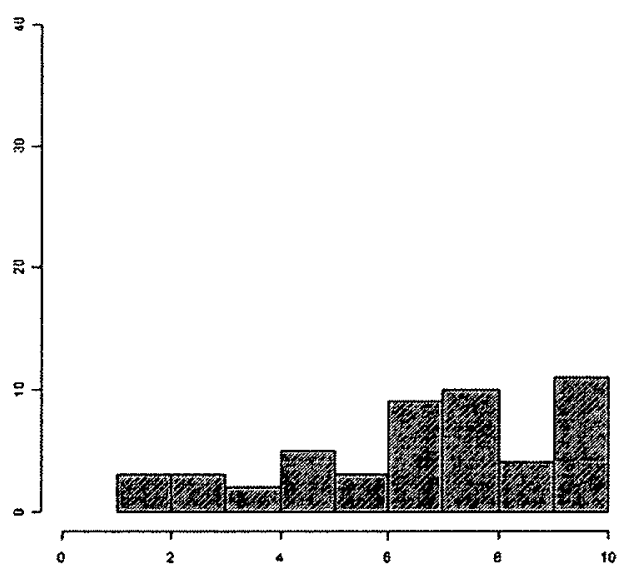

(c) I look for reviews before I download software to my computer

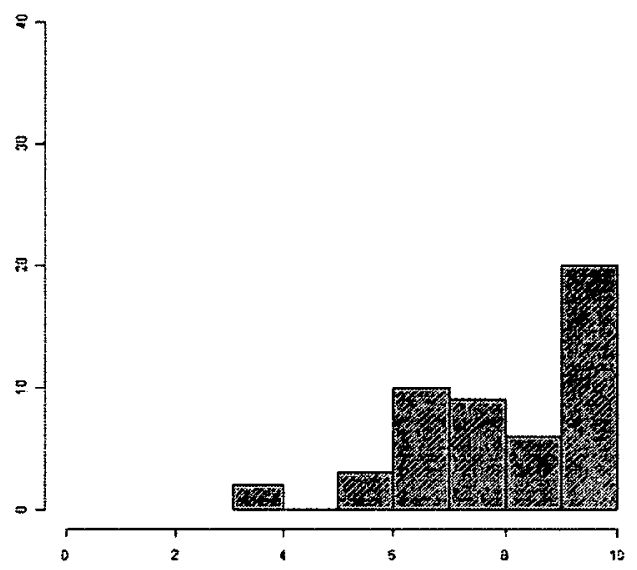

(b) I usually download software to my computer only if it looks trustworthy

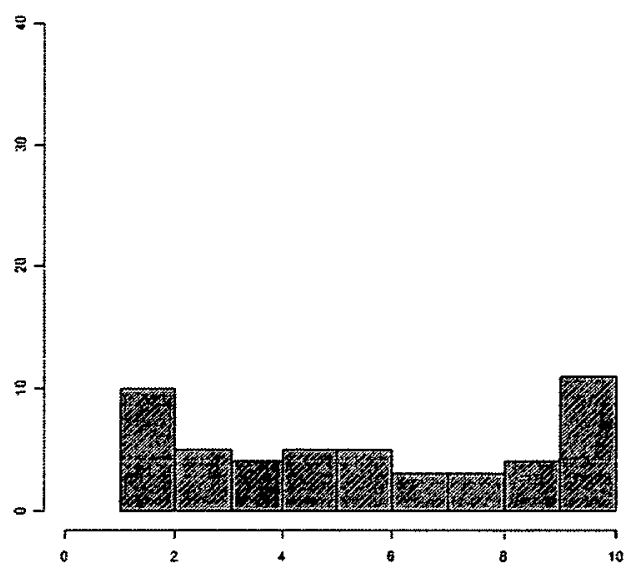

(d) I have a trusted person that always helps me with computer issues

Figure 30: Pretest Questions 


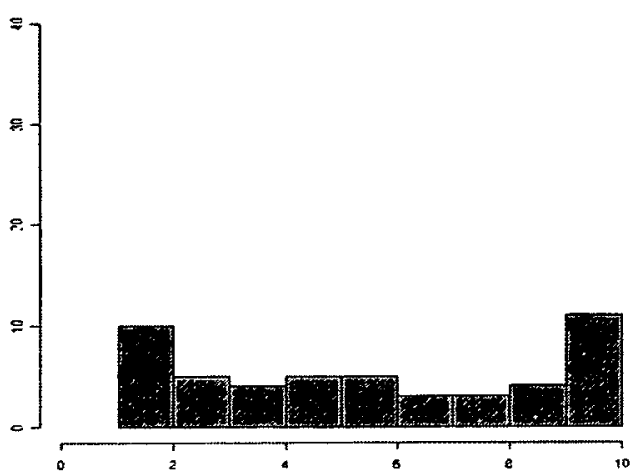

(a) I have a trusted person that always helps me with computer issues

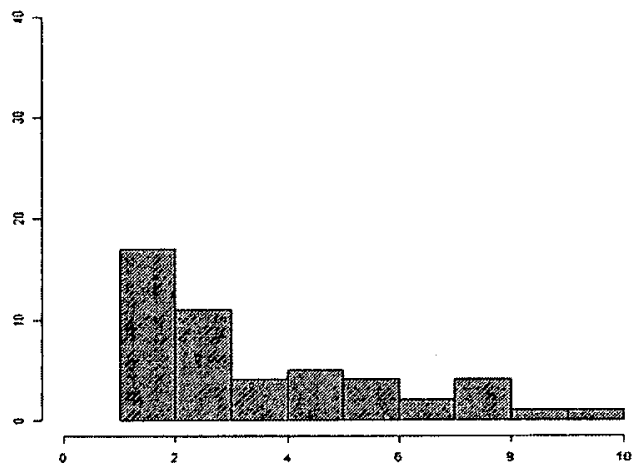

(c) I'm not worried about having my computer compromised

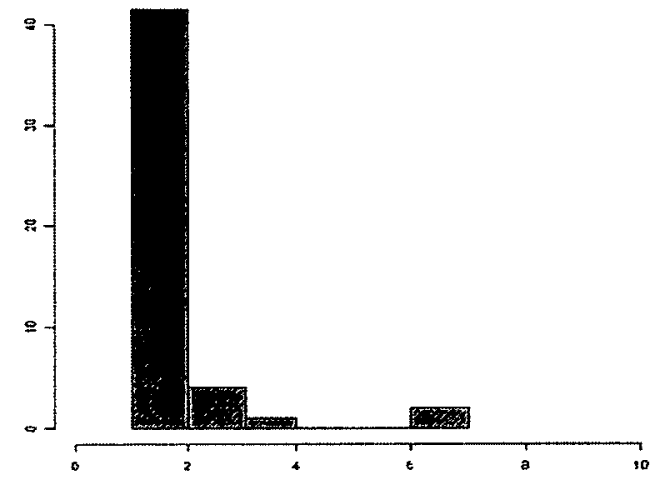

(b) I never use my computer for entertainment

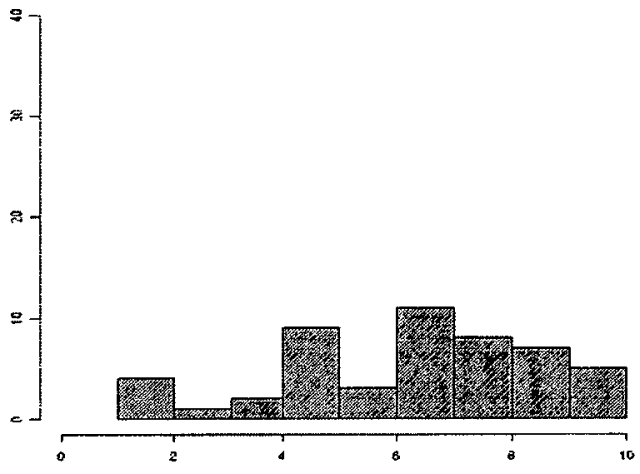

(d) I feel confident that an anti.virus program will protect my computer from any malicious application I may download

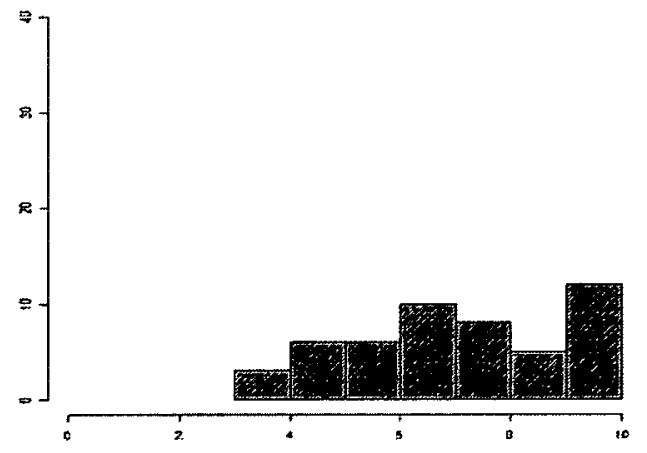

(e) I believe I know about the threats involved when downloading software to my computer

Figure 31: Pretest Questions 


\section{Appendix F}

\section{Post-test questionnaire}

Welcome to the post-test questionnaire. Please answer all questions carefully and accurately - we are interested in your true experience with the ON Watch System.

1. Please enter your username

Please rate the statements 2 to 32 on a scale of 1 to 10 , where 1 is strongly disagree and 10 is strongly agree.

2. Based on your experience, ONWatch is an effective way for making software security advice easily available.

3. ONWatch provided me with good advice that improved my decision.

4. It was hard to use the tool in order to see the advice.

5. I did not depend on the source of advice" to choose my answer.

6. I found the advice given to me useful.

7. I distrust the advice given.

8. I would likely use a tool like ONWatch if it were available for me. 
9. I would NOT be willing to pay for an authority to give me advice about computer security.

10. I felt more confidence in choosing the suggested alternate software than the one that was first suggested.

11. I do not bother looking for alternatives. I always download the first one that shows up on Google results.

12. What was your source of advice? (please choose only one of the following)

- Alex McSmart

- CISA

- Symansoft

- General people from the Internet

- My friends from Facebook

For those who answered "Alex McSmart":

13. I would trust a specific friend better than an unpaid security authority (such as Better Business Bureau).

14. I would trust a specific friend better than a paid security authority (such as Symantec or Microsoft).

15. I would trust a specific friend better than a summary of the advice of my friends from Facebook (or another social network).

16. I would trust a specific friend better than a summary of the advice from general people from the Web.

For those who answered "CISA": 
17. I would trust an unpaid security authority (such as Better Business Bureau) better thana specific friend.

18. I would trust an unpaid security authority (such as Better Business Bureau) better than a paid security authority (such as Symantec or Microsoft).

19. I would trust an unpaid security authority (such as Better Business Bureau) better than a summary of the advice from my friends from Facebook (or another social network).

20. I would trust an unpaid security authority (such as Better Business Bureau) better than a summary of the advice from general people from the Web. For those who answered "Facebook":

21. I would trust a summary of the advice from my friends from Facebook (or another social network)better thana specific friend.

22. I would trust a summary of the advice my friends from Facebook (or another social network) better than a paid security authority (such as Symantec or Microsoft).

23. I would trust a summary of the advice of my friends from Facebook (or another social network) better than a specific friend.

24. I would trust a summary of the advice from my friends from Facebook (or another social network) better than a summary of the advice from general people from the Web.

For those who answered "General people from the Internet":

25. I would trust a summary of the advice from general people from the Webbetter than a specific friend. 
26. I would trust a summary of the advice from general people from the Web better than a paid security authority (such as Symantec or Microsoft).

27. I would trust a summary of the advice from general people from the Web better than the advice of my friends from Facebook (or another social network)

28. I would trust a summary of the advice from general people from the Web better than the advice of an unpaid security authority (such as Better Business Bureau).

For those who answered "Symansoft":

29. I would trust a paid security authority (such as Symantec or Microsoft)better than a specific friend.

30. I would trust a paid security authority (such as Symantec or Microsoft)better thana unpaid security authority (such as Better Business Bureau).

31. I would trust a paid security authority (such as Symantec or Microsoft) better than the advice of my friends from Facebook (or another social network).

32. I would trust the advice from a paid security authority (such as Symantec or Microsoft) better than a summary of the advice from general people from the Web.

33. Did you use On Watch in every decision? (please choose only one of the following)

- Yes

Why?

- No

Why not? 
34. In some situations my decision was different from the advice given because: (please choose all that apply)

- I didn't trust the advice

- It was a personal choice, not related to security

- That didn't happen to me. I trusted all the advice given.

- Other:

35. If you have more comments about why you didn't trust the advice, please provide them below.

36. If you have any further comments about your general experience with ON Watch, please provide them in the space below. 


\section{Appendix G}

\section{Post-test questionnaire answers}




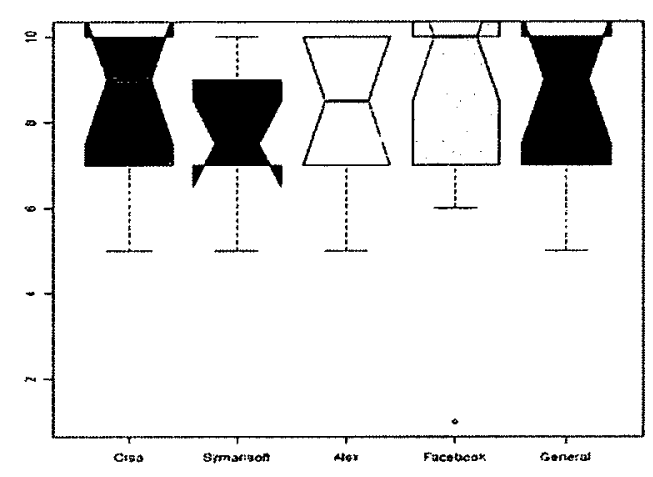

(a) I would likely use a tool like ONWatch if it were available for me.

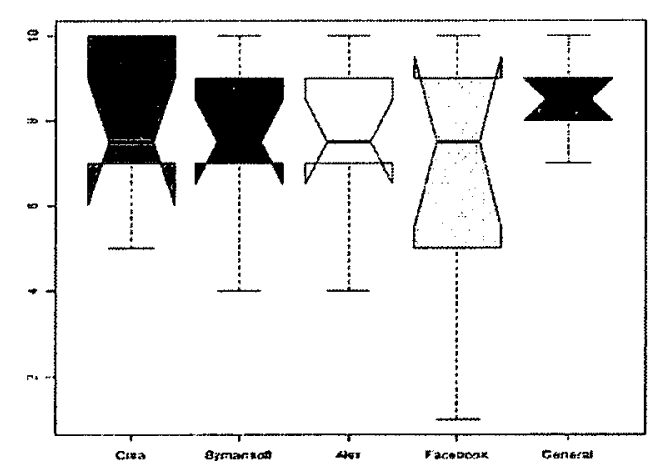

(c) I felt more confidence in choosing the suggested alternate software than the one that was first suggested.

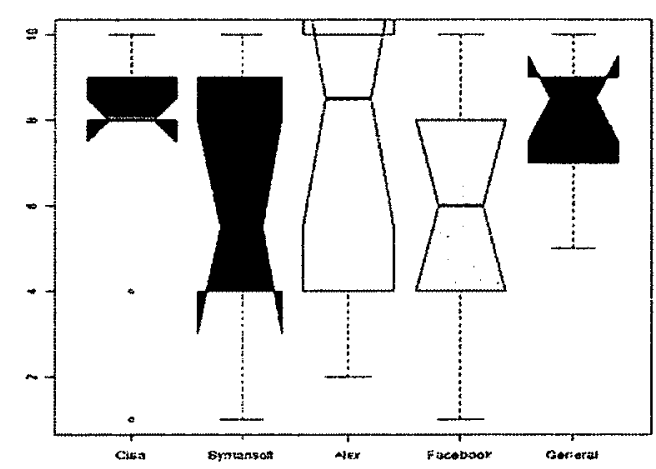

(b) I would NOT be willing to pay for an authority to give me advice about computer security.

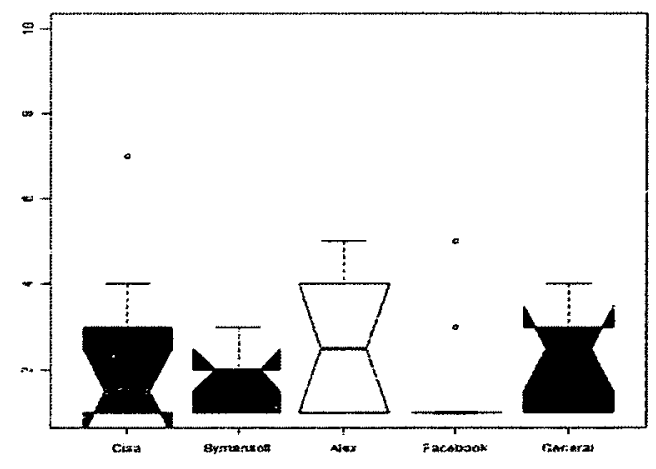

(d) I do not bother looking for alternatives. I always download the first one that shows up on Google results.

Figure 32: Post-test Questions 


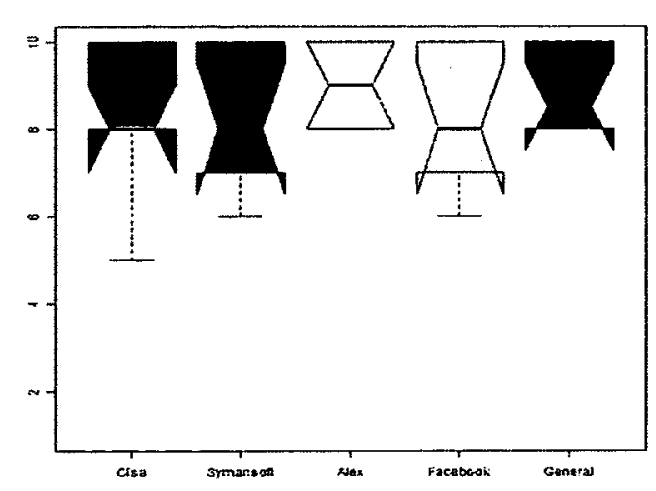

(a) Based on your experience. ONWatch is an effective way for making software security advice easily available.

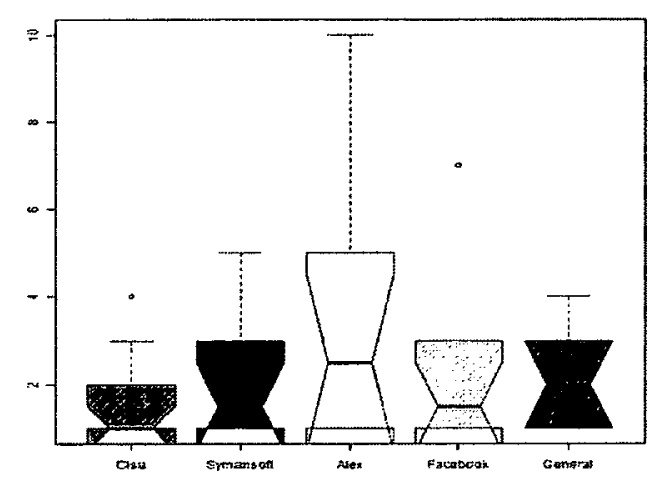

(c) It was hard to use the tool in order to see the advice.

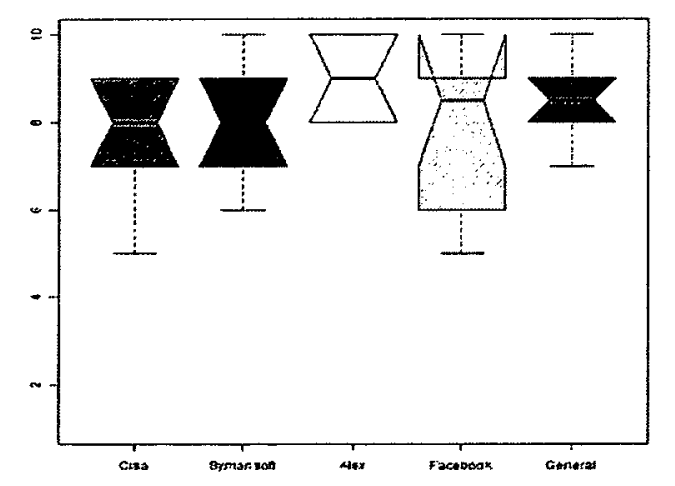

(e) I found the advice given to me useful.

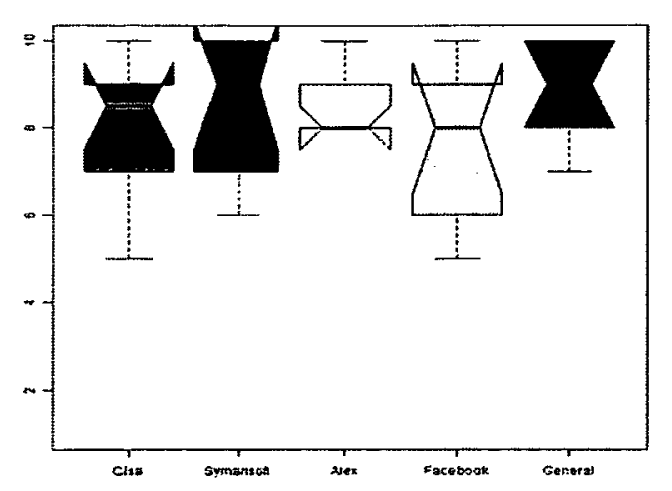

(b) ONWatch provided me with good advice that improved my decision.

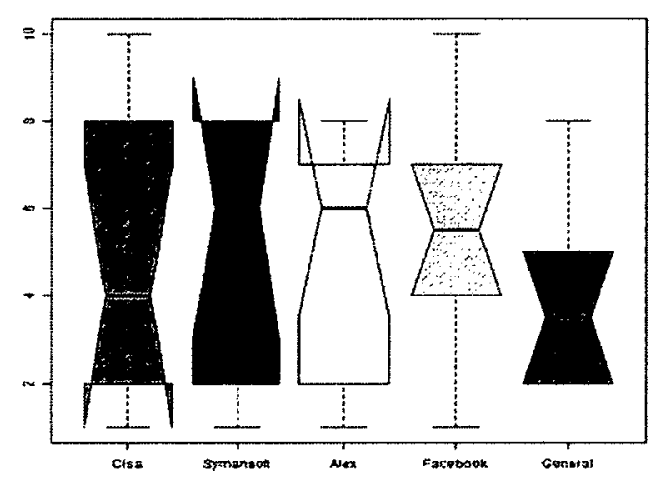

(d) I did not depend on the source of advice to choose my answer.

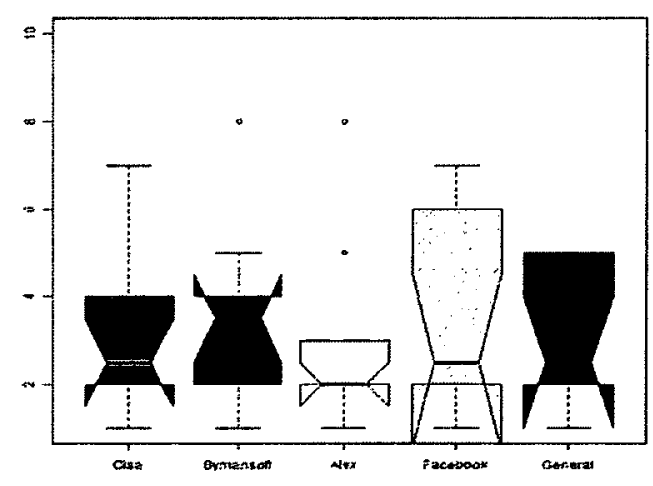

(f) I distrust the advice given.

Figure 33: Post-test Questions 


\section{Appendix $\mathbf{H}$}

\section{The website}

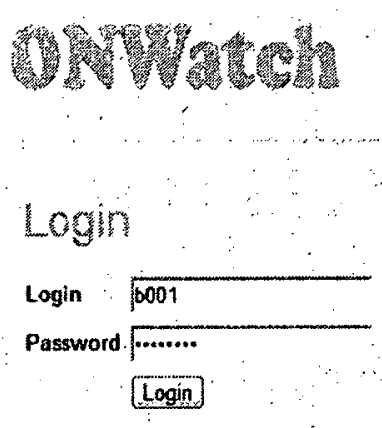

Dont have an account yet? ceate new account

Figure 34: ONWatch website: login page

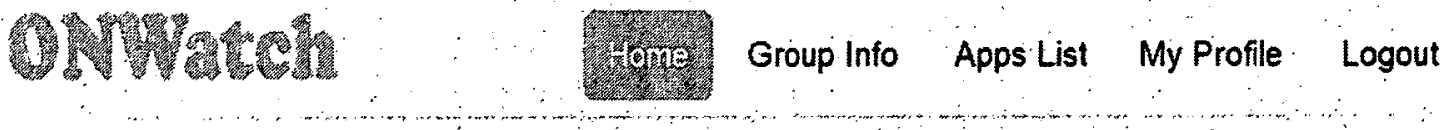

Onme Weighorhood Watoh

Hello Bruna!

Welcome to OptWatch, the Online Neighbonood Watch

The Online Neighbohood Watch is an online social network vhere members are interested in

learning security or promoting it. It is inspired by the Neighboorhood Watch program, which is

is an organized group of citizens devoled to crime and vandalism presention within a

neighborhood.

In ONWatch each member belongs to a group, and this group is made by people that triust

each other.

Figure 35: ONWatch website: home page 


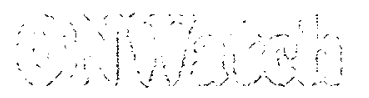

Home

Baser On?

You have been logged out

Clikk here to login

Figure 36: ONWatch website: logout page

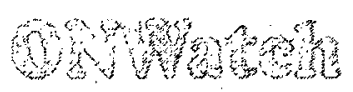

Home

\section{Sign Un?}

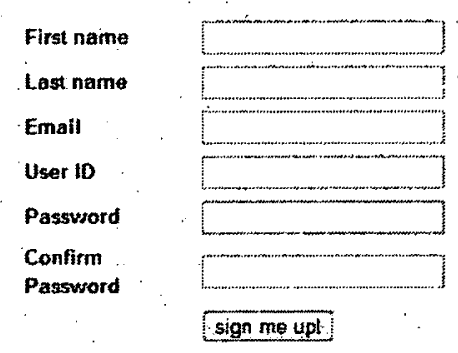

Figure 37: ONWatch website: sign up page
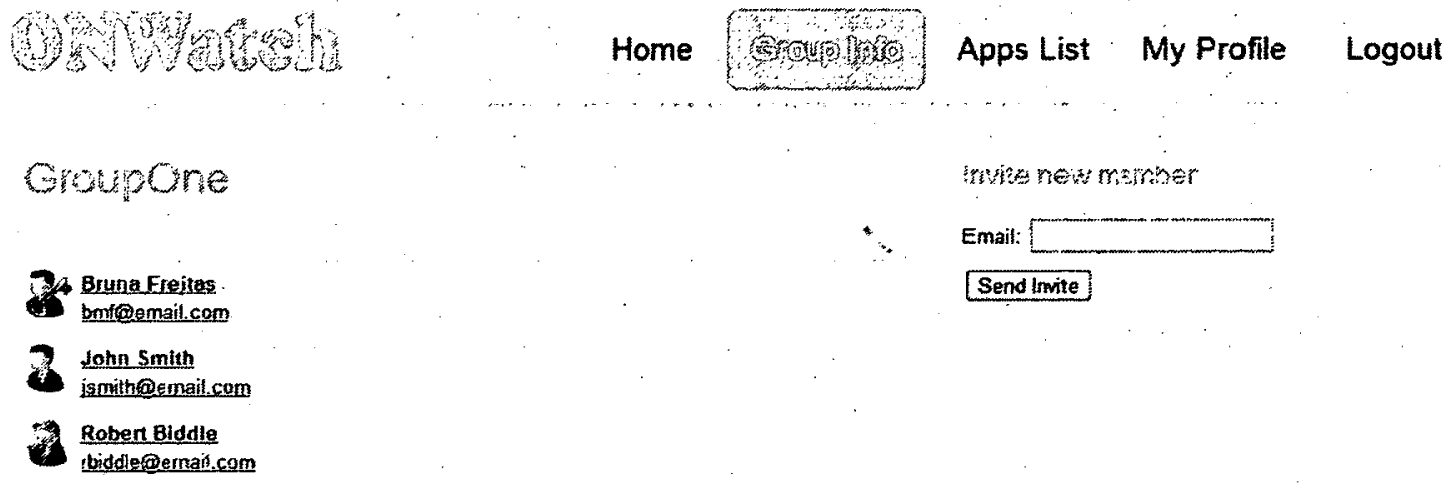

Figure 38: ONWatch website: group page 


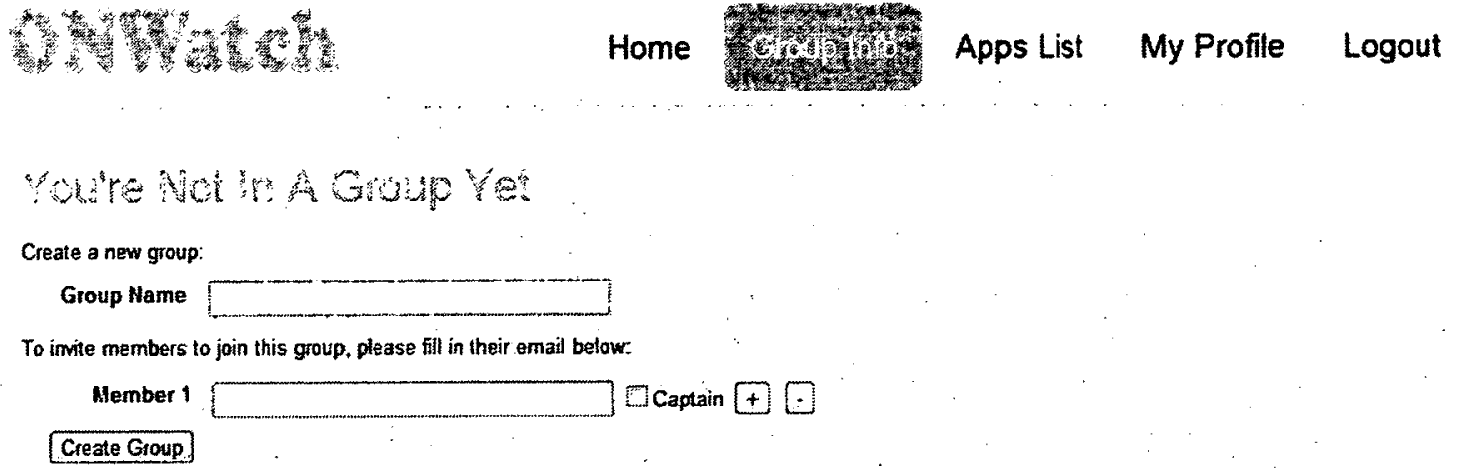

Figure 39: ONWatch website: create a group page

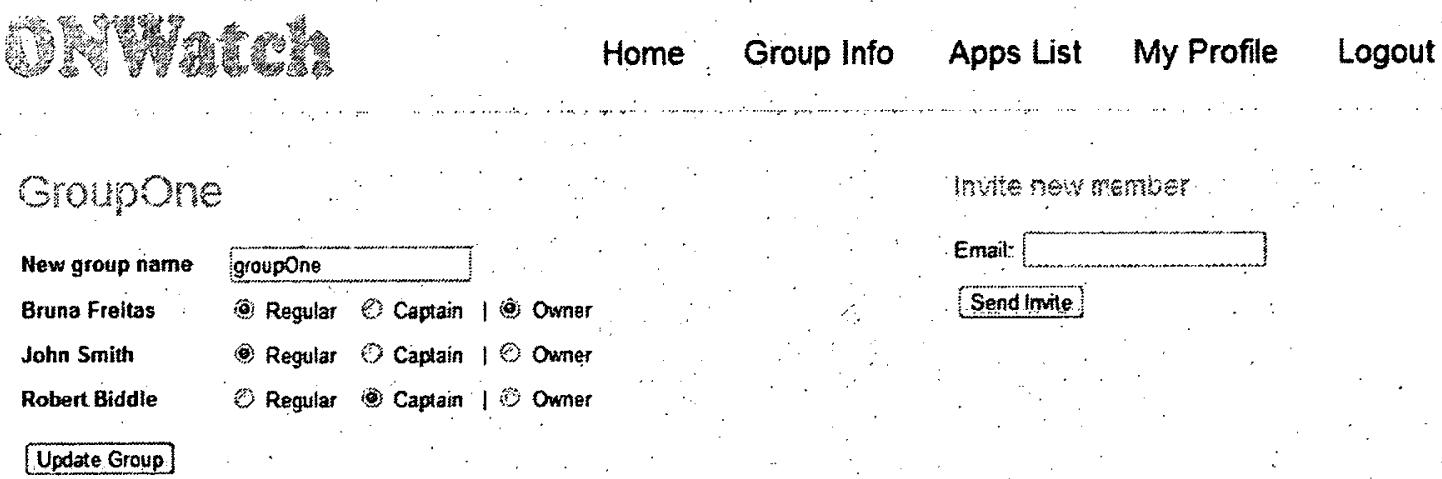

Figure 40: ONWatch website: edit group information page

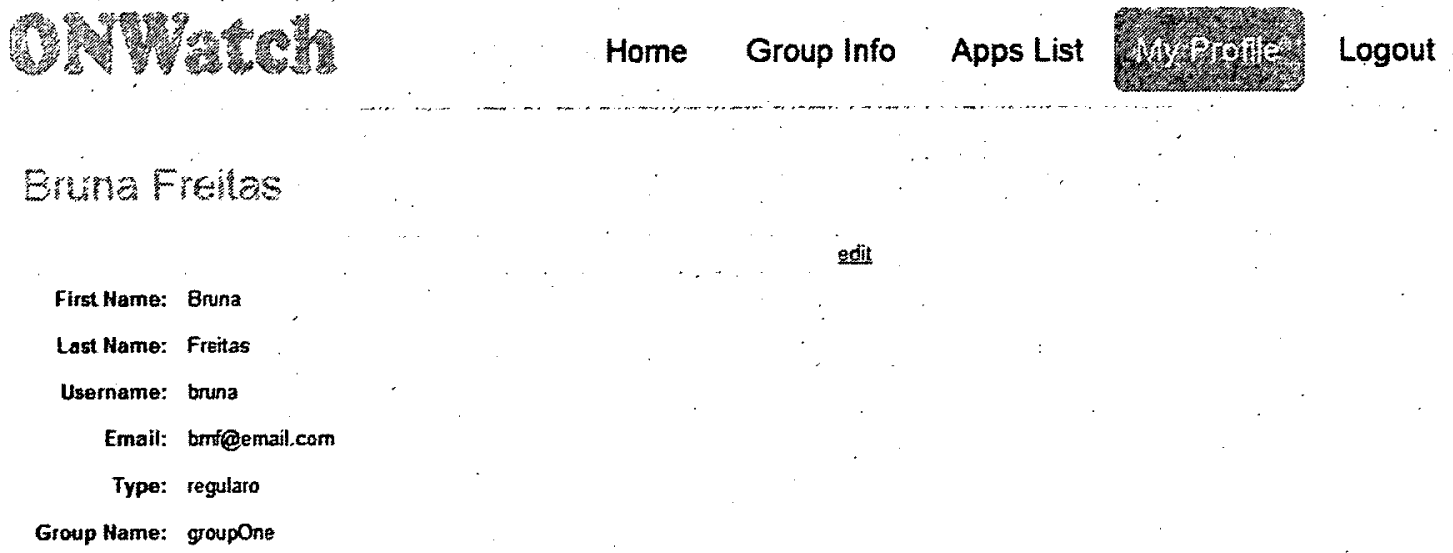

Figure 41: ONWatch website: profile page 


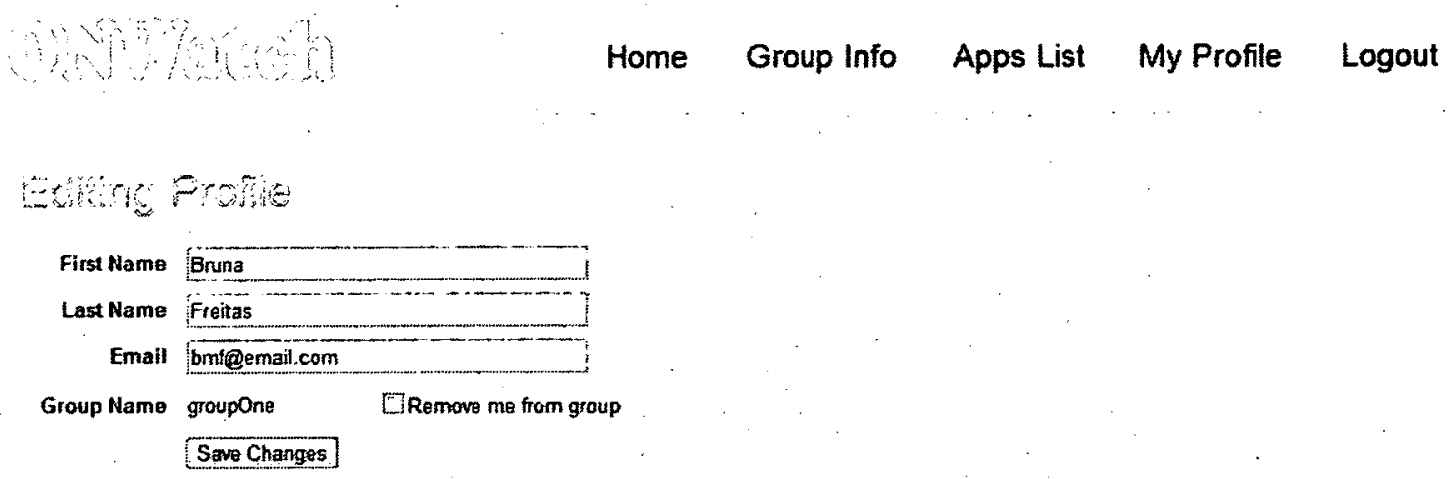

Figure 42: ONWatch website: edit profile page

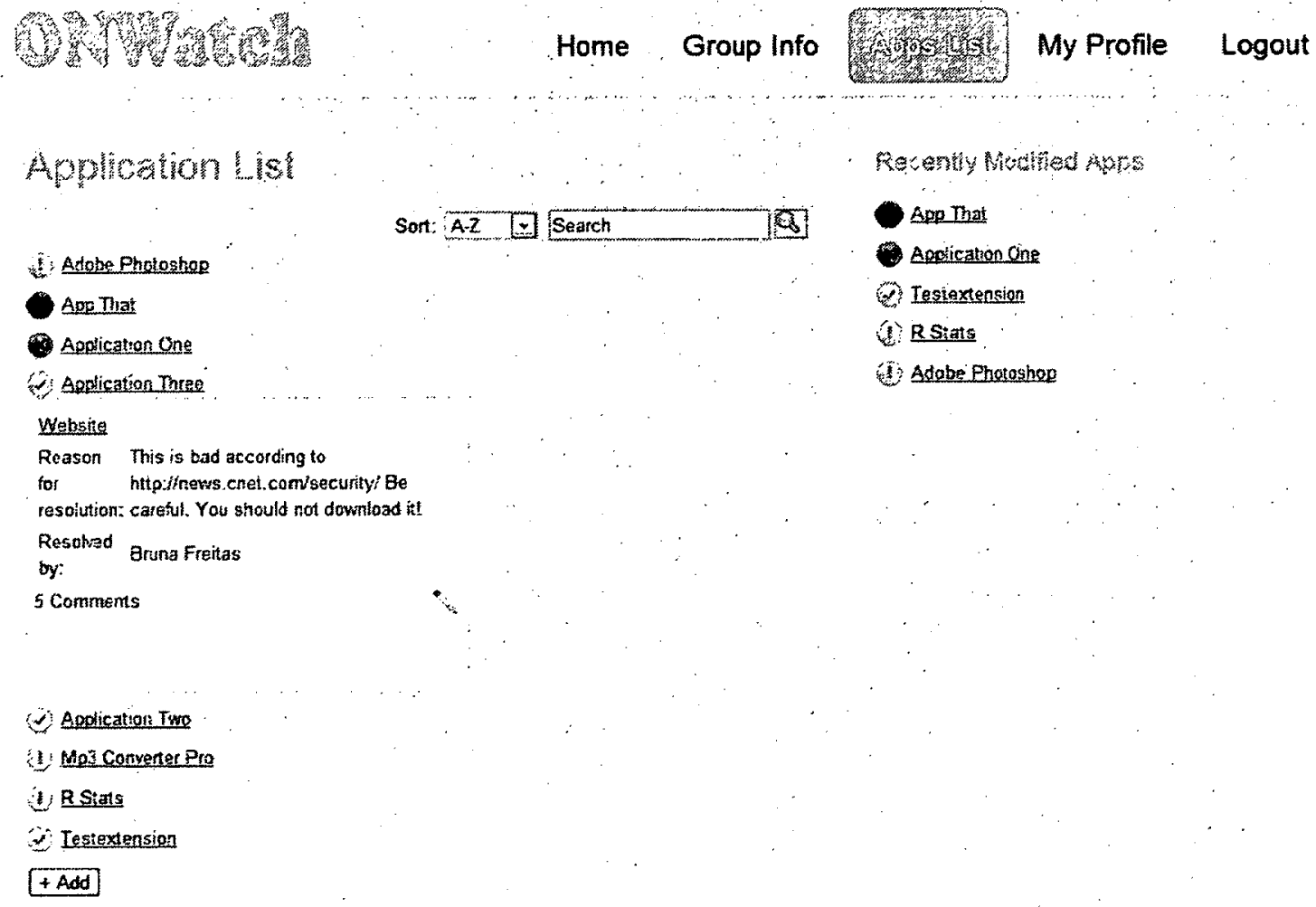

Figure 43: ONWatch website: applications page 


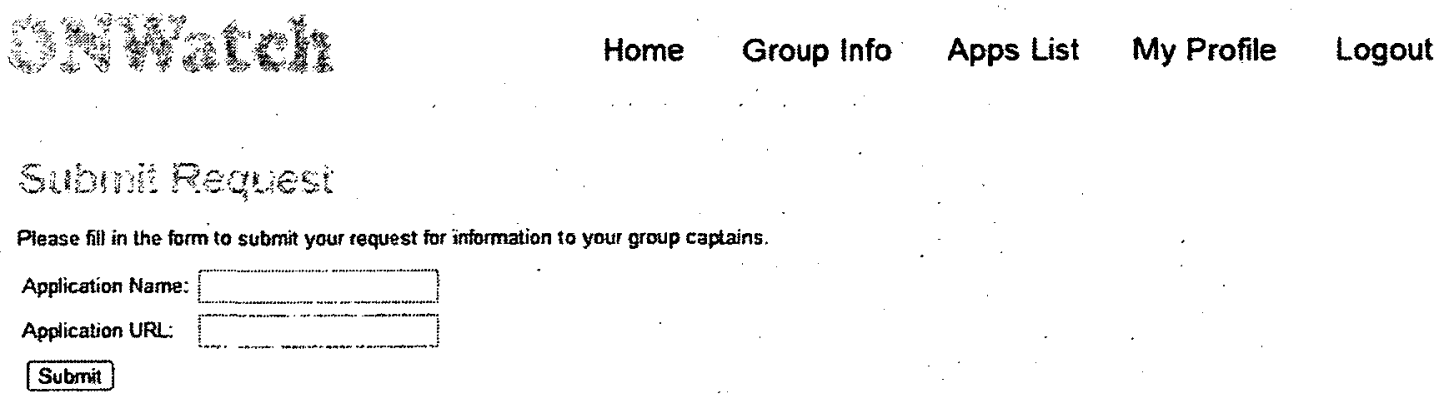

Figure 44: ONWatch website: adding new application page

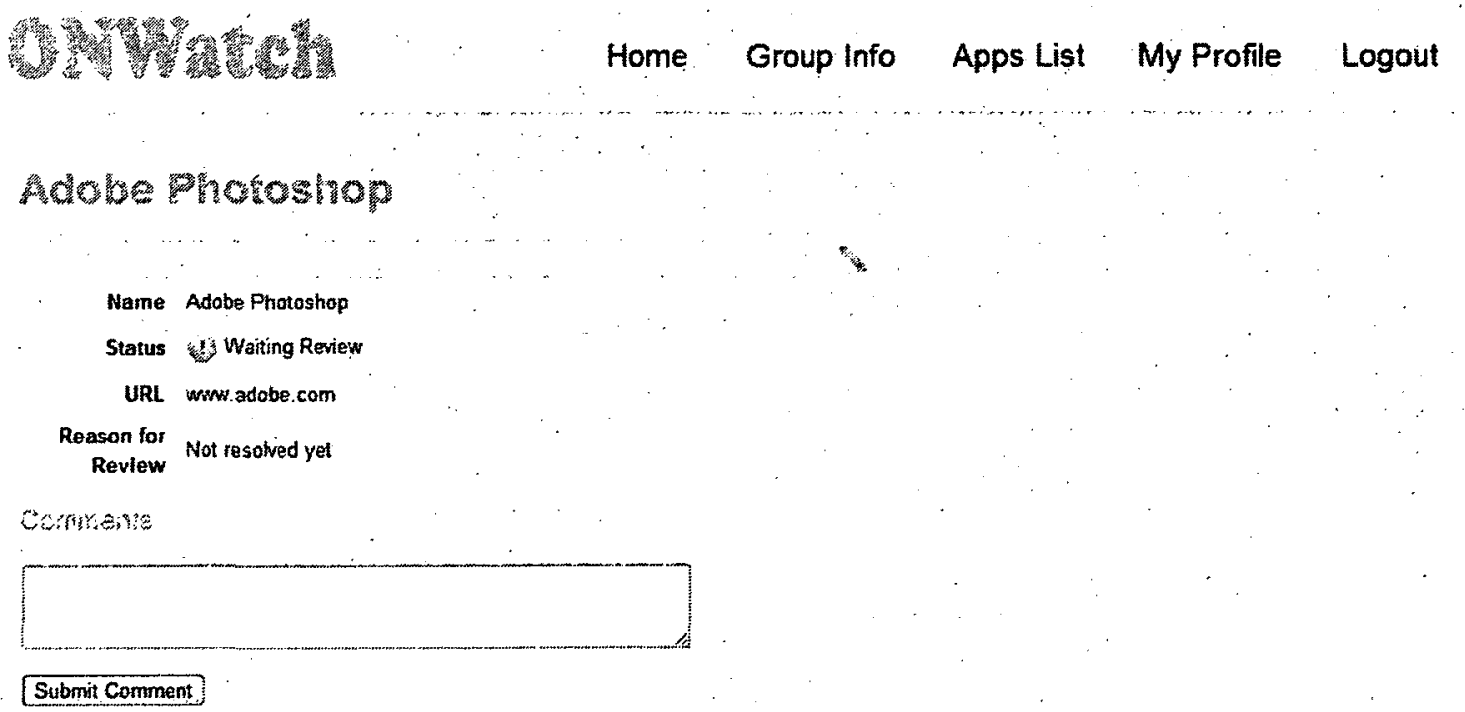

Figure 45: ONWatch website: application information page 


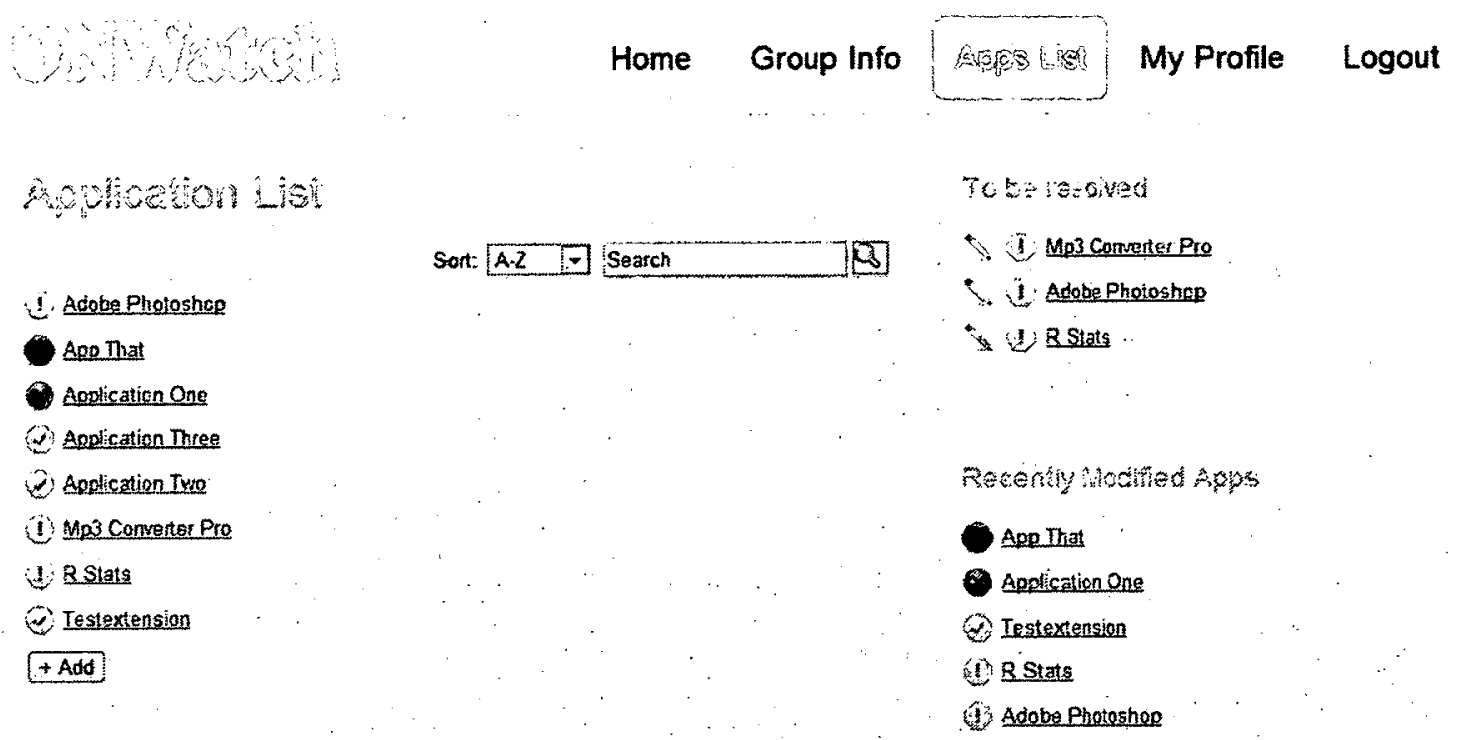

Figure 46: ONWatch website: captain's view of the application page

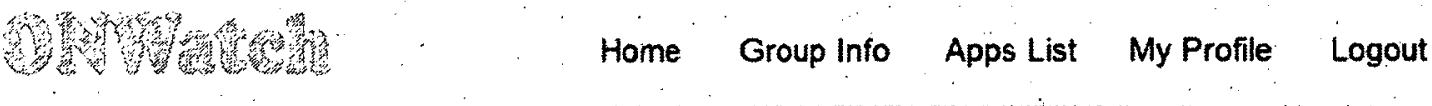

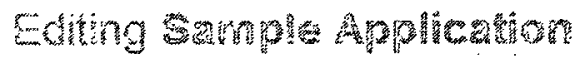

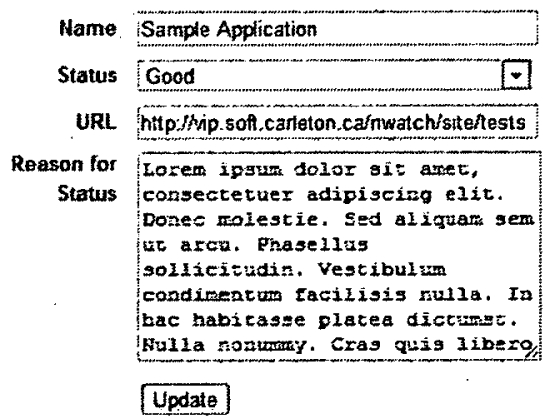

Figure 47: ONWatch website: captain writing the advice 


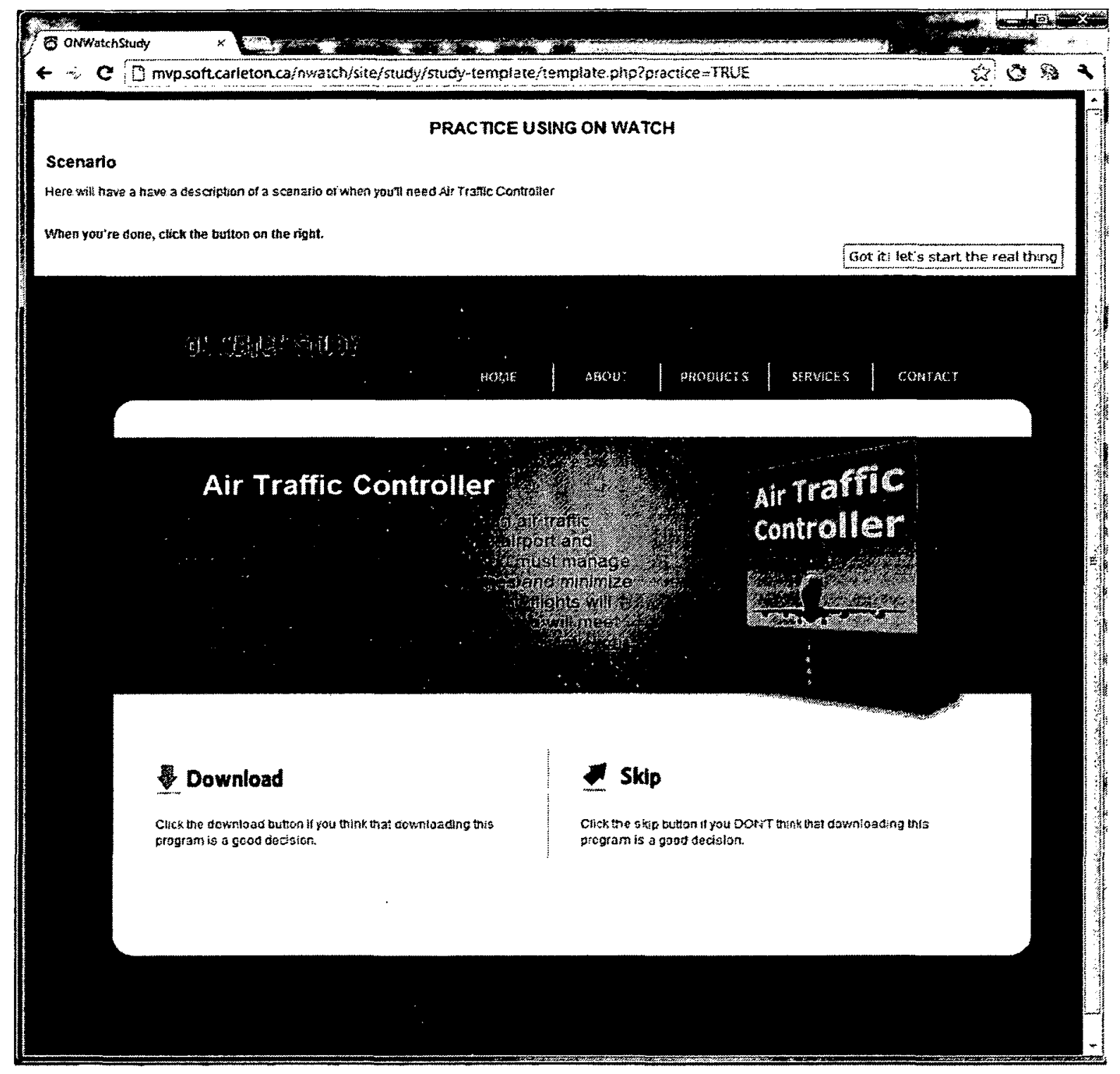

Figure 48: ONWatch study: page showed when participant was practicing using the system 


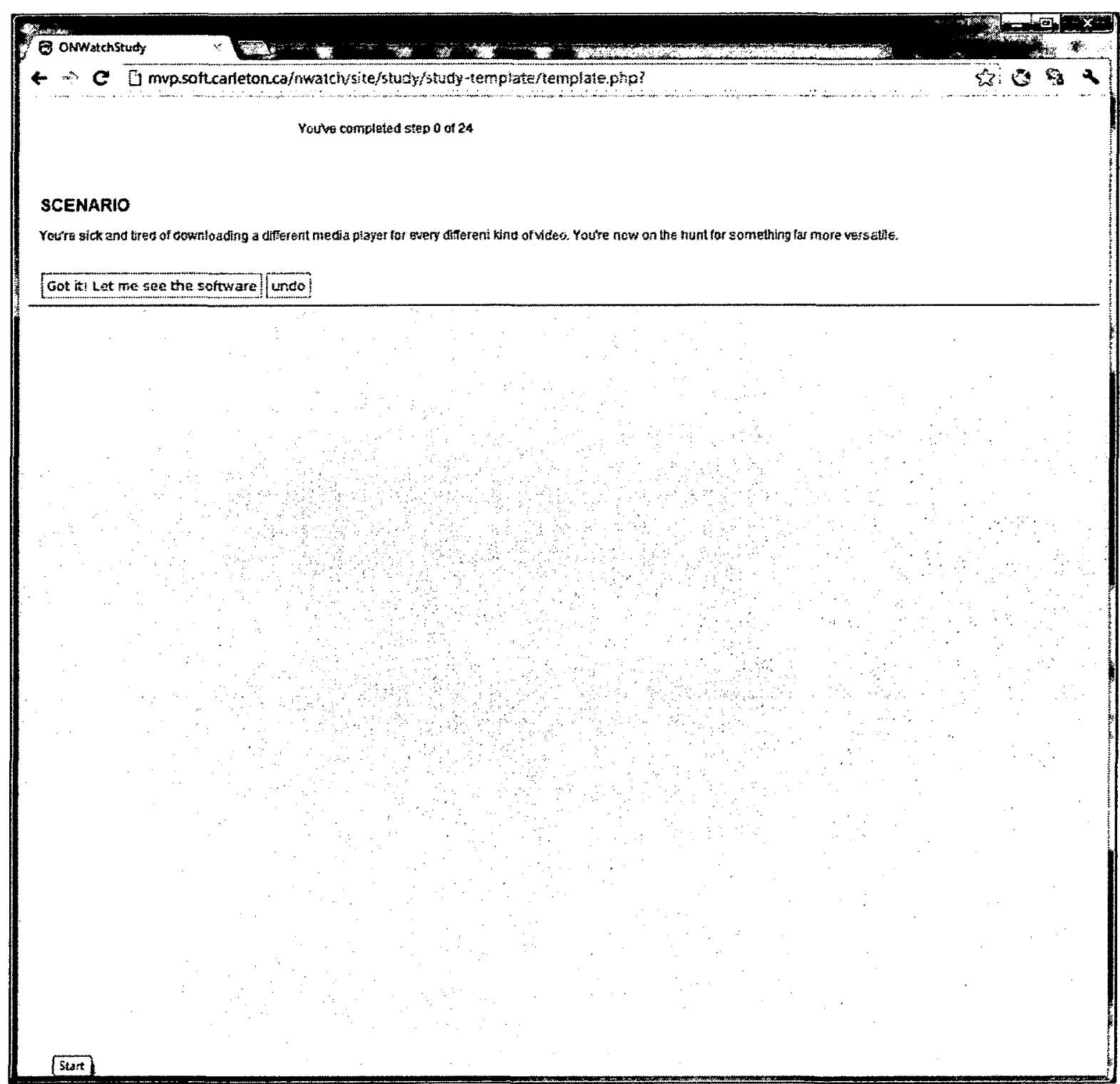

Figure 49: ONWatch study: page displayed when participants were in the actual study. The participant would read the scenario, and then click the button to see the application 


\section{List of References}

[1] O. P. Service. "Neighbourhood watch, member guide." www.ottawapolice.ca (2003).

[2] F. Stajano and P. Wilson. "Understanding scam victims: seven principles for systems security." Commun. ACM 54(3), 70-75. ISSN .0001-0782 (2011).

[3] Brod. "Are you having a (mac) flashback?" http://www.f-secure.com/ weblog/archives/00002336.html (2012).

[4] C. Smith and D. E. Dilger. "Fake adobe flash malware seeks to disable mac os $\mathrm{x}$ anti-malware protection." http://appleinsider.com/articles/11/10/19/ fake_adobe_flash_malware_seeks_to_disable_mac_os_x_anti_malware_ protection.html (2012).

[5] Facebook. "Facebook website." http://www.facebook.com/ (2012).

[6] T. A. Press. "Number of active users at facebook over the years." http://finance.yahoo.com/news/ number-active-users-facebook-over-years-214600186--finance.html (2012).

[7] MySpace. "Myspace website." http://www.myspace.com/ (2012).

[8] orkut. "Orkut website." http://www.orkut.com/ (2012).

[9] LinkedIn. "Linkedin website." http://www.linkedin.com/ (2012).

[10] A. Makridakis, E. Athanasopoulos, S. Antonatos, D. Antoniades, S. Ioannidis, and E. Markatos. "Understanding the behavior of malicious applications in social networks." Network, IEEE 24(5), 14 -19. ISSN 0890-8044 (2010).

[11] R. Chandramouli. "Emerging social media threats: Technology and policy perspectives." In "Cybersecurity Summit (WCS), 2011 Second Worldwide," pages 1-4 (2011). 
[12] A. Zinman and J. Donath. "Is britney spears spam?" In "Fourth Conference on Email and Anti-Spam," Mountain View, CA (2007).

[13] D. Irani, S. Webb, K. Li, and C. Pu. "Large online social footprints-an emerging threat." In "Proceedings of the 2009 International Conference on Computational Science and Engineering - Volume 03," CSE '09, pages 271-276. IEEE Computer Society, Washington, DC, USA. ISBN 978-0-7695-3823-5 (2009).

[14] Y. Boshmaf, I. Muslukhov, K. Beznosov, and M. Ripeanu. "The socialbot network: when bots socialize for fame and money." In "Proceedings of the 27th Annual Computer Security Applications Conference," ACSAC '11, pages 93102. ACM, New York, NY, USA. ISBN 978-1-4503-0672-0 (2011).

[15] F. Nagle and L. Singh. "Can friends be trusted? exploring privacy in online social networks." In "Proceedings of the 2009 International Conference on Advances in Social Network Analysis and Mining," ASONAM '09, pages 312-315. IEEE Computer Society, Washington, DC, USA. ISBN 978-0-7695-3689-7 (2009).

[16] P. Resnick, K. Kuwabara, R. Zeckhauser, and E. Friedman. "Reputation systems." Communications of the ACM 43(12), 45-48. ISSN 0001-0782 (2000).

[17] D. Gambetta. Can We Trust Trust? Basil Blackwell (1988).

[18] A. Jøsang, R. Ismail, and C. Boyd. "A survey of trust and reputation systems for online service provision." Decision Support Systems 43(2), 618-644. ISSN 01679236. ice:title ¿Emerging Issues in Collaborative Commerce $i /$ ce:title $_{i}$ (2007).

[19] A. Abdul-Rahman and S. Hailes. "Supporting trust in virtual communities." In "Proceedings of the 33rd Hawaii International Conference on System SciencesVolume 6 - Volume 6," HICSS '00, pages 6007-. IEEE Computer Society, Washington, DC, USA. ISBN 0-7695-0493-0 (2000).

[20] P. Obreiter. "A case for evidence-aware distributed reputation systems." In C. Jensen, S. Poslad, and T. Dimitrakos, editors, "Trust Management," volume 2995 of Lecture Notes in Computer Science, pages 33-47. Springer Berlin / Heidelberg. ISBN 978-3-540-21312-3 (2004).

[21] M. Kinateder and K. Rothermel. "Architecture and algorithms for a distributed reputation system." In "Proceedings of the 1st international conference on Trust management," iTrust'03, pages 1-16. Springer-Verlag, Berlin, Heidelberg. ISBN 3-540-40224-1 (2003). 
[22] T. Jiang. Distributed trust management in autonomic networks. Ph.D. thesis, College Park, MD, USA. AAI3297379 (2007).

[23] P. Resnick, R. Zeckhauser, J. Swanson, and K. Lockwood. "The value of reputation on ebay: A controlled experiment." Experimental Economics 9, 79-101 (2003).

[24] Z. Fox. "How amazon became the worlds largest online retailer." http:// mashable.com/2011/11/17/amazon-facts/ (2011).

[25] Amazon. "Amazon website." http://www .amazon.com/ (2012).

[26] Epinions. "Epinions website." http://www.epinions.com/ (2012).

[27] L. Page, S. Brin, R. Motwani, and T. Winograd. "The pagerank citation ranking: Bringing order to the web." Technical Report 1999-66, Stanford InfoLab. Previous number $=$ SIDL-WP-1999-0120 (1999).

[28] S. Bonaccio and R. S. Dalal. "Advice taking and decision-making: An integrative literature review, and implications for the organizational sciences." Organizational Behavior and Human Decision Processes 101(2), 127 - 151. ISSN 0749-5978 (2006).

[29] J. A. Sniezek and L. M. V. Swol. "Trust, confidence, and expertise in a judgeadvisor system." Organizational Behavior and Human Decision Processes 84(2), 288 - 307. ISSN 0749-5978 (2001).

[30] L. M. van Swol and J. A. Sniezek. "Factors affecting the acceptance of expert advice." British Journal of Social Psychology 44(3), 443-461. ISSN 2044-8309 (2005).

[31] I. Yaniv and E. Kleinberger. "Advice taking in decision making: Egocentric discounting and reputation formation." Organizational Behavior and Human Decision Processes 83(2), 260 - 281. ISSN 0749-5978 (2000).

[32] F. Gino and D. A. Moore. "Effects of task difficulty on use of advice." Journal of Behavioral Decision Making 20(1), 21-35. ISSN 1099-0771 (2007).

[33] J. A. Sniezek and T. Buckley. "Cueing and cognitive conflict in judge-advisor decision making." Organizational Behavior and Human Decision Processes 62(2), 159 - 174. ISSN 0749-5978 (1995). 
[34] D. J. GOLDSMITH and K. FITCH. "The normative context of advice as social support." Human Communication Research 23(4), 454-476. ISSN 1468-2958 (1997).

[35] J. Yates, P. C. Price, J. W. Lee, and J. Ramirez. "Good probabilistic forecasters: The 'consumer's' perspective." International Journal of Forecasting 12(1), 4156. ISSN 01692070 (1996).

[36] D. V. Budescu and H.-T. Yu. "Aggregation of opinions based on correlated cues and advisors." Journal of Behavioral Decision Making 20(2), 153-177. ISSN 1099-0771 (2007).

[37] S. Bonaccio and R. S. Dalal. "Evaluating advisors: A policy-capturing study under conditions of complete and missing information." Journal of Behavioral Decision Making 23(3), 227-249. ISSN 1099-0771 (2010).

[38] L. M. V. Swol. "Forecasting anothers enjoyment versus giving the right answer: Trust, shared values, task effects, and confidence in improving the acceptance of advice." International Journal of Forecasting 27(1), 103-120. ISSN 0169-2070. ¡ce:title $\_$Group-Based Judgmental Forecastingi/ce:title ${ }_{i}$ (2011).

[39] W. of Trust. "Web of trust." http://www.mywot.com/ (2012).

[40] P. Chia, A. Heiner, and N. Asokan. "Use of ratings from personalized communities for trustworthy application installation." In T. Aura, K. Jrvinen, and K. Nyberg, editors, "Information Security Technology for Applications," volume 7127 of Lecture Notes in Computer Science, pages 71-88. Springer Berlin / Heidelberg. ISBN 978-3-642-27936-2 (2012).

[41] C. Herley. "So long, and no thanks for the externalities: the rational rejection of security advice by users." In "Proceedings of the 2009 workshop on New security paradigms workshop," NSPW '09, pages 133-144. ACM, New York, NY, USA. ISBN 978-1-60558-845-2 (2009).

[42] B. Arief, A. P. A. van Moorsel, D. Greathead, and L. M. Coventry. "Towards the implementation of an internet-based neighbourhood watch scheme-impacts of inclusive technologies on societies." In "CASON'11," pages 25-30 (2011).

[43] T. Bennett, K. Holloway, and D. Farrington. "The effectiveness of neighbourhood watch." (2008). 
[44] D. P. ROSENBAUM. "The theory and research behind neighborhood watch: Is it a sound fear and crime reduction strategy?" Crime and Delinquency 33(1), 103-134 (1987).

[45] B. J. Fogg. Persuasive Technology: Using Computers to Change what we Think and Do. Morgan Kaufmann, Amsterdam. ISBN 978-1-55860-643-2 (2003).

[46] P. Adams. Grouped: How small groups of friends are the key to influence on the social web. New Riders, California. ISBN 13:978-0-321-80411-2 (2012).

[47] A. D. Shaw, J. J. Horton, and D. L. Chen. "Designing incentives for inexpert human raters." In "Proceedings of the ACM 2011 conference on Computer supported cooperative work," CSCW '11, pages 275-284. ACM, New York, NY, USA. ISBN 978-1-4503-0556-3 (2011).

[48] Google. "Google chrome extensions." [Online; accessed 11-August-2012] (2012).

[49] "R (programming language)." [Online; accessed 10-Spetember-2012] (2012).

[50] N. Harvey and I. Fischer. "Taking advice: Accepting help, improving judgment, and sharing responsibility." Organizational Behavior and Human Decision Processes 70(2), 117 - 133. ISSN 0749-5978 (1997).

[51] Apple. "Apple support website." http://support.apple.com/kb/HT5290 (2013). 